\title{
Low-Quality Natural Gas Sulfur Removal/Recovery
}

\author{
Final Report
}

by

Membrane Technology and Research, Inc.

1360 Willow Road

Menlo Park, California 94025

Contract No. DE-AC21-92MC28133--01

Contract Period: September 30, 1992 to March 31, 1998

prepared for

The Department of Energy

Office of Fossil Energy

Morgantown Energy Technology Center

Morgantown, WV

January 29, 1998

Contributors:

K. Amo

R.W. Baker (P.I.)

V.D. Helm

T. Hofmann

K.A. Lokhandwala (P.M.)

I. Pinnau

M.B. Ringer

T.T. Su

L. Toy

J.G. Wijmans 


\begin{abstract}
A significant fraction of U.S. natural gas reserves are subquality due to the presence of acid gases and nitrogen; $13 \%$ of existing reserves (19 trillion cubic feed) may be contaminated with hydrogen sulfide. For natural gas to be useful as fuel and feedstock, this hydrogen sulfide has to be removed to the pipeline specification of $4 \mathrm{ppm}$. The technology used to achieve these specifications has been amine, or similar chemical or physical solvent, absorption. Although mature and widely used in the gas industry, absorption processes are capital and energy-intensive and require constant supervision for proper operation. This makes these processes unsuitable for treating gas at low throughput, in remote locations, or with a high concentration of acid gases. The U.S. Department of Energy, recognizes that exploitation of smaller, more sub-quality resources will be necessary to meet demand as the large gas fields in the U.S. are depleted. In response to this need, Membrane Technology and Research, Inc. (MTR) has developed membranes and a membrane process for removing hydrogen sulfide from natural gas. During this project, high-performance polymeric thinfilm composite membranes were brought from the research stage to field testing. The membranes have hydrogen sulfide/methane selectivities in the range 35 to 60, depending on the feed conditions, and have been scaled up to commercial-scale production. A large number of spiral-wound modules were manufactured, tested and optimized during this project, which culminated in a field test at a Shell facility in East Texas. The short field test showed that membrane module performance on an actual natural gas stream was close to that observed in the laboratory tests with cleaner streams. An extensive technical and economic analysis was performed to determine the best applications for the membrane process. Two areas were identified: the low-flow-rate, high-hydrogen-sulfide-content region and the high-flow-rate, high-hydrogen-sulfide-content region. In both regions the MTR membrane process will be combined with another process to provide the necessary hydrogen sulfide removal from the natural gas. In the first region the membrane process will be combined with the SulfaTreat fixed-bed absorption process, and in the second region the membrane process will be combined with a conventional absorption process. Economic analyses indicate that these hybrid processes provide $20-40 \%$ cost savings over stand-alone absorption technologies.
\end{abstract}




\section{TABLE OF CONTENTS}

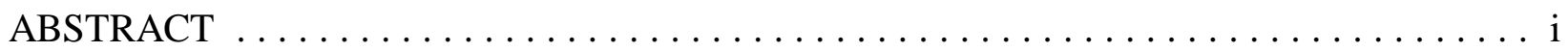

EXECUTIVE SUMMARY $\ldots \ldots \ldots \ldots \ldots \ldots \ldots \ldots \ldots \ldots \ldots \ldots \ldots$

1. IDENTIFICATION AND SIGNIFICANCE OF THE PROBLEM $\ldots \ldots \ldots \ldots \ldots$

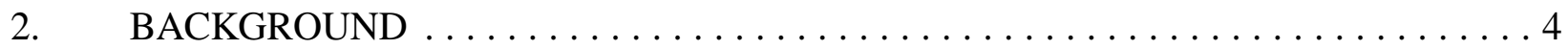

2.1 Current Technologies and Their Shortcomings $\ldots \ldots \ldots \ldots \ldots \ldots \ldots \ldots$

2.2 Membrane Processes and Their Applicability $\ldots \ldots \ldots \ldots \ldots \ldots \ldots$

3. PROJECT OBJECTIVES AND APPROACH $\ldots \ldots \ldots \ldots \ldots \ldots \ldots \ldots \ldots \ldots$

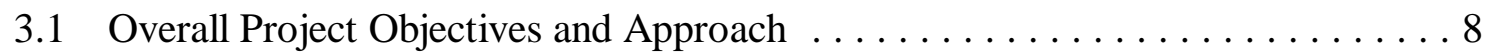

3.2 Task 2 Activities . . . . . . . . . . . . . . . . . . . . . . . 11

3.3 Task 3 Activities . . . . . . . . . . . . . . . . . 11

4. MEMBRANE AND MODULE DEVELOPMENT $\ldots \ldots \ldots \ldots \ldots \ldots \ldots \ldots \ldots \ldots$

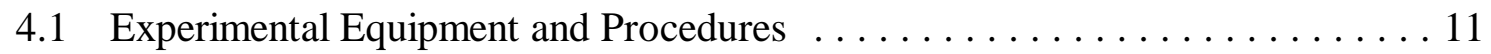

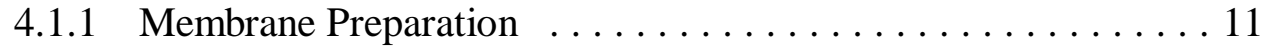

4.1.2 Evaluation of Membrane Properties . . . . . . . . . . . . 13

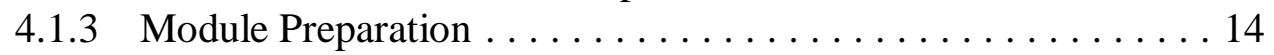

4.1.4 Evaluation of Module Properties . . . . . . . . . . . . 15

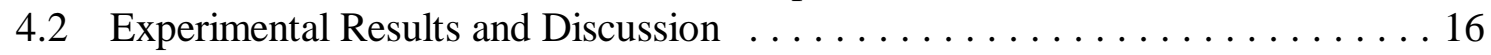

4.2.1 Parametric Test Plan for Membrane Experiments . . . . . . . . . . 16

4.2.2 Selection of Membrane Material . . . . . . . . . . . . . 17

4.2.3 Parametric Tests with Pebax 4011 and Pebax 1074

Membranes ...................... 18

4.2.4 Comparison of the Membrane Selectivity for Hydrogen

Sulfide and Carbon Dioxide Over Methane in Pebax 4011

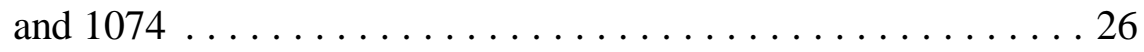

4.2.5 Preparation and Testing of Laboratory-Scale Pebax 4011 Membrane Modules . . . . . . . . . . . . . . . . 27

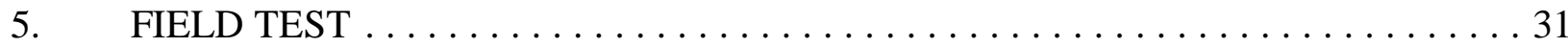

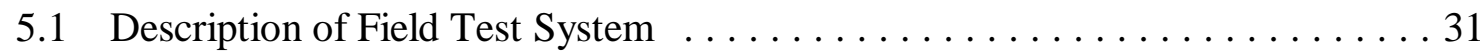

5.2 Description of Plant Site and Placement of Membrane System in Plant . . . . . 34

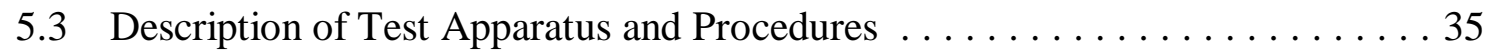

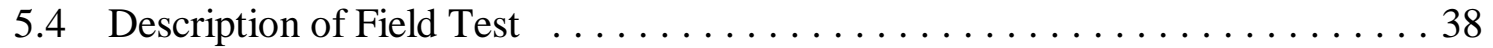

5.5 Results and Discussions of Field Test Data . . . . . . . . . . . . 41

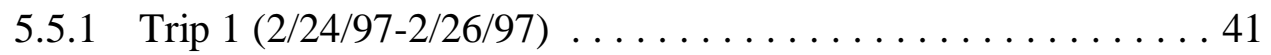

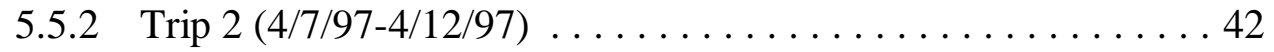

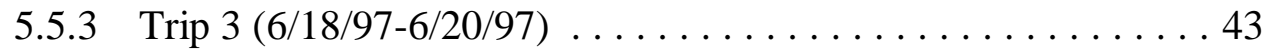

5.5 .4 Trip $4(8 / 11 / 97-8 / 14 / 97) \ldots \ldots \ldots \ldots \ldots \ldots \ldots \ldots \ldots \ldots \ldots \ldots$ 
TABLE OF CONTENTS - continued

6. POTENTIAL MEMBRANE APPLICATIONS $\ldots \ldots \ldots \ldots \ldots \ldots \ldots \ldots \ldots$

6.1 Identification of Hydrogen Sulfide-Contaminated Formations and Fields . . . . . 48

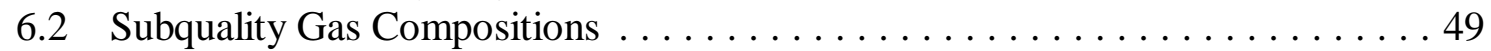

6.3 Survey of Potential Applications and Possible Membrane Process Designs . . . . 49

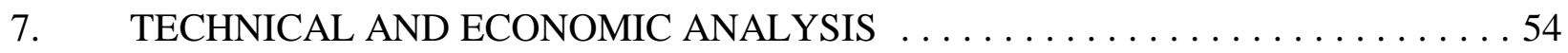

7.1 Low-Flow Applications: Membrane/SulfaTreat Hybrid Process . . . . . . . . . 54

7.1 .1 Process Design ......................... 54

7.1.2 Design and Cost of An Industrial-Scale Plant . . . . . . . . 63

7.2 High-Flow/High-Hydrogen-Sulfide-Content Applications: Membrane-Amine

Hybrid Process . . . . . . . . . . . . . . . . . . . . . 67

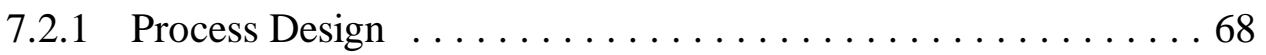

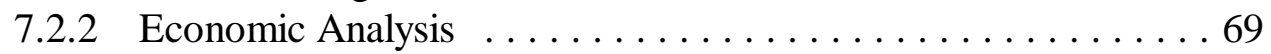

7.3 Specific Case Studies ............................... 73

7.3.1 Case Study No. 1: Debottlenecking Absorption Trains ...... 73

7.3.2 Case Study No. 2: Refinery Debottlenecking ............ 75

7.3.3 Case Study No. 3: Bulk Acid Gas Separation from Natural Gas - Permeate to Claus Plant ................ 78

7.3.4 Case Study No. 4: Bulk Acid Gas Separation - Permeate to Reinject ....................... 80

8. SUMMARY AND CONCLUSIONS $\ldots \ldots \ldots \ldots \ldots \ldots \ldots \ldots \ldots \ldots \ldots \ldots \ldots$

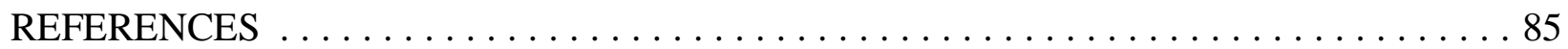

APPENDIX A

Analysis of Membrane System Configurations for Sour Gas Treatment $\ldots . \ldots \ldots$ A-1 


\section{LIST OF FIGURES}

Figure 1. Generic structure of a polyamide-polyether copolymer $\ldots \ldots \ldots \ldots \ldots$

Figure 2. Schematic diagram of an MTR composite membrane $\ldots \ldots \ldots \ldots$

Figure 3. Schematic diagram of a spiral-wound membrane module $\ldots \ldots \ldots \ldots$

Figure 4. Schematic diagram of a support membrane casting machine $\ldots \ldots \ldots 12$

Figure $5 . \quad$ Schematic diagram of thin-film coating apparatus $\ldots \ldots \ldots \ldots \ldots \ldots$

Figure 6. Flow diagram of mixed gas permeation test system $\ldots \ldots \ldots \ldots \ldots$

Figure 7. Schematic diagram of module-winding apparatus $\ldots \ldots \ldots \ldots \ldots$

Figure 8. P\&ID and photograph of the module testing system used for evaluating the performance of the modules in the laboratory $\ldots \ldots \ldots \ldots \ldots \ldots \ldots \ldots \ldots \ldots \ldots$

Figure 9. Correlation between the hydrogen sulfide/methane and the carbon dioxide/methane selectivity of four different Pebax grades . . . . . . . . . . 18

Figure 10. Pressure-normalized permeation flux through Pebax ${ }^{\circledR} 4011$ of each component of the feed mixture as a function of the total acid gas partial

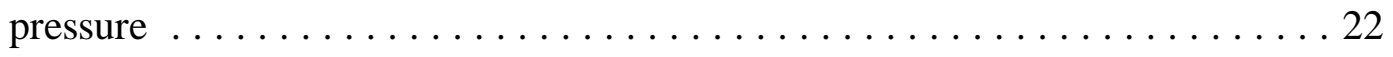

Figure 11. Pressure-normalized permeation flux through Pebax® 1074 of each component of the feed mixture as a function of the total acid gas partial

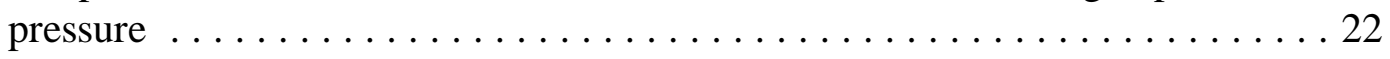

Figure 12. Selectivity for hydrogen sulfide and carbon dioxide over methane of Pebax® 1074 as a function of the total acid gas partial pressure . . . . . . . . . 23

Figure 13. Selectivity for hydrogen sulfide and carbon dioxide over methane of Pebax® 4011 as a function of the total acid gas partial pressure . . . . . . . . 23

Figure 14. Arrhenius-type plot of the pressure-normalized permeation flux of hydrogen sulfide, carbon dioxide, and methane in Pebax ${ }^{\circledR} 4011$ as a function of

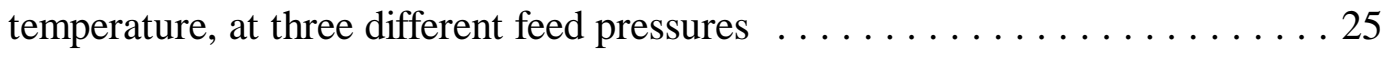

Figure 15. Arrhenius-type plot of the pressure-normalized permeation flux of hydrogen sulfide, carbon dioxide, and methane in Pebax ${ }^{\circledR} 1074$ as a function of

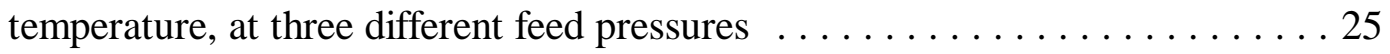




\section{LIST OF FIGURES - Continued}

Figure 16. Effect of feed gas temperature on membrane selectivity to hydrogen sulfide and carbon dioxide over methane for Pebax ${ }^{\circledR} 4011 \ldots \ldots \ldots \ldots 26$

Figure 17. Effect of feed gas temperature on membrane selectivity to hydrogen sulfide and carbon dioxide over methane for Pebax ${ }^{\circledR} 1074 \ldots \ldots \ldots . \ldots 26$

Figure 18. Comparison of the separation performance of the two Pebax grades studied . . 27

Figure 19. Effect of feed pressure on (a) the carbon dioxide/methane selectivity and (b) the hydrogen sulfide/methane selectivity of three Pebax 4011/PVDF

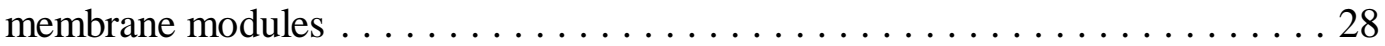

Figure 20. Effect of feed pressure on (a) carbon dioxide/methane and (b) hydrogen sulfide/methane selectivity in stamps and modules made from the redesigned

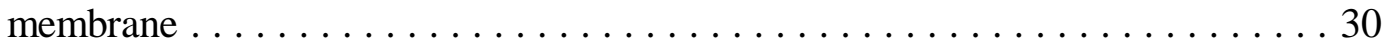

Figure 21. Permeation flux in modules manufactured with the new membrane

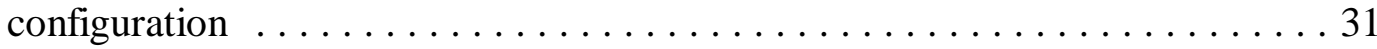

Figure 22. P\&ID of test skid used in field tests of hydrogen sulfide separation modules . . 33

Figure 23. Schematic of test skid hook-in at Bryans Mill Facility . . . . . . . . . . 35

Figure 24. Sample gas chromatograph obtained from column B . . . . . . . . 36

Figure 25. Schematic diagram showing the method of connecting sample canisters to gas

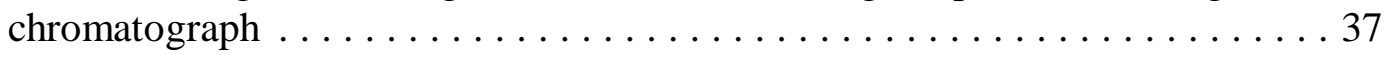

Figure 26. Schematic diagram of a Tutweiler buret $\ldots \ldots \ldots \ldots \ldots \ldots \ldots \ldots$

Figure 27. Schematic diagram of the Tutweiler testing apparatus $\ldots \ldots \ldots \ldots$

Figure 28. Hydrogen sulfide/methane selectivity over a range of feed pressures for module tests in the field compared with results obtained for membrane stamps

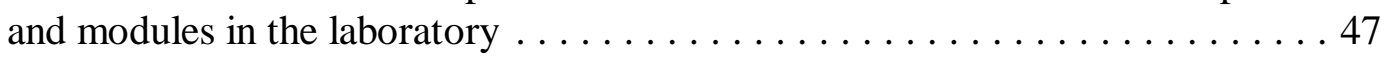

Figure 29. Carbon dioxide/methane selectivity over a range of feed pressures for module tests in the field compared with results obtained for modules in the

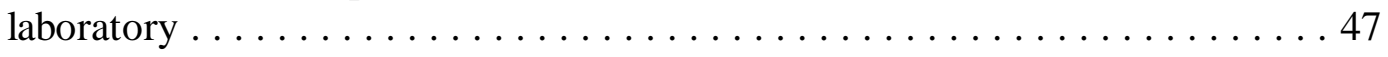




\section{LIST OF FIGURES - Continued}

Figure 30. Hydrogen sulfide and carbon dioxide content of natural gas reserves in eight states (indicated by different symbols) that are known to contain hydrogen

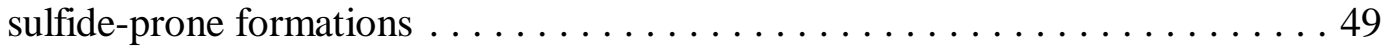

Figure 31. Overall treatment scheme for hydrogen sulfide-contaminated, subquality

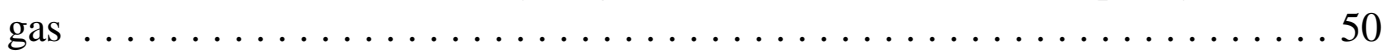

Figure 32. Application envelopes for absorption and membrane processes to treat sour

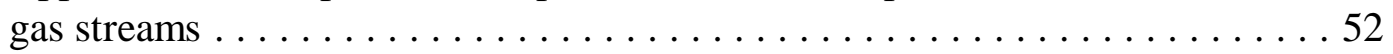

Figure 33. Three possible membrane process configurations for sour gas treatment . . . . 53

Figure 34. Schematic diagram of the membrane/SulfaTreat ${ }^{\circledR}$ hybrid process $\ldots \ldots \ldots 5$

Figure 35 . Schematic diagram of amine adsorption process $\ldots \ldots \ldots \ldots \ldots$

Figure 36. Effect of varying hydrogen sulfide and carbon dioxide feed concentration on the installed capital cost at a feed flow rates from 2 to 20 MMscfd . . . . . 60

Figure 37. Effect of varying hydrogen sulfide and carbon dioxide feed concentration on the installed capital cost at feed flow rates from 2 to 20 MMscfd . . . . . . 62

Figure 38. Design for a complete sulfur removal/recovery system for the removal of hydrogen sulfide from subquality natural gas . . . . . . . . . . . 64

Figure 39. Flow diagram of membrane/amine absorption hybrid process $\ldots \ldots \ldots . \ldots 68$

Figure 40. Comparison of installed capital cost for a membrane/amine hybrid process and

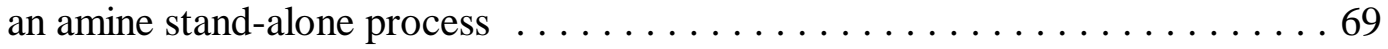

Figure 41. Comparison of processing costs for a membrane/amine hybrid process and an

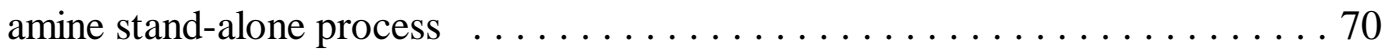

Figure 42. Effect of fuel gas cost on the processing cost for the two configurations

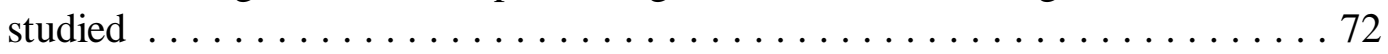

Figure 43. Effect of membrane cost on the installed capital cost for the two

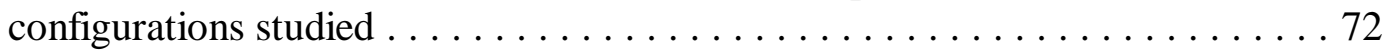

Figure 44. Effect of membrane cost on the processing cost for the two configurations

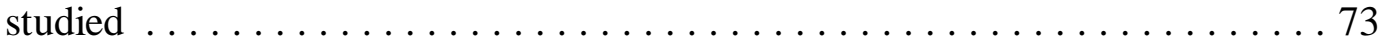




\section{LIST OF FIGURES - Continued}

Figure 45. Schematic diagram of membrane system and position in amine train $\ldots \ldots \ldots 76$

Figure 46. Schematic diagram of a two-and-one-half-stage membrane process for debottlenecking the amine section of a hydrotreater in a refinery . . . . . . 78

Figure 47. Schematic diagram of a two-and-one-half stage membrane process for bulk hydrogen sulfide removal from natural gas $\ldots \ldots \ldots \ldots \ldots . \ldots 79$

Figure 48. Schematic diagram of a membrane/absorption hybrid process for hydrogen

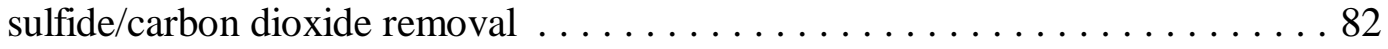




\section{LIST OF TABLES}

Table 1. Pipeline Specifications and Range of Natural Gas Compositions Found in the

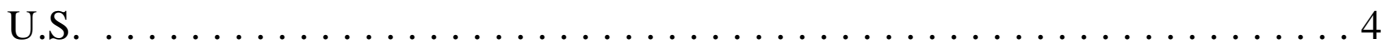

Table 2. Feed Gas Compositions Used in Parametric Testing of Selected Membranes ........................... 17

Table 3. Permeation Properties of the Pebax® 4011 Membrane with Various Feed Gas Compositions at Three Feed Pressures . . . . . . . . . . . . . . . . . . . 19

Table 4. Permeation Properties of the Pebax ${ }^{\circledR} 1074$ Membrane with Various Feed Gas Compositions at Three Feed Pressures . . . . . . . . . . . . . . . 20

Table $5 . \quad$ Composition of Gas from Well BMU $-12 \ldots \ldots \ldots \ldots \ldots \ldots$

Table 6. Compositions of Gas Mixtures Used to Calibrate the Gas Chromatograph . . . 36

Table 7. Summary of Trips to Bryans Mill Field Test Site Shell Plant in Texas . . . . . 39

Table 8 List of Modules Manufactured for the Field Test $\ldots \ldots \ldots \ldots \ldots$

Table 9. System Operating Conditions at Field Site $\ldots \ldots \ldots \ldots \ldots \ldots \ldots$

Table 10. Results of Low-Pressure Tests on Pilot System Modules . . . . . . . . . . 42

Table 11. Results of Pressure and Flow Rate Variation Experiments on Module 935 . . . 43

Table 12. Results Obtained from Pressure and Flow Rate Variation Experiments on

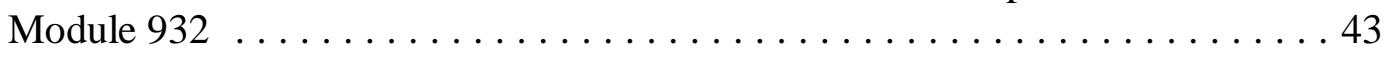

Table 13. Feed and Residue Conditions for Four Tests Performed at the Bryans Mill Field Site ........................ 44

Table 14. Performance of Modules Tested at the Bryans Mill Field Site . . . . . . . . . 44

Table 15. Operating Conditions of System Upon Departure from Test Site

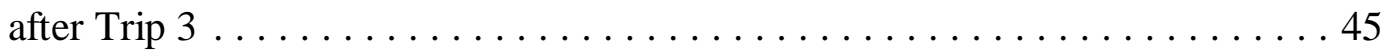

Table 16. Averaged Results from Stamp Tests on Hydrogen Sulfide Module

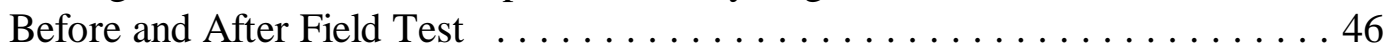

Table 17. Options for Bulk Removal of Acid Gases from Subquality Natural Gas . . . . . 50

Table 18. Options for Secondary Polishing Treatment to Meet Pipeline Specification . . . 51 


\section{LIST OF TABLES - continued}

Table 19. Options for Recovery of Sulfur from Hydrogen-Sulfide-Enriched Stream . . . . 51

Table 20. Natural Gas Compositions Used in the Design and Economic Evaluation . . . . 57

Table 21. Base-Case Process-Related Conditions Used in Economic Calculations for Membrane Process . . . . . . . . . . . . . . . . . 57

Table 22. Cost Assumptions Used in Economic Calculations for the Membrane/

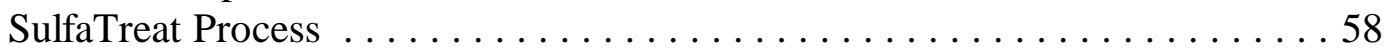

Table 23. Cost Assumptions Used in Economic Calculations for the Amine Absorption Process . . . . . . . . . . . . . . . . . . . . . . . . . . . 58

Table 24. Feed Gas Conditions for 0.1 Ton Sulfur (as hydrogen sulfide)/Day Plant . . . 64

Table 25. Main Equipment Requirements for Hydrogen Sulfide Removal Step . . . . . . 65

Table 26. Main Equipment Requirements for Locat-II Sulfur Recovery Step . . . . . 65

Table 27. Capital and Processing Costs for Complete 0.1 Ton Sulfur (as Hydrogen Sulfide)/Day Sulfur Removal/Recovery Process Plant . . . . . . . . . . . . . 66

Table 28. Base-Case Feed Conditions for Membrane/Amine Hybrid Process. . . . . . . . . 67

Table 29. Base-Case Process Conditions for Membrane/Amine Hybrid Process . . . . . . 68

Table 30. Situation 1: Debottlenecking Amine Absorbers for Increased Production . . . . 74

Table 31. Situation 2: Debottlenecking Amine Absorbers for Changed Acid Gas

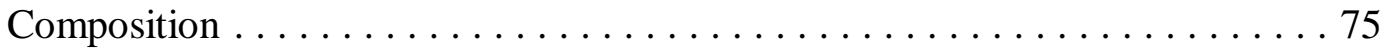

Table 32. Assumed Feed Conditions for Refinery Debottlenecking Application . . . . . . 76

Table 33. Residue and Permeate Compositions and Conditions for Three Cases of Hydrogen Sulfide Removal by the Membrane Process . . . . . . . . . . . . . . 77

Table 34. Membrane Area Requirements and Membrane System Capital Cost Estimates .............................. 77

Table 35. Basis for Calculations for Case Study No. $3 \ldots \ldots \ldots \ldots \ldots \ldots$

Table 36. Basis for Calculations for Case Study No. $4 \ldots \ldots \ldots \ldots \ldots \ldots \ldots$ 


\section{LIST OF TABLES - continued}

Table 37 Membrane System Costs for Three Different Hydrogen Sulfide Removals _ . . 82 


\section{EXECUTIVE SUMMARY}

The objective of this project was to develop and demonstrate a membrane process to remove hydrogen sulfide and other impurities (carbon dioxide and water vapor) from low-quality natural gas. Recent studies of U.S. natural gas needs and reserves have shown that projected demand will exceed supplies by the year 2000. For the United States to be self-sufficient in this important energy resource, new fields and formations will have to be tapped. However, recent studies suggest that a significant portion of existing reserves are low-quality due to presence of hydrogen sulfide, carbon dioxide, and nitrogen. New gas fields are expected to be more remote and smaller than those operating currently. Also, more than $13 \%$ of current reserves are known to be contaminated with hydrogen sulfide. A Purvin and Gertz study for GRI projects that $\$ 30-40$ million will be invested in new natural gas treatment facilities every year. The U.S. Department of Energy (DOE) has recognized these trends and has identified a specific need to develop new technology for the economical removal and recovery/disposal of sulfur from sulfur-contaminated natural gas (sour gas) in an environmentally acceptable manner. DOE has also stressed a particular need for processes applicable to small-scale plants.

Membrane Technology and Research, Inc. (MTR) has developed membranes that are extremely selective in separating hydrogen sulfide and water from natural gas and are modestly selective for carbon dioxide. A process based on these membranes to remove hydrogen sulfide and water vapor, as well as significant amounts of carbon dioxide, from natural gas will be costcompetitive with the amine absorption processes used currently, especially in small-scale plants. Membrane processes offer significant advantages over current processes, including greater operational reliability, lower maintenance, and greater flexibility to changing feed conditions. Membrane processes are particularly suitable for off-shore gas processing.

In the first phase of the project, an experimental study was carried out to assess the performance of MTR's membranes under various feed conditions. Composite membranes made from four different polymers were investigated to determine their hydrogen sulfide/methane and carbon dioxide/methane selectivity. Two polymers were selected for a further parametric study. The following variables were studied: the hydrogen sulfide and carbon dioxide content of the feed gas, the presence of water vapor in the feed gas, and the temperature of the feed gas. Experiments were performed over the feed-pressure range 400-1,000 psig.

The parametric study showed that the membranes have a hydrogen sulfide/methane selectivity of 40-70 and a carbon dioxide/methane selectivity of 14-16. These selectivities are maintained at pressures as high as $1,000 \mathrm{psig}$ and with water vapor present in the feed gas. The methane flux of these membranes is twice that of commercially available cellulose acetate membranes; the hydrogen sulfide/methane selectivity is two to three times higher.

Membrane preparation was scaled up successfully to produce 40 -inch-wide continuous rolls of membrane on MTR's commercial-scale coating machine. The membranes were tested in the form of spiral-wound modules using a high-pressure module test system designed for complete recycle 
operation. The results of the laboratory module tests were encouraging, and indicated readiness to move to field testing to establish stable long-term performance and hydrogen sulfide/methane selectivities under typical real-world operating conditions.

In the second phase of the project, the membrane process was field tested at a Shell facility in East Texas. In this short-duration test, the membranes were exposed to raw natural gas after only simple vapor-liquid separation. The gas contained $3.0 \mathrm{~mol} \%$ hydrogen sulfide. The results were encouraging. Analysis indicated a hydrogen sulfide/methane selectivity of about 35 under those conditions. This selectivity was only slightly lower than that obtained in the laboratory testing with much cleaner gas streams. Unfortunately, a long-term stability test could not be performed due to changing conditions at the plant, which curtailed the test. Another, longer-term field test is planned for 1998 to further demonstrate the technology.

Potential applications of the MTR membranes to sour gas treatment and appropriate membrane process designs were studied. The technical and economic aspects of these membrane processes were analyzed. A single-stage membrane step combined with a SulfaTreat ${ }^{\circ}$ polishing step to remove hydrogen sulfide to pipeline specifications was found to be less expensive than conventional amine-based absorption processes, particularly for streams with low flow rates and high acid gas contents. In another region of the application envelope-high flow rates and high hydrogen sulfide concentrations (750 MMscfd and 10\% hydrogen sulfide)—calculations indicated that a membrane/amine hybrid system may offer substantial economic advantages. In this region the membrane process will typically reduce the hydrogen sulfide content by $50-80 \%$ prior to amine absorption to bring the gas to pipeline specifications. 


\section{IDENTIFICATION AND SIGNIFICANCE OF THE PROBLEM}

Natural gas provides more than one-fifth of all the primary energy used in the United States. Much raw gas is "subquality," that is, it exceeds the pipeline specifications for nitrogen, carbon dioxide, and/or hydrogen sulfide content, and much of this low-quality natural gas cannot be produced economically with present processing technology.

Against this background, a number of industry-wide trends are affecting the natural gas industry. Despite the current low price of natural gas, long-term demand is expected to outstrip supply, requiring new gas fields to be developed. Several important consequences will result. First, gas fields not being used because of low-quality products will have to be tapped. In the future, the proportion of the gas supply that must be treated to remove impurities prior to delivery to the pipeline will increase substantially. ${ }^{1,2}$ The extent of treatment required to bring the gas up to specification will also increase. Gas Research Institute studies have shown that a substantial capital investment in facilities is likely to occur over the next decade. The estimated overall investment for all gas processing facilities up to the year 2000 alone is approximately $\$ 1.2$ Billion, of which acid gas removal and sulfur recovery are a significant part in terms of invested capital. ${ }^{3}$ This large market size and the known shortcomings of conventional processing techniques will encourage development and commercialization of newer technologies such as membrane processes.

Second, much of today's gas production is from large, readily accessible fields. As new reserves are exploited, more gas will be produced from smaller fields in remote or off-shore locations. The result is an increasing need for technology able to treat small-scale gas streams.

Third, $80 \%$ of raw gas that is over specification in carbon dioxide also contains hydrogen sulfide. ${ }^{2}$ About $13 \%$ of presently known and predicted reserves are prone to hydrogen sulfide contamination. ${ }^{1}$ As subquality fields are exploited, the need for better, cheaper hydrogen sulfide removal and sulfur recovery processes will increasing.

Finally, atmospheric discharge of sulfur compounds, either by venting or flaring, now commonly used, will be increasingly regulated for environmental reasons. ${ }^{4}$

The U.S. Department of Energy (DOE) has recognized these trends and has identified a specific need to develop new technology for the economical removal and recovery/disposal of sulfur from sulfur-contaminated natural gas (sour gas) in an environmentally acceptable manner. DOE is seeking advanced technologies that can meet the pipeline specification of no more than $4 \mathrm{ppm}$ hydrogen sulfide, while minimizing methane loss and satisfying environmental regulations. DOE has also stressed a particular need for processes applicable to small-scale plants. 


\section{BACKGROUND}

\subsection{Current Technologies and Their Shortcomings}

A representative range of the gas compositions found in the United States is compared to the specifications that must be met to bring the gas to pipeline quality in Table 1 .

Table 1. Pipeline Specifications and Range of Natural Gas Compositions Found in the U.S.

\begin{tabular}{|c|c|c|}
\hline Component/Parameter & $\begin{array}{c}\text { Pipeline } \\
\text { Specification }^{\mathrm{a}}\end{array}$ & $\begin{array}{l}\text { Range in Well } \\
\text { Compositions }\end{array}$ \\
\hline Hydrogen sulfide & $<4 \mathrm{ppm}$ & $\begin{array}{ll}76 \%: & <4 \mathrm{ppm} \\
11 \%: & 4-1,000 \mathrm{ppm} \\
4 \%: & 1,000-10,000 \mathrm{ppm} \\
8 \%: & >10,000 \mathrm{ppm}^{\mathrm{b}}\end{array}$ \\
\hline Water & $84-148$ ppm & $800-1,200$ ppm \\
\hline Carbon dioxide & $<1-3 \%$ & $\begin{array}{ll}72 \%: & <1 \% \\
18 \%: & 1-3 \% \\
7 \%: & 3-10 \% \\
3 \%: & >10 \%\end{array}$ \\
\hline $\begin{array}{l}\text { Inerts }\left(\mathrm{CO}_{2}, \mathrm{~N}_{2}, \mathrm{He}, \mathrm{Ar} \text {, }\right. \\
\text { etc. }) \\
\text { Oxygen }\end{array}$ & $\begin{array}{l}<3-4 \% \\
<0.4 \%\end{array}$ & $\begin{array}{l}- \\
-\end{array}$ \\
\hline $\begin{array}{l}\text { Hydrocarbon dew point at } \\
800 \text { psig }\end{array}$ & $\begin{array}{l}<15^{\circ} \mathrm{F} \\
>700 \mathrm{psig}\end{array}$ & $\begin{array}{l}- \\
-\end{array}$ \\
\hline $\begin{array}{l}\text { Delivery pressure } \\
\text { Heating value }\end{array}$ & 950-1,100 Btu/scf & - \\
\hline
\end{tabular}

${ }^{\text {a }}$ Pipeline specifications vary slightly from state to state. Values shown are typical ranges.

${ }^{\mathrm{b}}$ Composition given is that of producing wells reported in a 1982 American Petroleum Institute Survey. ${ }^{5}$ Unexploited reserves are expected to contain a significantly higher fraction of subquality gas.

Currently, more than half of the gas produced in the United States can be brought to pipeline specification after minimal treatment, such as glycol dehydration, to remove water. ${ }^{1}$ The remainder 
is treated to remove one or more of the following contaminants: carbon dioxide, hydrogen sulfide, heavy hydrocarbons, and nitrogen. Raw gas known to be high in nitrogen content, high in nitrogen plus carbon dioxide content, or high in hydrogen sulfide content is usually left in the ground. However, these reserves are likely to be used in the future to meet demand. In this section, the existing technologies to treat subquality, sour natural gas are discussed.

At present, large sour gas streams containing above 200 ppm hydrogen sulfide use aminebased technology. Amines commonly used include MEA, DEA, DIPA, DGA, and MDEA. ${ }^{6}$ The plants can remove both carbon dioxide and hydrogen sulfide. When the amine solution is spent, the acid gases are flashed off and the solution is regenerated. Operational reliability is probably the weakest feature of amine plants; the mechanical equipment in an amine plant makes it susceptible to failure. The plant includes heaters, air coolers, pumps, etc. and requires frequent quality checks and maintenance. Corrosion in the amine regeneration reboiler is an issue, and problems associated with foaming and amine losses from stripper overhead are frequently cited and discussed in the literature. ${ }^{6}$

Low-volume, low-concentration sour gas streams ${ }^{7-11}$ are best treated by specialized scavenging or Redox sulfur recovery processes, such as Stretford, LO-CAT, Sulfa-Scrub, SulfaCheck, Chemsweet, Supertron 600, solid iron sponge or solid zinc oxide. However, many scavengers present substantial disposal problems, and in a number of states, the spent scavenger constitutes toxic waste.

Small gas streams can also be treated by membrane plants; it is estimated that about 100 have been installed. These plants principally remove carbon dioxide, but hydrogen sulfide is also extracted. The problem here is the selectivity of the membranes; as much as $12 \%$ methane, or more, may be lost with the sour stream.

Disposal of acid gas from the treatment plant is also a significant issue. A 1982 survey $^{5}$ showed that $15 \%$ of acid gas streams were vented, $30 \%$ flared, $11 \%$ incinerated, and only $26 \%$ subjected to sulfur recovery. Sulfur recovery, when practiced, was mostly by the Claus process ( $85 \%)$ and by liquid Redox treatment in the remainder of cases. ${ }^{2}$ Since the 1982 survey, regulations governing sulfur emissions have tightened considerably. At present, a Federal Guideline requires States to perform a Prevention of Significant Deterioration (PSD) review in situations where emissions correspond to 2 long tons/day or more of sulfur. Within this guideline, state regulations still vary widely. For example, in Texas, Standard Exemption Number 66 allows venting of up to $4 \mathrm{lb} / \mathrm{h}$ of raw hydrogen sulfide, although, above a certain concentration, flaring is required. The same exemption allows emission of up to 25 ton/year of sulfur dioxide. In Wyoming, no specific exemptions exist, but a permit, or waiver of permit, may be granted following a ground level dispersion review. Acid gas from amine plants is often reinjected into the formation. In Oklahoma, 100 ton/year of sulfur dioxide may be flared. Above this limit, a BACT (Best Available Control Technology) review is needed, the best available technology being a Claus plant. 
From these few specific examples, it can be seen that present regulations are diverse, and that, in many cases, little or no sulfur recovery technology is practiced. As dirtier fields are exploited, this cannot continue.

\subsection{Membrane Processes and Their Applicability}

The membrane separation system for removing hydrogen sulfide from natural gas developed by MTR is based on a family of polymers that can be formed into membranes with remarkable hydrogen sulfide separating properties. This membrane differs from those already used in natural gas processing for carbon dioxide removal.

Membrane systems can be scaled to handle large or small gas flows. They can also be adapted to handle a wide range of hydrogen sulfide concentrations and gas flows that vary over time. This versatility is a powerful advantage over other technologies. Membrane systems are light in weight compared with amine plants, have no moving parts, require little supporting equipment, do not need regenerating, and require essentially no maintenance. These attributes make them ideal for use in remote locations and in small-scale applications and give them attractive technical and operational advantages over amine plants.

Depending on the reserves, the productivity of a gas field decreases with time. Upon exhaustion of the reserves in a particular formation, it would be desirable to move the treatment plant to another location. This is virtually impossible for conventional processes. However, membrane systems are skid-mounted, making it relatively simple to move them from one location to another. This feature of membrane processes may be especially useful to operators exploring smaller fields within a formation, by reducing the cost of gathering systems and/or by allowing the use of the same system at different locations without incurring a large investment in new installations.

Based on these attributes, it appears reasonable to suppose that membranes will be applicable and will have advantages in the following situations:

1. The gas is contaminated with hydrogen sulfide, but is at or near specification in carbon dioxide content (2-5\%). An amine plant may not be economically attractive in such a situation.

2. The gas field is in a remote location, where operational simplicity and reliability are of paramount importance.

3. The field is relatively small, producing less than $50 \mathrm{MMscfd}$.

4. An off-shore gas production platform is to be constructed.

It should be noted that the environments identified in 1-4 above as particularly appropriate for membrane systems match very closely the environments in which reserves are not now exploited 
because of inadequate technology. A membrane system with adequate hydrogen sulfide separating capabilities will proved the government and the private sector with a technology to make utilization of low-quality natural gas possible.

A number of workers have examined membrane materials for hydrogen sulfide removal from natural gas in the past. ${ }^{12,13}$ Some materials with hydrogen sulfide/methane selectivities in the range 20-30 have been found. In our opinion, these selectivities are not adequate to make a hydrogen sulfide removal process with membranes attractive. Our calculations show that a membrane selectivity of greater than 50 , and preferably 80 or more, is required.

In a previous DOE project (DE-AC-87PC79856), we had identified a class of polymers based on polyamide-polyether copolymers and available as Pebax® (Atochem Inc., Glen Rock, NJ), that exhibit remarkable permeability and selectivity when tested with natural gas mixtures. ${ }^{13}$ The generic structure of this family of thermoplastic elastomer resins is shown in Figure 1. The polymers consist of linear chains of rigid polyamide blocks and flexible polyether blocks.

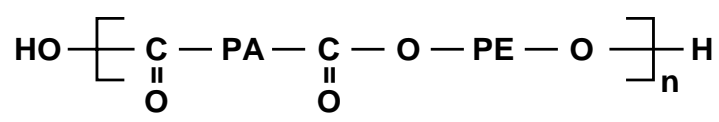

$241 \mathrm{~A}-\mathrm{F}$

Figure 1. Generic structure of a polyamide-polyether copolymer. PA is a polyamide segment; PE is a polyether segment.

To be industrially useful, a membrane must have high flux as well as high selectivity. Also, the membrane manufacturing process has to be optimized to produce ultrathin, defect-free membranes continuously. MTR produces composite membranes having the structure illustrated in Figure 2 . The basic structure of the membrane comprises a tough, open microporous polymer layer that provides mechanical robustness and an ultrathin, dense polymer coating that is responsible for the separation properties. $^{14}$ These membranes have high fluxes.

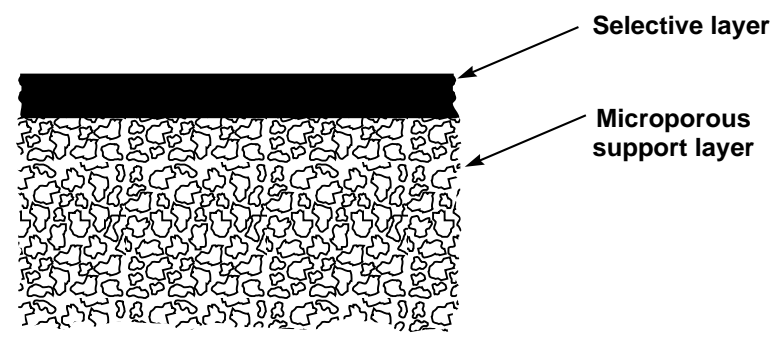

Figure 2. Schematic diagram of an MTR composite membrane.

The membranes are fabricated into spiral-wound membrane modules. In these modules, the membrane is supported on the feed and permeate sides by plastic mesh spacers. The membrane and spacers are wound spirally around a central collection pipe. A schematic of a membrane module is 
given in Figure 3. Feed gas enters the module and flows between the membrane layers. The component of the feed that is preferentially permeated by the membrane spirals inward to the central collection pipe. The remainder of the feed flows across the membrane surface and exits as the residue. To meet the capacity and separation requirements for particular applications, modules are connected in serial or parallel flow arrangements.

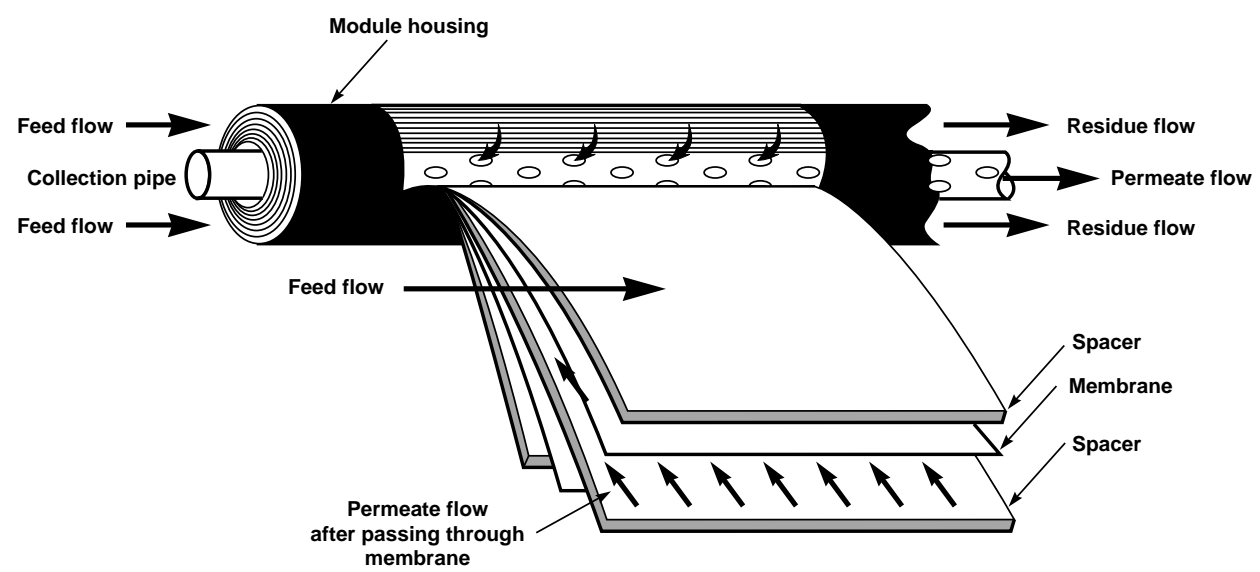

Figure 3. Schematic diagram of a spiral-wound membrane module.

\section{PROJECT OBJECTIVES AND APPROACH}

\subsection{Overall Project Objectives and Approach}

The overall project comprised three tasks:

Task 1. Prepare NEPA Information.

Task 2. Proof of Concept/Conceptual Design.

Task 3. Bench Scale Testing.

The objective of Task 2, the proof-of-concept phase of the project, was to develop a better understanding of the process and of the technical feasibility and range of applications of membrane technology for hydrogen sulfide separation in the gas industry. The Task 2 work provided answers to the following questions:

1. Can the existing membrane selectivity data be verified in laboratory membrane test cells and small laboratory membrane modules using simulated natural gas mixtures? Do other components, such as water, carbon dioxide and higher hydrocarbons, adversely affect the hydrogen sulfide separation properties?

To answer these questions, the "best" membrane was selected from a family of polyamide-polyether copolymers, based on the separation performance. This membrane was further developed and production was scaled up. Extensive 
parametric testing was performed with membrane stamps, then with modules. To perform these tests, equipment that could be used safely with hydrogen sulfide was built. The results of this study provided the technical data needed to evaluate the feasibility and to assess the likely optimum applications for the membranes.

2. Based on the experimental membrane flux and selectivity data, what are the optimum applications and types of feed gas compositions for these membranes? How can these membranes best be integrated with other separation technologies?

To obtain information to answer these questions, formations within the Lower-48 states and fields within those formations that are contaminated with hydrogen sulfide were identified. To evaluate the fraction of reserves that can be treated with membranes, the feed composition data from these formations were characterized. GRI-sponsored research in the form of the EMPRESS data base characterizing the Lower- 48 reserves was consulted for this task. ${ }^{2}$

3. Based on a design study for a gas stream containing 0.1 ton/day of sulfur, how do the economics of this process compare with alternative technologies? What is the optimum method of recovering the removed hydrogen sulfide for ultimate conversion to sulfur?

To answer these questions, a conceptual design of a plant to remove and recover 0.1 ton/day of sulfur from subquality natural gas was prepared. The plant comprises a membrane process to remove the bulk of the hydrogen sulfide and carbon dioxide, a SulfaTreat bed to polish the treated gas to pipeline specification for hydrogen sulfide, and a LOCAT-II process to recover the sulfur in the membrane permeate stream as a solid product. The capital and operating costs of this plant were compared with those of a conventional amine absorption and Redox process.

In Task 3, the principal questions to be addressed were:

1. Can the membranes and modules be scaled up to the size required for an industrial process?

Membrane production was scaled up from 5-ft-long sheets about 12 in wide to 200 -ft-long rolls of 40 -in-wide membrane. Scale-up of the membrane production required some innovative modifications to our existing coating process, because the coating solution had to be maintained at a high temperature. Viscous Pebax solution at $50^{\circ} \mathrm{C}$ was continuously circulated in the coating tray to produce a uniform nondefective thin coating. During this task we also developed a new support membrane with greater pressure stability for natural gas applications. 
Module production was scaled up from single-sheet, 12-in-wide, 1-ft-long spiralwound modules to double-sheet, 3 -in-wide, 3-ft-long modules. In related projects, which fed from the experience accumulated from this project, spiral-wound modules were successfully scaled up to state-of-the-art 8-in-diameter modules.

2. When tested with gas streams under field conditions, do these modules have the reliability and performance required?

The field tests with spiral-wound modules gave encouraging results. The membrane modules were exposed to raw natural gas with only a simple knock-out drum to remove liquids from the gas stream. The feed gas, containing $3 \mathrm{~mol} \%$ hydrogen sulfide, was upgraded to approximately $50 \mathrm{~mol} \%$ hydrogen sulfide in the permeate stream in the performance test. This corresponds to a hydrogen sulfide/methane membrane selectivity of about 35 , only $10-15 \%$ lower than that obtained with a clean laboratory stream.

3. Using actual field performance data, does the complete process show sufficient benefits compared to alternative existing technology to encourage industry adoption?

The technical and economic analysis was performed using the selectivities obtained in the field test. Two regions in the application envelope were identified wherein a membrane process can add value to gas treatment. The first application is streams with at low flow rates ( $<10 \mathrm{MMscfd})$ and high hydrogen sulfide contents ( $>5 \mathrm{~mol} \%$ ). The use of a membrane/SulfaTreat hybrid portion could result in lower capital and operating expenses than conventional amine systems. The key issue to be addressed in this application is the final disposition of the acid gas stream.

The second area in which membranes are likely to find an application is bulk acid gas separation for streams with high flow rates and high acid gas contents. A membrane/amine hybrid process will lower the capital and operating costs compared to conventional amine- alone treatment processes. 


\subsection{Task 2 Activities}

The activities within Task 2 were divided into the following ten subtasks:

2.1 Prepare Membranes and Modules

2.2 Construct Test System

2.3 Hydrogen Sulfide/Carbon Dioxide/Methane Mixture Test Experiments

2.4 Modify Membranes

2.5 Laboratory-Scale Module Test

2.6 Initial Survey of Potential Membrane Applications

2.7 Select Optimum Applications

2.8 Design and Cost Industrial-Scale Plant

$2.9 \quad$ Prepare Bench-Scale Research Plan

2.10 Program Management/Prepare Reports

\subsection{Task 3 Activities}

The activities within Task 3 were divided into the following eight subtasks:

3.1 Membranes and Modules

3.2 Design and Construct Test System

3.3 Evaluate System in Laboratory

3.4 Prepare System Manuals

3.5 Select Field Site

3.6 Install and Operate System at Field Site

3.7 Prepare Technical and Economic Evaluation

3.8 Program Management/Prepare Reports

All of these tasks were fully completed; the results of the work are presented and discussed in the following sections.

\section{MEMBRANE AND MODULE DEVELOPMENT}

\subsection{Experimental Equipment and Procedures}

\subsubsection{Membrane Preparation}

The composite membranes were made by a multistep process: microporous support casting, followed by coating with a sealing layer and then the ultrathin selective layer. Membranes prepared for the initial part of the project comprised only a selective layer coated directly onto the support layer. As the membrane was developed further, a sealing layer was added between the support and selective layers (see Section 4.2.5). 
The casting machine used to prepare the microporous support is shown in Figure 4. The casting solution, consisting of the polymer dissolved in a water-miscible solvent, is doctored onto a moving web. The web passes into a water bath, which precipitates the polymer to form the film. The web is then collected on a take-up roll, after which the membrane is washed overnight to remove any remaining solvent and dried to form the support film. A 12-inch-wide casting machine is used to prepare membranes for stamp tests and a 40-inch-wide casting machine is used to prepare membranes for full-sized modules. The quality of the microporous support membrane is important in preparing ultrathin, highly selective composite membranes.

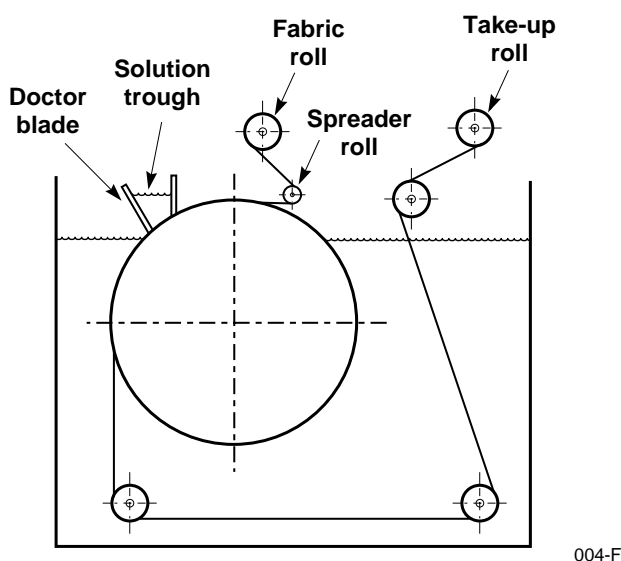

Figure 4. Schematic diagram of a support membrane casting machine.

The equipment used to deposit the other polymer layers on the support membrane is shown in Figure 5. The support membrane from a feed roll passes through a coating station, which contains a dilute solution of the polymer and coats the traveling membrane support with a liquid layer. After evaporation of the solvent in a drying oven, a polymer film is left on the membrane.

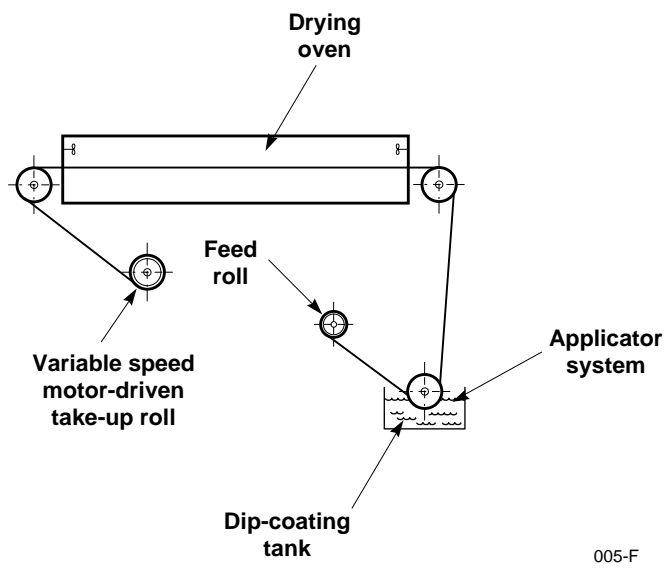

Figure 5. Schematic diagram of thin-film coating apparatus.

The thickness of the selective coating is calculated by comparing the nitrogen flux of the composite membrane with that of a thick film of the same selective material. As part of our normal QA/QC procedures, all composite membranes are checked for integrity of the selective layer by 
measuring the nitrogen, methane and carbon dioxide fluxes and calculating the pure gas selectivity of the membrane. These selectivity values are then compared with those of a perfect thick film.

\subsubsection{Evaluation of Membrane Properties}

Defect-free composite membranes were evaluated with gas mixtures using the permeation test system shown in Figure 6. The membranes were tested with different multicomponent mixtures representing the range of probable hydrogen-sulfide-containing natural gas compositions in actual fields.

Feed gas for the tests is taken from custom-made gas mixtures. The permeate side of the membrane is always maintained at close to atmospheric pressures. The compositions of feed, residue and permeate gases are analyzed by gas chromatography using a Hayesep-Q column and a thermal conductivity detector. The test system is operated inside a fume hood. The exhaust streams from the tests are treated with a lead acetate trihydrate to remove most of the hydrogen sulfide; the residual stream is then vented into the fume hood exhaust. Bubble flow meters are used to determine the flow rates of the permeate and residue streams.

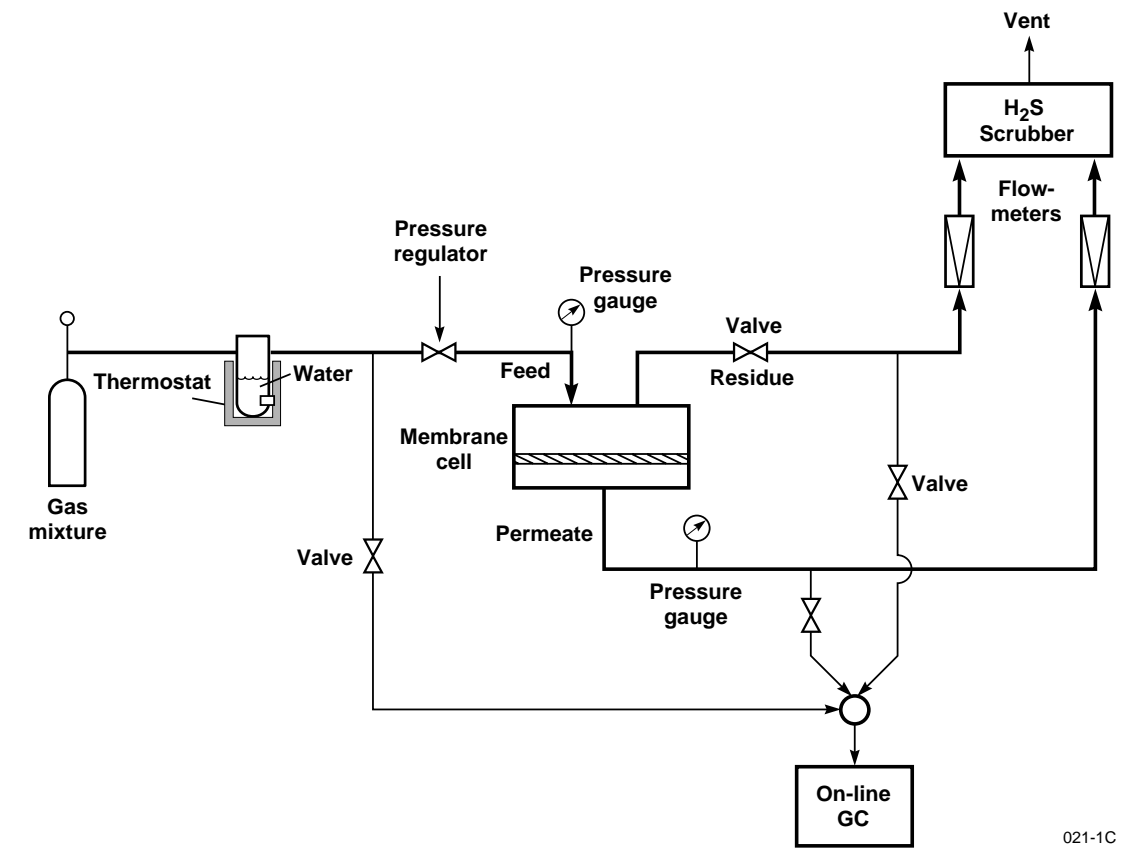

Figure 6. Flow diagram of mixed gas permeation test system. Samples can be withdrawn from feed, residue and permeate for GC analysis.

The pressure-normalized flux, $\mathrm{Q}\left[\mathrm{cm}^{3}(\mathrm{STP}) / \mathrm{cm}^{2} \cdot \mathrm{s} \cdot \mathrm{cmHg}\right]$, of each gas component is calculated from the relationship:

$$
Q=\frac{C_{p e r m} \cdot F_{p e r m}}{A \cdot\left[\left(p_{\text {feed }} \cdot C_{\text {feed }}\right)-\left(p_{\text {perm }} \cdot C_{\text {perm }}\right)\right]}
$$


where $\mathrm{C}_{\text {perm }}$ and $\mathrm{C}_{\text {feed }}$ are the concentrations of the gas component (volume fractions) in the permeate and feed streams, respectively; $F_{\text {perm }}$ is the total permeate volume flow rate $\left[\mathrm{cm}^{3}(\mathrm{STP}) / \mathrm{s}\right] ; A$ is the membrane area $\left[\mathrm{cm}^{2}\right]$; and $\mathrm{p}_{\text {feed }}$ and $\mathrm{p}_{\text {perm }}$ are the pressures $[\mathrm{cmHg}$ absolute] on the feed and permeate side of the membrane, respectively. The selectivities of the composite membrane for gas mixtures are calculated from the ratio of permeate fluxes for any gas pair.

Equation (1) is valid for calculating the permeation flux and selectivity of the membrane at very low stage-cuts (the ratio of permeate to feed flow) when the feed composition is equal to the residue composition. Stamp tests are used to obtain separation performance data for the membrane, rather than to demonstrate removal of the faster permeating component.

\subsubsection{Module Preparation}

The module-winding operation is shown schematically in Figure 7. The membrane is cut to size and folded around the feed spacer material and the product distribution pipe. The membrane envelope is then moved to the wind-up machine. The product collection pipe is placed in the jaws of a motor clutch, and the product spacer material is glued to the pipe. During the winding operation, the material is kept under a slight tension and the membrane envelope is glued along the edges and ends. When the module is fully wound, a layer of reinforced tape is used to seal it. The module is then housed in a stainless steel pressure vessel.

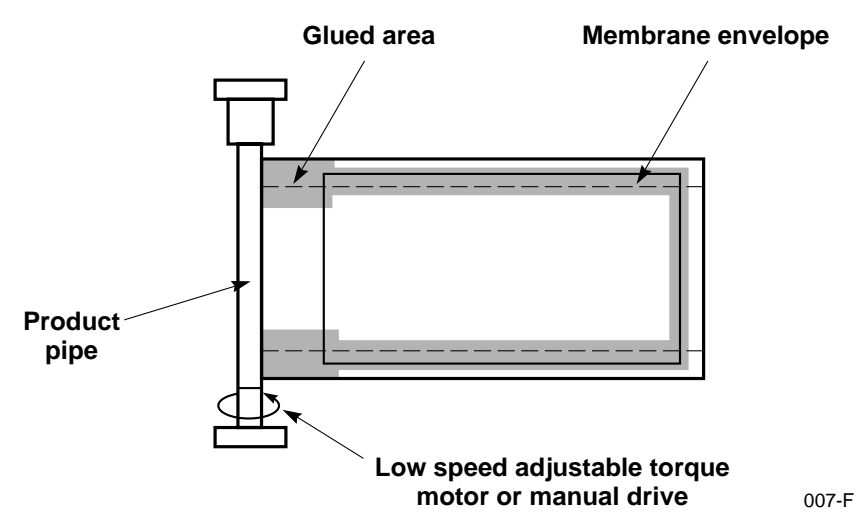

Figure 7. Schematic diagram of module-winding apparatus.

The selection of appropriate feed and permeate spacers and of the sealing glues is crucial to making a high-performance module. The dimensions and structures of the feed and permeate spacers strongly affect the overall separation performance of the membrane in module form. During Task 2 of this project we used our standard high-pressure feed and permeate spacers. In Task 3, we optimized module components to maximize the protection of the membrane from the spacer materials under high-pressure operation. 


\subsubsection{Evaluation of Module Properties}

An existing system was extensively redesigned for laboratory-scale module testing. Figure 8 shows the modified P\&ID and a photograph of this system. The entire system and the HOM-GAS compressor are enclosed in a specially constructed walk-in hood, which is connected to the main exhaust system of the building. The hood is surrounded by flexible plastic sheets to ensure maximum updraft within the hood. The entire system is mounted on a two-level skid: the top level contains all the control instrumentation; the bottom rack holds the coolant delivery system and the exhaust gas treatment system.
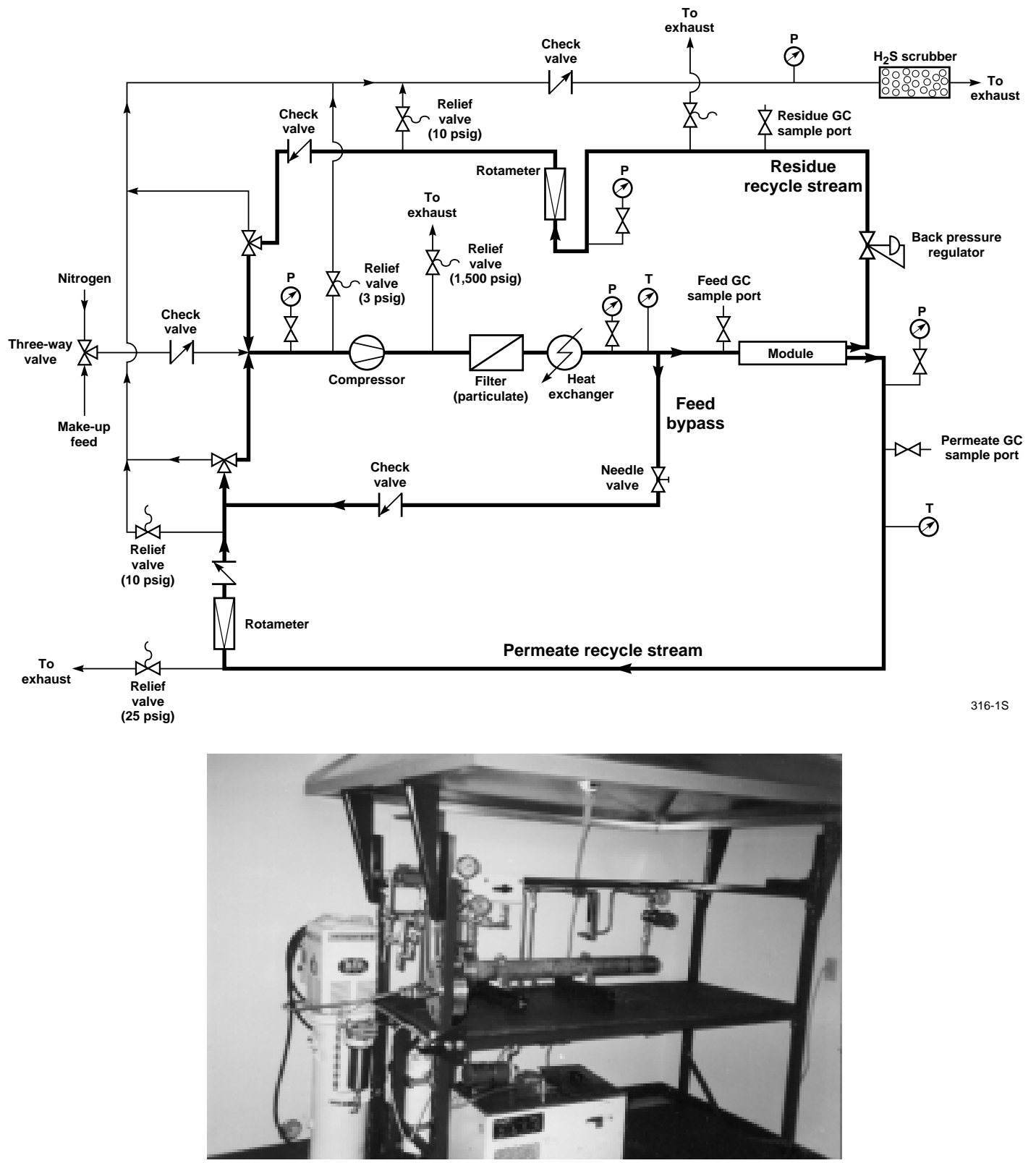

Figure 8. P\&ID and photograph of the module testing system used for evaluating the performance of the modules in the laboratory. 
The system is equipped with three ports for sampling the feed, permeate and residue streams, and rotameters for measuring the flow rates of the residue and permeate streams. Gas composition analysis is performed by gas chromatography using a Hayesep-Q column and thermal conductivity detector.

The system is built to minimize the loss of natural gas. Even for laboratory-scale modules with about $0.4 \mathrm{~m}^{2}$ membrane area, the amount of gas used for a single measurement is large. To allow long-term laboratory experiments, the gas is recycled by remixing the residue and permeate streams from the modules and feeding the mixture back to a compressor. The gas is then recompressed to the operating pressure and fed back into the module. This system minimizes the loss of gas, and allows continuous experiments to be run for as long as 8 hours. The HOM-GAS compressor has a discharge capacity of about $2 \mathrm{scfm}$, which limits the module feed flow rate. The reciprocating three-stage compressor can deliver discharge pressures of up to 3,600 psig. The flow rate of the feed gas entering into the module can be controlled by adjusting the bypass flow rate, allowing changes in the stage-cut in the module to be made.

As shown in Figure 8, the residue stream is expanded across a back-pressure regulator to near atmospheric pressure to measure its flow rate. The permeate stream is withdrawn from the module at atmospheric pressure. At the end of the experiment, the pressure in the system is slowly decreased to atmospheric by discharging both the residue and the permeate stream to the atmosphere through two lead acetate solid-absorbent columns. The hydrogen-sulfide-free methane is then discharged into the fume hood exhaust system.

Calculation of the permeation flux and selectivity of a membrane in a module experiment is more involved than for membrane stamps because the feed and residue compositions are not equal. During module experiments, the following parameters are measured: feed, residue and permeate compositions; residue and permeate flow rates; and feed and permeate pressures. A computer program based on the standard gas transport equation is used to calculate the pressure-normalized flux for each component from these data.

\subsection{Experimental Results and Discussion}

\subsubsection{Parametric Test Plan for Membrane Experiments}

The first step of the overall test plan consisted of screening several different polymers in the polyether-polyamide family and selecting the two most suitable polymers for further parametric testing. The polymers were tested as composite membranes, in which the polymer was coated onto a PVDF support membrane.

The screening experiments were designed to determine the membrane permeation fluxes and selectivities for hydrogen sulfide and carbon dioxide over methane. The tests were performed with a gas mixture containing about 800 ppmv hydrogen sulfide, $4 \%$ carbon dioxide, and the balance methane. 
After selection of the two best selective materials, a parametric test plan was designed to determine the effect on the separation performance of the following parameters:

- Feed hydrogen sulfide and carbon dioxide content

- Feed gas pressure

- Presence of water vapor in the feed gas

- Feed gas temperature

Table 2 lists the feed gas compositions used in the parametric testing. Gas mixtures 1 and 2 are two-component mixtures, whereas mixtures 3 through 6 are three-component mixtures. The tests were carried out at three feed pressures: 400, 600, and 970 psig.

Table 2. Feed Gas Compositions Used in Parametric Testing of Selected Membranes.

\begin{tabular}{||c|c|c|c|}
\hline \multirow{2}{*}{ Mixture No. } & \multicolumn{3}{|c|}{ Feed Gas Composition (vol\%) } \\
\cline { 2 - 4 } & $\mathrm{H}_{2} \mathrm{~S}$ & $\mathrm{CO}_{2}$ & $\mathrm{CH}_{4}$ \\
\hline 1 & 0.000 & 4.00 & 96.00 \\
\hline 2 & 0.097 & 0.00 & 99.90 \\
\hline 3 & 0.087 & 4.12 & 95.79 \\
\hline 4 & 0.986 & 4.12 & 94.90 \\
\hline 5 & 1.830 & 10.80 & 87.34 \\
\hline 6 & 0.095 & 8.14 & 91.77 \\
\hline
\end{tabular}

Tests to determine the effect of a water-saturated feed stream on the membrane permeation properties were performed using mixture no. 3. The test apparatus shown in Figure 6 was suitably modified to saturate the feed stream with water vapor.

Tests to determine the effect of temperature on the separation performance of the membrane were performed at 23,35 , and $45^{\circ} \mathrm{C}$. The feed gas temperature was controlled using heating tapes. Gas temperatures were monitored continuously during the experiments using in-line thermocouples.

\subsubsection{Selection of Membrane Material}

Composite membranes prepared from four grades of Pebax, 5533, 2533, 1074, and 4011, were evaluated in the initial screening of the selective polymer. A small stamp of each membrane was tested with mixture no. 3. Figure 9 shows the correlation between the carbon dioxide/methane and hydrogen sulfide/methane selectivity. This plot shows that, for this series of rubbery polymers, an increase in the carbon dioxide/methane selectivity results in a corresponding increase in the hydrogen 
sulfide/methane selectivity. Based on these screening tests, the Pebax 4011 and 1074 grades were selected for parametric testing.

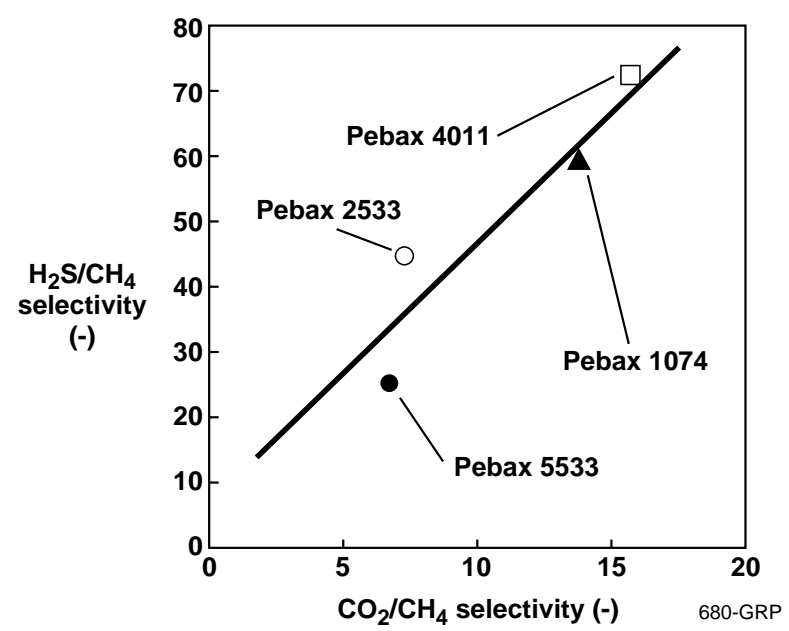

Figure 9. Correlation between the hydrogen sulfide/methane and the carbon dioxide/methane selectivity of four different Pebax grades. Tests were run with gas mixtures no. $3(4.12 \%$ $\mathrm{CO}_{2}, 0.087 \% \mathrm{H}_{2} \mathrm{~S}$ ) at 400 psig feed pressure.

\subsubsection{Parametric Tests with Pebax 4011 and Pebax 1074 Membranes}

\section{Effect of Feed Gas Composition}

The effect of varying the hydrogen sulfide and carbon dioxide content of the feed gas on the separation properties of the Pebax 4011 and 1074 membranes was determined. The results of the experiments for each of the gas mixtures listed in Table 2 are given in Tables 3 and 4 for Pebax 4011 and 1074, respectively. 
Table 3. Permeation Properties of the Pebax ${ }^{\circledR} 4011$ Membrane with Various Feed Gas Compositions at Three Feed Pressures.

\begin{tabular}{|c|c|c|c|c|c|c|}
\hline \multirow{2}{*}{$\begin{array}{c}\text { Feed Gas } \\
\text { Mixture }\end{array}$} & \multirow{2}{*}{$\begin{array}{l}\text { Feed } \\
\text { Pressure } \\
\text { (psig) }\end{array}$} & \multicolumn{3}{|c|}{$\begin{array}{l}\text { Pressure-Normalized Flux } \\
\left(10^{-6} \mathrm{~cm}^{3}(\mathrm{STP}) / \mathrm{cm}^{2} \cdot \mathrm{s} \cdot \mathrm{cmHg}\right)\end{array}$} & \multicolumn{2}{|c|}{$\begin{array}{c}\text { Membrane Selectivity } \\
(-)\end{array}$} \\
\hline & & $\mathrm{H}_{2} \mathrm{~S}$ & $\mathrm{CO}_{2}$ & $\mathrm{CH}_{4}$ & $\mathrm{H}_{2} \mathrm{~S} / \mathrm{CH}_{4}$ & $\mathrm{CO}_{2} / \mathrm{CH}_{4}$ \\
\hline \multirow{3}{*}{$\begin{array}{c}1 \\
0 \% \mathrm{H}_{2} \mathrm{~S} \\
4 \% \mathrm{CO}_{2}\end{array}$} & 392 & - & 31 & 1.9 & - & 17 \\
\hline & 589 & - & 30 & 1.9 & - & 16 \\
\hline & 960 & - & 29 & 2.0 & - & 15 \\
\hline \multirow{3}{*}{$\begin{array}{c}2 \\
0.097 \% \mathrm{H}_{2} \mathrm{~S} \\
0 \% \mathrm{CO}_{2}\end{array}$} & 388 & 91 & - & 1.8 & 51 & - \\
\hline & 588 & 74 & - & 1.8 & 41 & - \\
\hline & 970 & 73 & - & 1.8 & 41 & - \\
\hline \multirow{3}{*}{$\begin{array}{c}3 \\
0.087 \% \mathrm{H}_{2} \mathrm{~S} \\
4.12 \% \mathrm{CO}_{2}\end{array}$} & 386 & 140 & 31 & 1.9 & 70 & 16 \\
\hline & 589 & 115 & 30 & 2.0 & 56 & 15 \\
\hline & 974 & 110 & 29 & 2.2 & 52 & 14 \\
\hline \multirow{3}{*}{$\begin{array}{c}4 \\
0.986 \% \mathrm{H}_{2} \mathrm{~S} \\
4.12 \% \mathrm{CO}_{2}\end{array}$} & 389 & 113 & 32 & 2.0 & 55 & 16 \\
\hline & 586 & 103 & 31 & 2.0 & 51 & 15 \\
\hline & 971 & 97 & 29 & 2.0 & 48 & 14 \\
\hline $\begin{array}{c}5 \\
1.83 \% \mathrm{H}_{2} \mathrm{~S} \\
10.80 \% \mathrm{CO}_{2}\end{array}$ & 965 & 121 & 34 & 2.4 & 50 & 14 \\
\hline \multirow{3}{*}{$\begin{array}{c}6 \\
0.095 \% \mathrm{H}_{2} \mathrm{~S} \\
8.14 \% \mathrm{CO}_{2}\end{array}$} & 391 & 93 & 26 & 1.6 & 58 & 16 \\
\hline & 585 & 108 & 32 & 2.0 & 52 & 15 \\
\hline & 970 & 93 & 28 & 1.9 & 48 & 14 \\
\hline \multirow{3}{*}{$\begin{array}{c}\text { 3, satd. with } \\
\text { water }\end{array}$} & 387 & 77 & 19 & 1.0 & 75 & 18 \\
\hline & 588 & 74 & 20 & 1.2 & 61 & 17 \\
\hline & 970 & 69 & 18 & 1.2 & 59 & 16 \\
\hline
\end{tabular}


Table 4. Permeation Properties of the Pebax ${ }^{\circledR} 1074$ Membrane with Various Feed Gas Compositions at Three Feed Pressures.

\begin{tabular}{|c|c|c|c|c|c|c|}
\hline \multirow{2}{*}{$\begin{array}{l}\text { Feed Gas } \\
\text { Mixture }\end{array}$} & \multirow{2}{*}{$\begin{array}{l}\text { Feed } \\
\text { Pressure } \\
\text { (psig) }\end{array}$} & \multicolumn{3}{|c|}{$\begin{array}{l}\text { Pressure-Normalized Flux } \\
\left(10^{-6} \mathrm{~cm}^{3}(\mathrm{STP}) / \mathrm{cm}^{2} \cdot \mathrm{s} \cdot \mathrm{cmHg}\right)\end{array}$} & \multicolumn{2}{|c|}{$\begin{array}{c}\text { Membrane Selectivity } \\
(-)\end{array}$} \\
\hline & & $\mathrm{H}_{2} \mathrm{~S}$ & $\mathrm{CO}_{2}$ & $\mathrm{CH}_{4}$ & $\mathrm{H}_{2} \mathrm{~S} / \mathrm{CH}$ & $\mathrm{CO}_{2} / \mathrm{CH}_{4}$ \\
\hline \multirow{3}{*}{$\begin{array}{c}1 \\
0 \% \mathrm{H}_{2} \mathrm{~S} \\
4 \% \mathrm{CO}_{2}\end{array}$} & 391 & - & 23 & 1.6 & - & 15 \\
\hline & 589 & - & 22 & 1.6 & - & 14 \\
\hline & 969 & - & 20 & 2.6 & - & 13 \\
\hline \multirow{3}{*}{$\begin{array}{c}2 \\
0.097 \% \mathrm{H}_{2} \mathrm{~S} \\
0 \% \mathrm{CO}_{2}\end{array}$} & 389 & 64 & - & 1.5 & 41 & - \\
\hline & 586 & 60 & - & 1.6 & 39 & - \\
\hline & 972 & 51 & - & 1.5 & 34 & - \\
\hline \multirow{3}{*}{$\begin{array}{c}3 \\
0.087 \% \mathrm{H}_{2} \mathrm{~S} \\
4.12 \% \mathrm{CO}_{2}\end{array}$} & 390 & 94 & 23 & 1.6 & 59 & 14 \\
\hline & 589 & 85 & 22 & 1.6 & 52 & 13 \\
\hline & 970 & 64 & 19 & 1.5 & 42 & 13 \\
\hline \multirow{3}{*}{$\begin{array}{c}4 \\
0.986 \% \mathrm{H}_{2} \mathrm{~S} \\
4.12 \% \mathrm{CO}_{2}\end{array}$} & 389 & 81 & 24 & 1.7 & 47 & 14 \\
\hline & 587 & 79 & 24 & 1.8 & 45 & 13 \\
\hline & 976 & 71 & 22 & 1.7 & 41 & 12 \\
\hline $\begin{array}{c}5 \\
1.83 \% \mathrm{H}_{2} \mathrm{~S} \\
10.80 \% \mathrm{CO}_{2}\end{array}$ & 595 & 98 & 27 & 2.0 & 48 & 13 \\
\hline \multirow{3}{*}{$\begin{array}{c}6 \\
0.095 \% \mathrm{H}_{2} \mathrm{~S} \\
8.14 \% \mathrm{CO}_{2}\end{array}$} & 389 & 88 & 24 & 1.8 & 50 & 14 \\
\hline & 588 & 78 & 24 & 1.8 & 42 & 13 \\
\hline & 974 & 68 & 22 & 1.8 & 38 & 12 \\
\hline \multirow{3}{*}{$\begin{array}{c}3 \text {, satd. } \\
\text { with } \\
\text { water }\end{array}$} & 390 & 59 & 16 & 1.1 & 56 & 15 \\
\hline & 590 & 57 & 16 & 1.1 & 51 & 14 \\
\hline & 970 & 52 & 16 & 1.2 & 43 & 13 \\
\hline
\end{tabular}


The selectivities and fluxes shown in Tables 3 and 4 are very good, especially for the Pebax 4011 membrane. The following observations can be made from the data:

- The hydrogen sulfide/methane selectivity of Pebax 4011 for all ternary mixtures is between 50 and 65, and the carbon dioxide/methane selectivity is between 14 and 16 in the range of pressures studied. The hydrogen sulfide/methane selectivity of the Pebax 4011 polymer is about three times higher than that of cellulose acetate, which is presently being used for acid gas separation, and the carbon dioxide/methane selectivity is only marginally lower. The hydrogen sulfide/methane selectivity of Pebax 1074, in the range 40-60 at the pressures studied, is lower than that of Pebax 4011.

- The presence of carbon dioxide in the feed gas increases the fluxes of both hydrogen sulfide and methane through the membrane. For example, for Pebax 4011 (Table 3), the hydrogen sulfide fluxes are about 25\% lower and the methane fluxes are about $15 \%$ lower with feed mixture 2, which contains no carbon dioxide, than with mixtures 3-6. This could be due to swelling of the polymer by dissolved carbon dioxide. Similar results were obtained for Pebax 1074.

- In general, for both polymer grades, the pressure-normalized fluxes of hydrogen sulfide and carbon dioxide decrease with increasing feed pressure, whereas those of methane increase. The decrease in the hydrogen sulfide and carbon dioxide fluxes can be explained by competitive sorption of these components in the polymer. As the feed pressure increases, both hydrogen sulfide and carbon dioxide molecules compete for the fixed number of sorption sites in the polymer. This results in a lower solubility coefficient (the ratio of the concentration in the polymer to the partial pressure) for each component. At the same time, the polymer swells, resulting in a higher diffusivity for all components, including methane. The net result is an increase in the methane flux and a decrease in the fluxes of the acid gases (hydrogen sulfide and carbon dioxide). We expect the solubility of the more polar components, hydrogen sulfide and carbon dioxide, to be lower in Pebax 1074 than in Pebax 4011. Thus, swelling would be less for Pebax 4011, and the methane flux would be affected less.

Figures 10 and 11 show the effect of the combined partial pressures of the acid gases in the feed mixture on the pressure-normalized fluxes of all the three components in the feed for the two Pebax grades. The data points are from the experiment with feed mixtures 3-6. The figures show that the pressure-normalized flux of hydrogen sulfide decreases slightly with increased acid gas partial pressure, whereas that of carbon dioxide is almost constant. The methane flux, on the other hand, increases slightly with an increase in the acid gas partial pressure. 


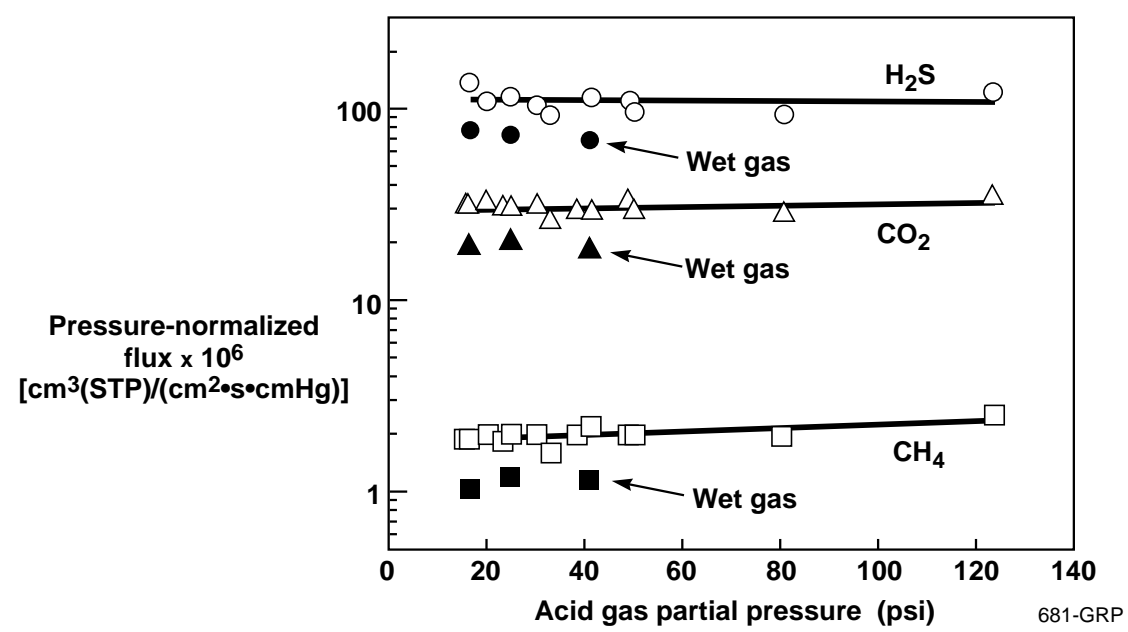

Figure 10. Pressure-normalized permeation flux through Pebax ${ }^{\circledR} 4011$ of each component of the feed mixture as a function of the total acid gas partial pressure. Solid symbols represent data obtained when the feed gas was saturated with water vapor.

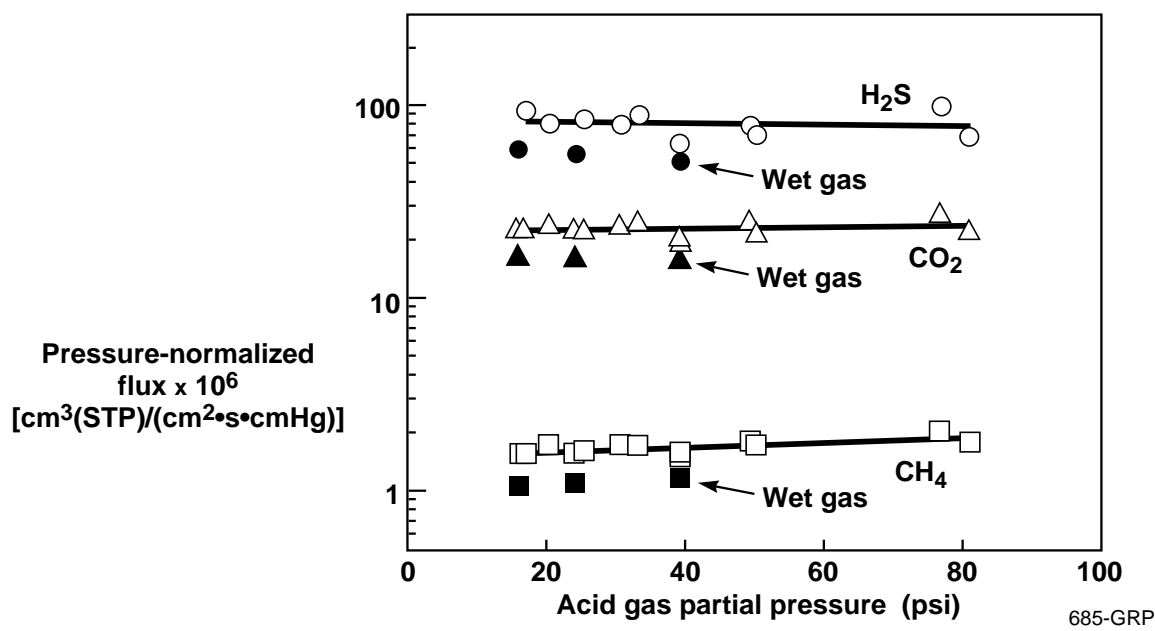

Figure 11. Pressure-normalized permeation flux through Pebax ${ }^{\circledR} 1074$ of each component of the feed mixture as a function of the total acid gas partial pressure. Solid symbols represent data obtained when the feed gas was saturated with water vapor.

Figures 12 and 13 show the effect of the acid-gas partial pressure on the membrane selectivities for hydrogen sulfide and carbon dioxide over methane. These figures show that both the hydrogen sulfide/methane and the carbon dioxide/methane selectivities decrease with increasing acid gas partial pressure. At higher partial pressures, the selectivities appear to reach a constant value. The hydrogen sulfide/methane selectivities are about 50 and 40, and the carbon dioxide/methane selectivities are about 14 and 12 for Pebax 4011 and 1074, respectively. 


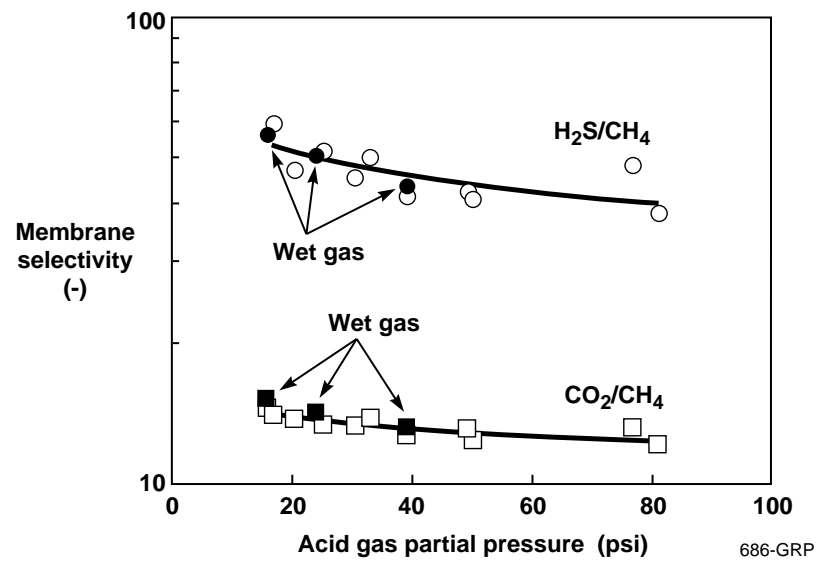

Figure 12. Selectivity for hydrogen sulfide and carbon dioxide over methane of Pebax® 1074 as a function of the total acid gas partial pressure. The solid symbols represent data obtained with a feed gas saturated with water vapor.

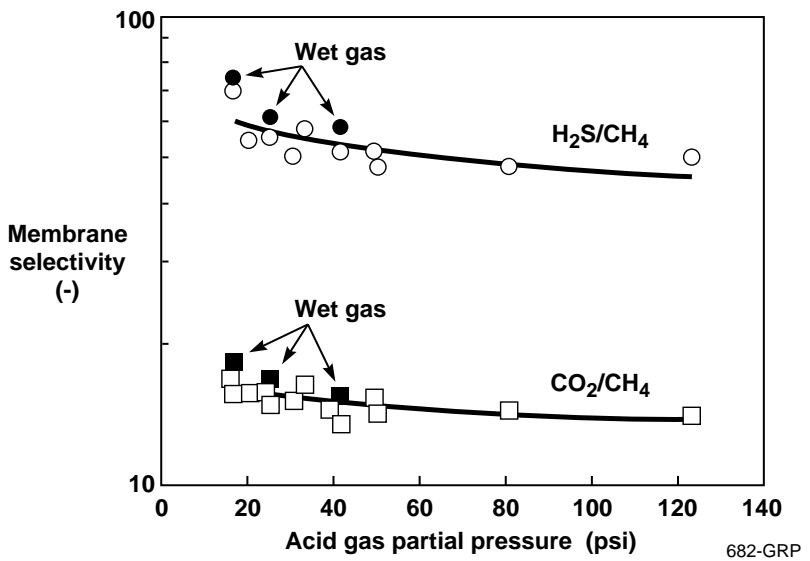

Figure 13. Selectivity for hydrogen sulfide and carbon dioxide over methane of Pebax® 4011 as a function of the total acid gas partial pressure. The solid symbols represent data obtained with a feed gas saturated with water vapor.

\section{Effect of Water Saturation of Feed}

The effect of water vapor in the feed on the permeation properties of the membrane is important because most natural gas streams are saturated with water. Unlike cellulose acetate and polyimide, currently the most widely used membrane materials, the Pebax membranes still retain their useful properties in the presence of water vapor. This means the gas stream can be safely delivered to the process wet, increasing the process reliability and lowering cost by eliminating a gas dehydration step.

Figures 10 through 13 include data points (solid symbols), which show the effect of saturating the feed gas with water vapor on the pressure-normalized fluxes and the membrane selectivities. The 
base-case gas mixture, no. 3 in Table 2, was used. As shown Figures 10 and 11, the fluxes of each of the components obtained with a water-vapor-saturated feed are considerably lower than those obtained in the absence of water vapor. For Pebax 4011, the pressure-normalized hydrogen sulfide and carbon dioxide fluxes were about $25 \%$ lower, and the methane fluxes were about $35 \%$ lower. Corresponding reductions for Pebax 1074 were 30-40\% and 30\%, respectively. This result can be explained as follows. Water is strongly sorbed by the polymer; the presence of water vapor in the polymer matrix can affect the permeation properties in two ways. Water molecules will displace both hydrogen sulfide and carbon dioxide from active sorption sites in the polymer. Also, by forming interchain hydrogen bonds, water vapor can restrict chain motion to some extent, thereby decreasing the diffusivity of other components. Both effects would result in lower permeation fluxes for hydrogen sulfide, carbon dioxide, and methane in the membrane.

The solid symbols in Figures 12 and 13 show the effect of the presence of water vapor in the feed on the membrane selectivity. Neither the hydrogen sulfide/methane nor the carbon dioxide/methane selectivities change significantly.

Exposure of the Pebax 4011 membrane to a water-vapor-saturated feed resulted in an reversible decrease in the permeation flux of all the components. The hydrogen sulfide flux decreased by about $18 \%$, the carbon dioxide flux by about $8-9 \%$, and the methane flux by about $6 \%$. The same membrane was used to determine the effect of temperature, discussed in the next section.

\section{Effect of Feed Gas Temperature}

As expected, the selectivities of the membrane decrease as the temperature increases, but remain well within the acceptable range even at $45^{\circ} \mathrm{C}$.

Figures 14 and 15, Arrhenius-type plots, show the effect of feed temperature on the pressurenormalized permeation flux of each of the three components in the feed gas in the two membranes. The effect of temperature is shown for three different pressures. The plot illustrates that, with increasing temperature, the permeation flux of each of the three components increases. The effect of temperature on permeation is usually characterized in terms of a heat of permeation $\left(E_{p}\right)$, which has two components, a heat of solution, $\mathrm{E}_{\mathrm{s}}$ of the component in the polymer matrix, and a heat of diffusion, $\mathrm{E}_{\mathrm{d}}$.

$$
E_{p}=E_{s}+E_{d}
$$

In most polymer/penetrant systems, $\mathrm{E}_{\mathrm{s}}$ is negative, that is, the process of solution is exothermic, and $\mathrm{E}_{\mathrm{d}}$ is positive, that is, diffusion is an endothermic process.

The plots indicate an endothermic permeation process, with the largest increase being for methane. The calculated heat of permeation for Pebax 4011 yields an average value of about $7 \mathrm{kcal} / \mathrm{mol}$ for methane, $4 \mathrm{kcal} / \mathrm{mol}$ for carbon dioxide, and about 2-3 kcal/mol for hydrogen sulfide. Corresponding values for Pebax 1074 are $9 \mathrm{kcal} / \mathrm{mol}, 5.5 \mathrm{kcal} / \mathrm{mol}$, and $3.8 \mathrm{kcal} / \mathrm{mol}$, respectively. 
These values of the heat of permeation are consistently higher than those for the Pebax 4011 membrane. The Pebax 4011 grade is more hydrophilic (i.e. more polar) than the Pebax 1074 grade, and would, therefore, exhibit a higher exothermic heat of solution due to stronger interaction between the gas and the polymer. The Pebax 1074 membrane would show a lower exothermic heat of solution, and, consequently, a higher endothermic heat of permeation.

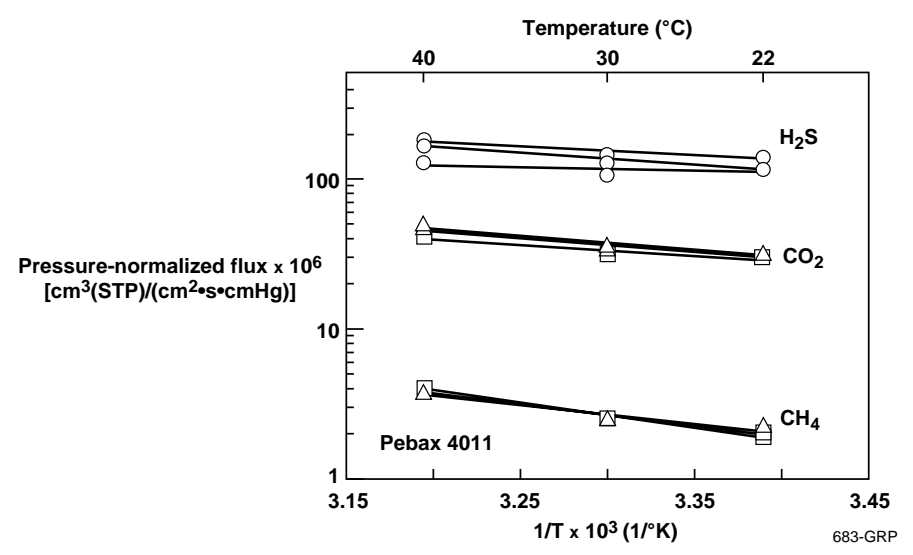

Figure 14. Arrhenius-type plot of the pressure-normalized permeation flux of hydrogen sulfide, carbon dioxide, and methane in Pebax ${ }^{\circledR} 4011$ as a function of temperature, at three different feed pressures.

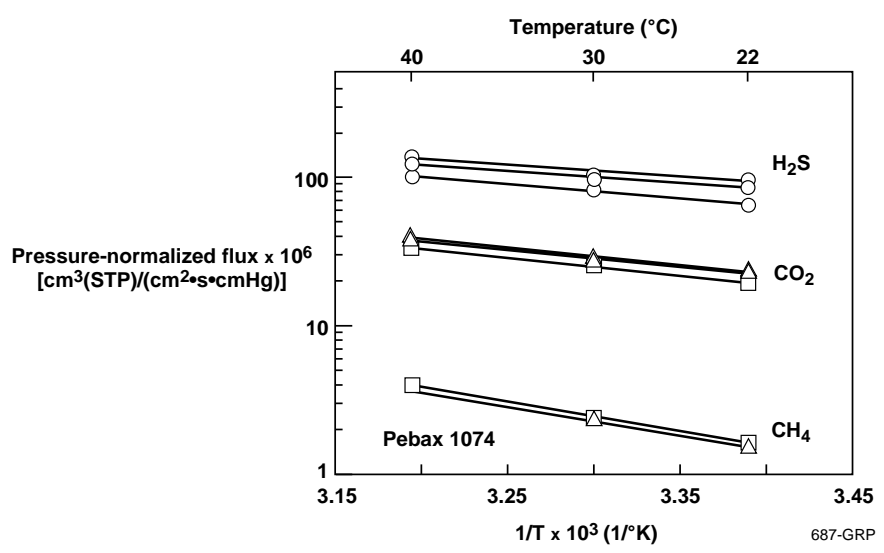

Figure 15. Arrhenius-type plot of the pressure-normalized permeation flux of hydrogen sulfide, carbon dioxide, and methane in Pebax® 1074 as a function of temperature, at three different feed pressures.

The lower values of the heat of permeation for carbon dioxide and hydrogen sulfide indicate that, for these components, the decrease in the solubility with increasing temperature is larger than the increase in diffusivity. This results in a lower membrane selectivity for hydrogen sulfide and carbon dioxide over methane at higher temperatures, as shown in Figures 16 and 17. For example, the hydrogen sulfide/methane selectivity of Pebax 4011 at a feed pressure of about 388 psig decreases 
from about 70 at $22^{\circ} \mathrm{C}$ to about 52 at $40^{\circ} \mathrm{C}$. For Pebax 1074 , the selectivity at a feed pressure of about 390 psig decreases from about 59 at $22^{\circ} \mathrm{C}$ to about 35 at $40^{\circ} \mathrm{C}$.

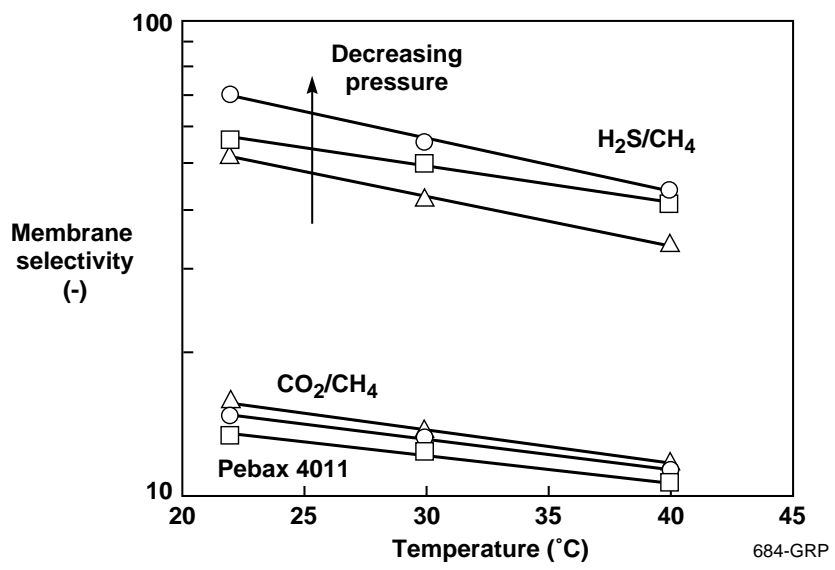

Figure 16. Effect of feed gas temperature on membrane selectivity to hydrogen sulfide and carbon dioxide over methane for Pebax® 4011.

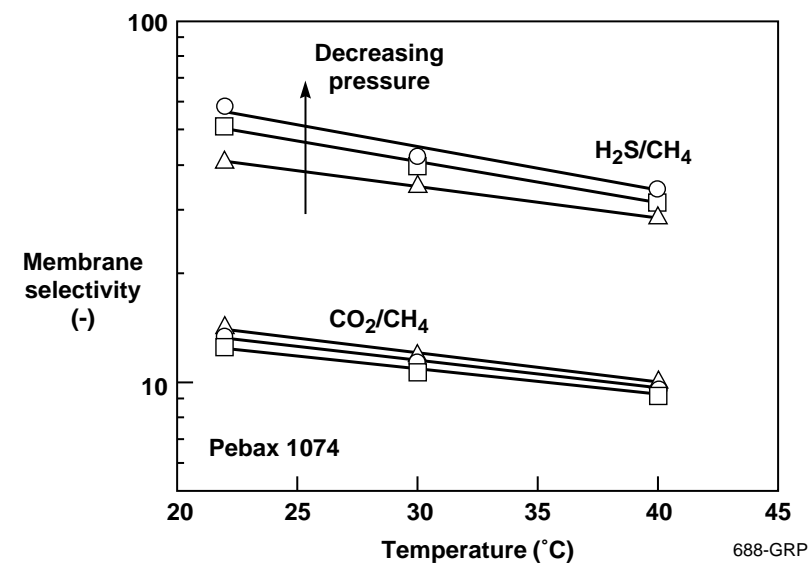

Figure 17. Effect of feed gas temperature on membrane selectivity to hydrogen sulfide and carbon dioxide over methane for Pebax® 1074.

\subsubsection{Comparison of the Membrane Selectivity for Hydrogen Sulfide and Carbon Dioxide Over Methane in Pebax 4011 and 1074}

Figure 18 compares the selectivities of the two Pebax grades, 4011 and 1074, that were evaluated as acid-gas separation membranes. Both the hydrogen sulfide/methane and the carbon dioxide/methane selectivities decrease with increasing acid gas partial pressure. Also, both selectivities are consistently lower for the Pebax 1074 grade than for the Pebax 4011 grade. However, the hydrogen sulfide/methane selectivity of both grades is two to three times higher than that of the currently used cellulose acetate membrane under similar conditions. These high selectivities are preserved at pressures as high as $950 \mathrm{psia}$, and at feeds containing up to $10 \%$ carbon dioxide and about $2 \%$ hydrogen sulfide. Such selectivities make the membranes very promising for sour gas 
treatment processes. The carbon dioxide/methane selectivity of the Pebax grades is, however, somewhat lower than that of a cellulose acetate membrane.

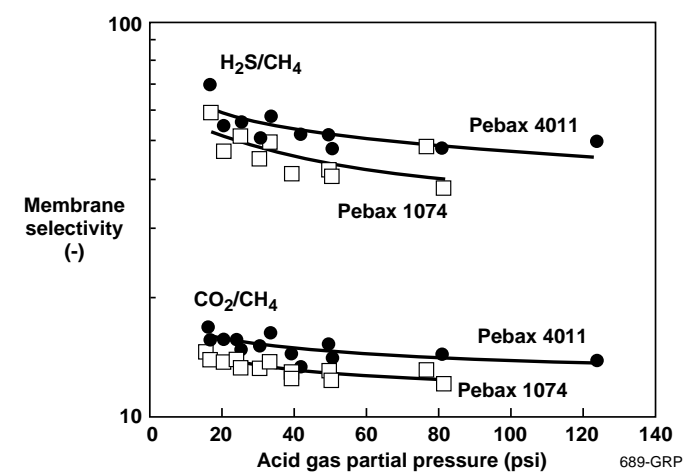

Figure 18. Comparison of the separation performance of the two Pebax grades studied.

\subsubsection{Preparation and Testing of Laboratory-Scale Pebax 4011 Membrane Modules}

Based on the promising results of the stamp tests for the Pebax 4011 membrane, this membrane was selected for scale up to laboratory-scale modules. Manufacturing high-pressure modules suitable for natural gas applications is a significant challenge; the issues that had to be addressed are summarized below.

Module Components and Rolling Procedures: Our existing module configuration and rolling procedures were adequate for modules to be used at low to medium pressures (80-250 psig), but not for modules to be used at higher pressures. Therefore, the module components and the module rolling procedures had to be reevaluated, particularly because even a relatively small defect can affect the separation performance of a low-flux membrane such as Pebax 4011. Changes were made in the feed and permeate spacer configurations, in the procedures used for rolling and taping the modules, and in pre-rolling membrane preparation and handling.

Support Membrane: Selection of an appropriate microporous support material for the Pebax layer is important. Such support materials tend to fail at high pressures due to the morphology of the pore structure. We identified a support material that is stable at high pressures for extended periods.

Module Selectivity: The separation achieved by the laboratory-scale modules was somewhat less than expected, based on membrane stamp data. Module performance can be affected by the formation of a stagnant boundary layer, particularly with membranes that have a high intrinsic selectivity and at low flow rates. However, the tests suggested that the low module selectivities were an artifact of the limited flow capacity of our test system and will not be a factor in a commercialscale unit.

To address these issues, we manufactured and tested numerous laboratory-scale modules. Modules were usually produced in pairs; changes made in each pair were based on the permeation and pressure stability test results and post-mortem tests of the previous modules. To extract the 
maximum amount of information from the module tests, we instituted a test protocol involving the following steps:

1. Initial pure gas nitrogen and oxygen permeation test at 10 and 50 psig feed pressure.

2. Pure gas carbon dioxide and nitrogen permeation test at 50 psig pressure in the high-pressure test system. These low-pressure tests were performed to identify any damage to the membrane during the rolling process, or defective glue lines.

3. High-pressure stability test at pressures up to $1,500 \mathrm{psig}$ using nitrogen as the test gas.

4. Repeat pure gas carbon dioxide and nitrogen permeation test to determine if defects were formed by exposure to high pressure.

5. Mixed gas test if deemed necessary from all previous results.

6. Dye test.

7. Postmortem dissection of the module and examination of the internals.

Development of the high-pressure module was started using our standard silicone rubber membrane. This allowed us to deal with module-rolling and support membrane issues quickly. We prepared a total of six modules using silicone rubber/PVDF and silicone rubber/polysulfone membranes. Tests showed that the silicone rubber membrane on a polysulfone support was stable at pressures up to $1,500 \mathrm{psig}$ and after five pressure cycles. On the other hand, the silicone rubber membrane on a PVDF support was stable only up to about 1,000 psig and failed at higher pressures. During these tests, issues related to module rolling were also isolated and resolved.

Module development was continued with the Pebax 4011 membrane on a PVDF support. These modules were tested with the base-case gas mixture, which comprises 600-1,300 ppm hydrogen sulfide, about $4 \%$ carbon dioxide, and the balance methane. Figure 19 shows the effect of feed pressure on the carbon dioxide/methane and the hydrogen sulfide/methane selectivities for three modules.

(a)

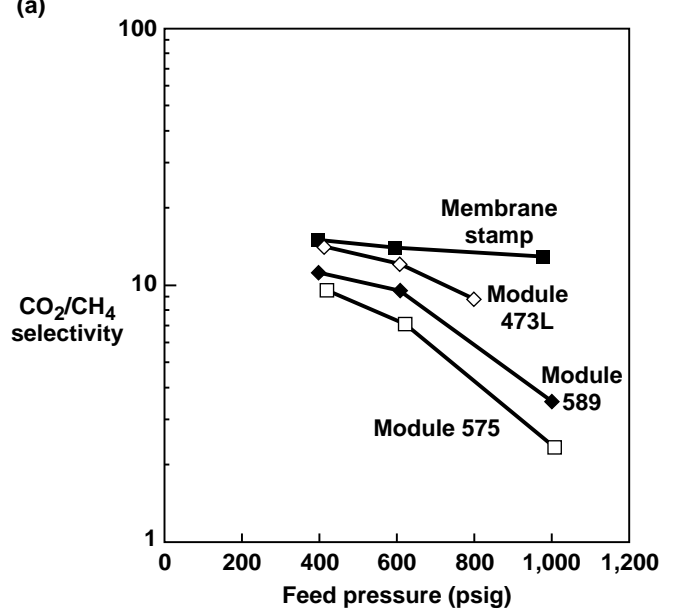

(b)

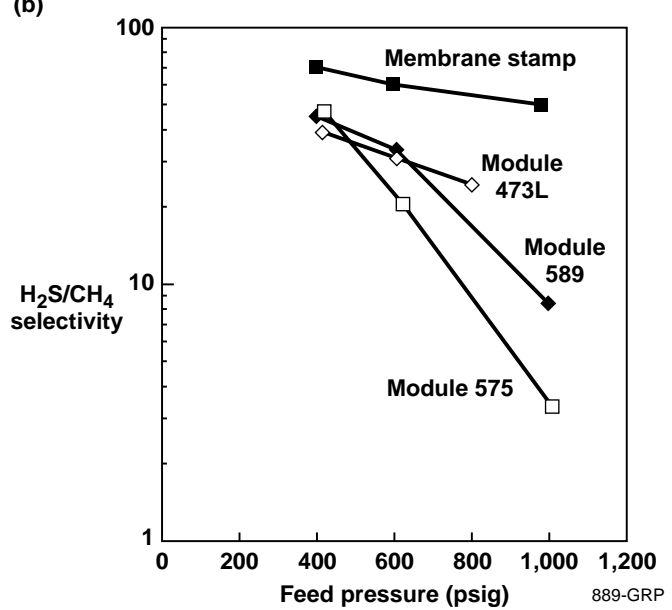

Figure 19. Effect of feed pressure on (a) the carbon dioxide/methane selectivity and (b) the hydrogen sulfide/methane selectivity of three Pebax 4011/PVDF membrane modules. 
In Figure 19, the line labeled "membrane stamp" in each plot indicates the selectivity obtained with membrane stamps, which corresponds to the maximum selectivity achievable in a module. Figure 19(a) shows that the carbon dioxide/methane module selectivity improved progressively; the selectivity of the latest module, no. $473 \mathrm{~L}$, at 400 psig was almost equal to that of the membrane stamps. The hydrogen sulfide/methane selectivity shown in Figure 20(a) is somewhat lower than that expected from the membrane stamps, especially at the lower pressure of $400 \mathrm{psig}$. This was almost certainly due to boundary layer formation in the modules in our test system.

The module tests indicate an increase in the methane flux, followed by a drop in the hydrogen sulfide/methane and carbon dioxide/methane selectivities at higher pressures of about 1,000 psig. Dye tests of these modules showed that a single defect typically causes module failure at the higher pressure. The origin of such a defect may be feed spacer contact at high pressure, or pressure instability of the support membrane. Subsequent tests with the PVDF-supported membrane indicated that the failure of the membrane at high pressures was due mainly to the instability of PVDF support. Substitution of the PVDF support with the more rigid polysulfone support used with silicone rubber did not seem to be a viable option because the Pebax solution plugged the pores of this support, reducing the flux of the membrane.

However, the issue of pore plugging in the rigid polysulfone support was overcome by modifying the membrane in two ways. The first was to prepare a more rigid and somewhat more open polyether-based support layer, polyetherimide, and the second equally important modification was to add a silicone rubber gutter layer between the support membrane and the selective Pebax 4011 membrane. These modifications increased the component fluxes in the membrane, allowed the use of a more viscous Pebax 4011 solution to provide more consistent coating of the membrane, and protected the Pebax 4011 from damage in the module rolling process. Additionally, the new support membrane increased the upper threshold of pressure stability due to its very high pressure stability and chemical stability.

This new membrane was manufactured successfully after a few months of development time. The membrane was stamp tested and subsequently was manufactured into modules for testing in the module test system. The results of these tests are shown in Figure 20. 
(a)

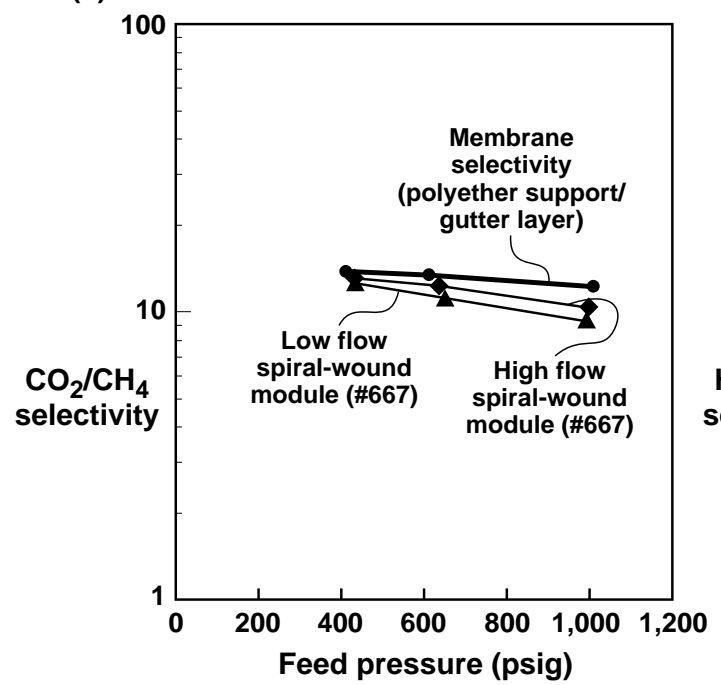

(b)

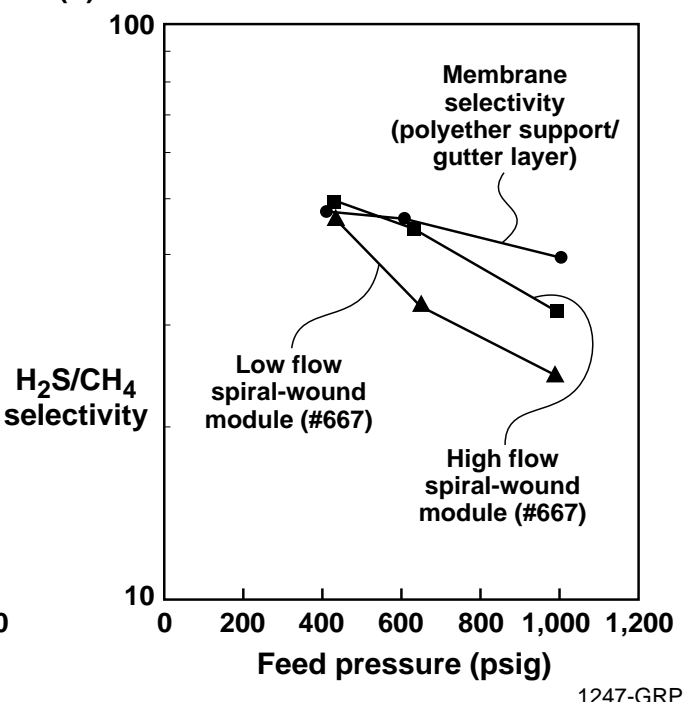

Figure 20. Effect of feed pressure on (a) carbon dioxide/methane and (b) hydrogen sulfide/methane selectivity in stamps and modules made from the redesigned membrane.

The following important observations can be made from the data in Figure 20:

- The intrinsic hydrogen sulfide/methane and carbon dioxide/methane selectivities for the new membrane are lower than those of the PVDF-supported membrane. The selectivity at 400 psig is about 50 compared to about 70 for the PVDFsupported membrane, and at 1,000 psig the selectivity is about 40 compared to 50 for the PVDF-supported membrane. The main reason for this difference is probably some influence on the separation of the silicone rubber gutter layer and the polyetherimide support, which is tighter then the PVDF support. However, the selectivities are still sufficiently high, making the trade-off for increased pressure stability acceptable.

- Figure 21 shows the permeation flux of each feed gas component in the modules. The first module made from the new membrane, module 667, had a methane flux of about $3.5 \times 10^{-6} \mathrm{~cm}^{3}(\mathrm{STP}) / \mathrm{s} \cdot \mathrm{cm}^{2} \cdot \mathrm{cmHg}$, which is about $70 \%$ higher than that obtained with earlier membranes. The selectivity was somewhat lower, but still in the acceptable range. After some optimization, module 722 showed a significantly improved permeation flux for all components. The methane flux in module 722 was about $5 \times 10^{-6} \mathrm{~cm}^{3}(\mathrm{STP}) / \mathrm{s}^{\cdot} \mathrm{cm}^{2} \cdot \mathrm{cmHg}$, which is more then twice that of earlier membranes. The hydrogen sulfide/methane and carbon dioxide/methane selectivities of module 722 were identical to those of module 667. These encouraging results marked a real advance in our capability to manufacture highperformance membrane modules for this application and indicated readiness to proceed to field tests on the modules. 


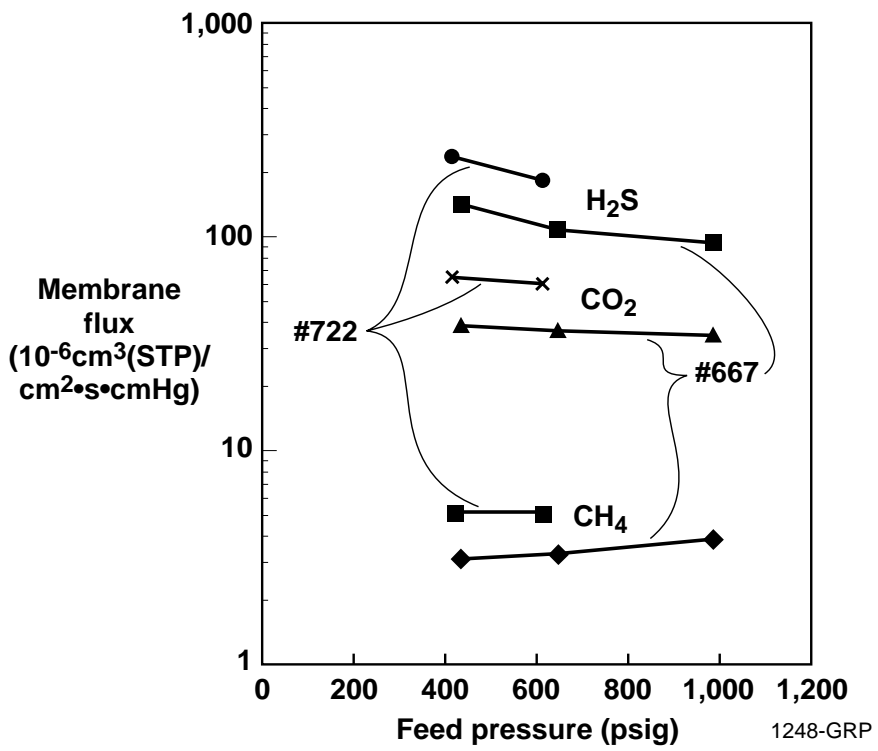

Figure 21. Permeation flux in modules manufactured with the new membrane configuration. The permeation flux was more than double that of previous membrane modules.

\section{FIELD TEST}

While the module development and laboratory testing was in progress we worked on obtaining a field test site for demonstrating the module performance on a real gas stream. Originally this task was assigned to Hoechst Celanese which was going to partner with us on this project. After Hoechst Celanese decided to limit its involvement in the project, MTR started to negotiate directly with interested parties for a field test. The following companies were contacted as possible end-users:

- Phillips Petroleum Corporation

- Chevron Corporation

- Shell Exploration and Production

After making a significant effort to convince these companies to host a field test, Shell Exploration and Production Company decided to try the process based on possible future needs for bulk hydrogen sulfide removal. Two potential sites within Shell's operations in the U.S. were identified; the site finally selected was a Shell Western E\&P gas processing plant in Bryans Mill, Texas.

\subsection{Description of Field Test System}

The test skid constructed for the project contains two module housings; each module housing holds one 3-inch membrane module suitably interconnected to allow tests with either one module, both modules in series, or both modules in parallel. A coalescing filter just upstream of the module housings removes any particles or entrained liquids. The feed flow rate and pressure are controlled 
using a flow regulating valve and back-pressure regulating valve. The flow rate is measured with mass flow meters installed in the feed stream and in both permeate streams. The feed, residue, and permeate stream conditions are monitored using in-line pressure and temperature gauges. The feed, residue and permeate streams can be sampled periodically to determine their composition and assess the separation performance of the membrane modules. A P\&ID of the test skid is shown in Figure 22. 


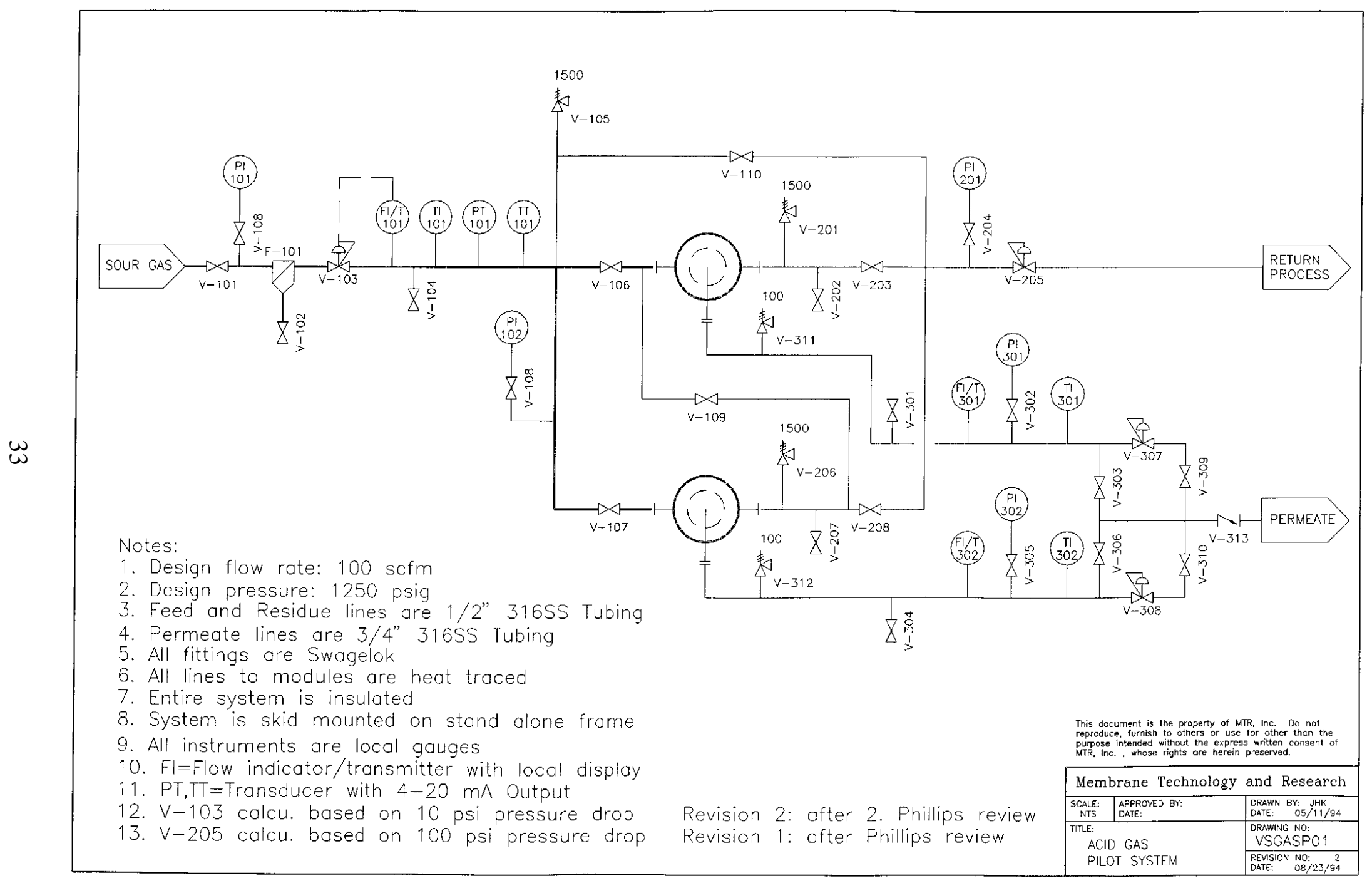

Figure 22. P\&ID of test skid used in field tests of hydrogen sulfide separation modules. 


\subsection{Description of Plant Site and Placement of Membrane System in Plant}

The field test was performed at one of Shell Exploration and Production's sour gas treatment plants located in Bryans Mill, TX (about 3 hours northeast of Dallas). This processing facility treats gas from a number of different wells. To remove the hydrogen sulfide, the plant uses Shell's Sulfinol process and solvent. The hydrogen sulfide removed in the absorbers is fed to a Claus Plant for conversion to elemental sulfur.

The various gas wells produce natural gas at different pressures. Upon entering the batterylimits of the plant, the gas stream enters one of a series of separator vessels. Our system was attached to the separator vessel from well BMU-12. At the start of the field test, the head pressure from BMU12 was approximately $900 \mathrm{psig}$. The composition of the gas from this well is shown in Table 5, and Figure 23 shows a diagram of how the test skid was incorporated into the plant.

Table 5. Composition of Gas from Well BMU-12

\begin{tabular}{||l|c||}
\hline \multicolumn{1}{|c|}{ Component } & Volume \% \\
\hline Hydrogen Sulfide & 3.0 \\
Nitrogen & 11.7 \\
Carbon Dioxide & 1.3 \\
Methane & 74.7 \\
Ethane & 6.3 \\
Propane & 1.2 \\
iso-Butane & 0.3 \\
n-Butane & 0.5 \\
iso-Pentane & 0.2 \\
n-Pentane & 0.2 \\
Hexanes & 0.3 \\
Heptanes + & 0.3 \\
\hline \hline
\end{tabular}




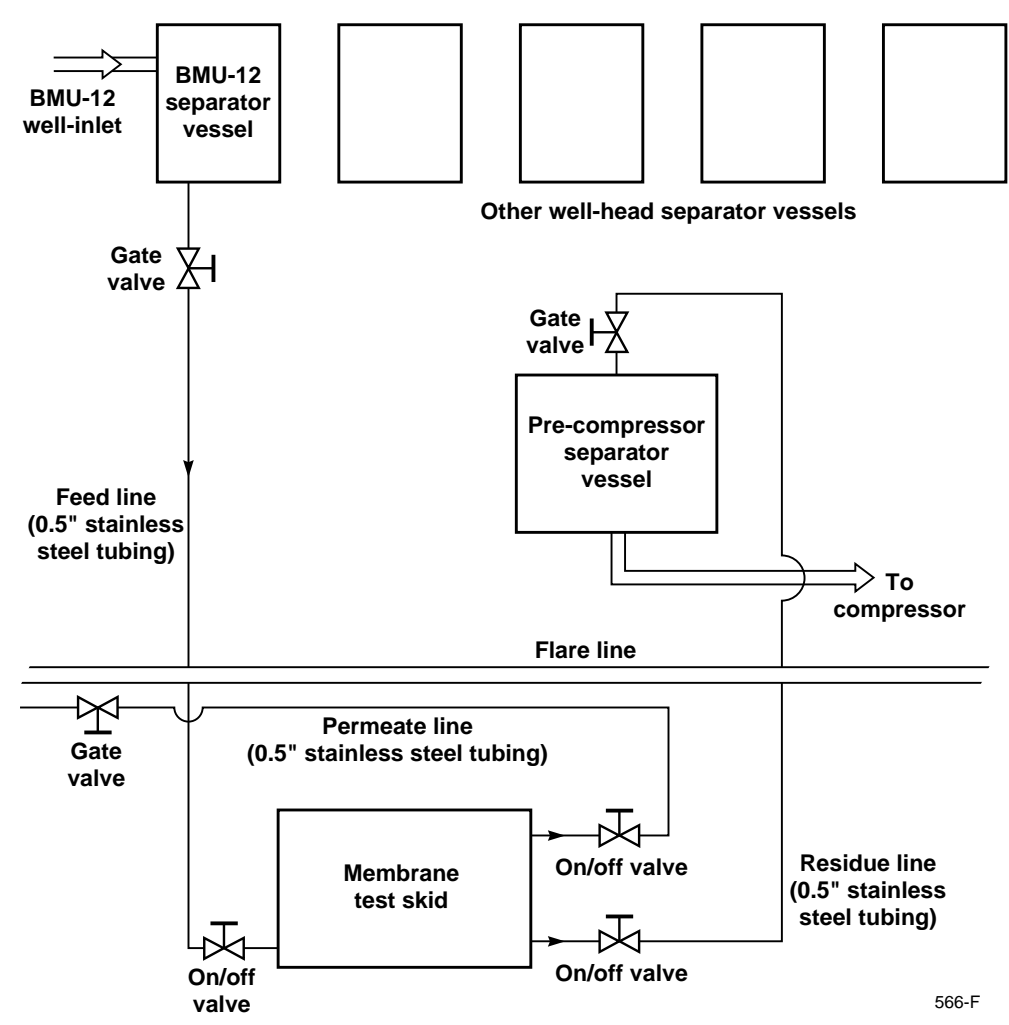

Figure 23. Schematic of test skid hook-in at Bryans Mill facility.

The membrane system was attached to the BMU-12 separator vessel with approximately $50 \mathrm{ft}$ of 0.5-in stainless steel tubing. To start gas flowing to the membrane system, a gate valve located on the BMU-12 vessel was opened manually. The residue stream was connected to a pre-compressor separator vessel using approximately $40 \mathrm{ft}$ of 0.5 -in stainless steel tubing. The pressure in this line remained at about $350 \mathrm{psig}$. The low-flow-rate, low-pressure permeate stream was fed directly to the plant flare line using $30 \mathrm{ft}$ of 0.5 -in stainless steel tubing. The pressure in the flare line remained at about atmospheric.

\subsection{Description of Test Apparatus and Procedures}

During the field test, the composition of the components in the feed, residue and permeate streams of the hydrogen sulfide test skid were determined by two different methods: gas chromatography and the Tutweiler test.

\section{Gas Chromatography}

At the test site, MTR's high performance MTI gas chromatograph was set up in a laboratory located about 200 yards from the test skid. The MTI device uses integrated circuit technology to detect concentrations down to ppm of natural gas components through heptanes in a fraction of normal gas chromatograph run times. This gas chromatograph uses two columns: column A for 
determining the amount of butanes and higher and column B for determining the amounts of the lighter hydrocarbons, carbon dioxide, nitrogen, and hydrogen sulfide. Figure 24 shows a sample chromatograph obtained using column B.

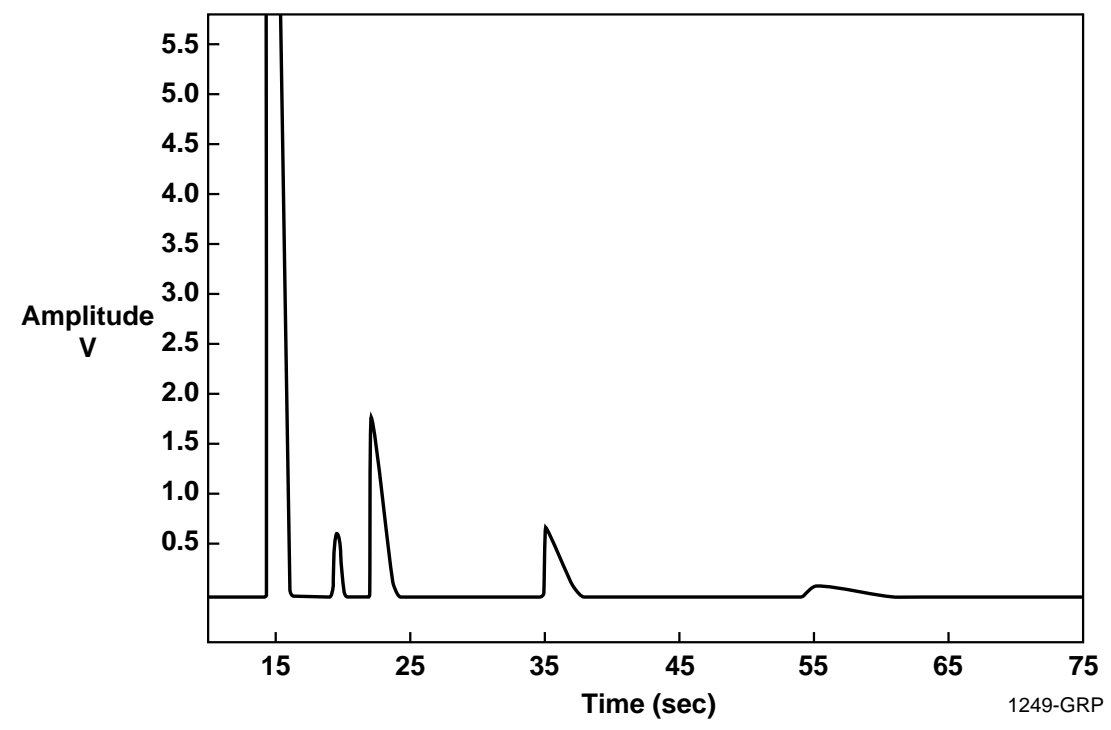

Figure 24. Sample gas chromatograph obtained from column B.

The gas chromatograph was calibrated using two gas calibration mixtures. The first contained only methane, carbon dioxide and hydrogen sulfide and the other was a natural gas reference standard. The compositions of the components in each mixture are listed in Table 6.

Table 6. Compositions of Gas Mixtures Used to Calibrate the Gas Chromatograph.

\begin{tabular}{|c|c|c|c|}
\hline \multicolumn{2}{|c|}{ Three-Component Mixture (vol\%) } & \multicolumn{2}{|c|}{ Natural Gas Standard (vol\%) } \\
\hline Methane & 87.37 & Methane & 70.4 \\
\hline Carbon Dioxide & 10.80 & Ethane & 9.0 \\
\hline \multirow[t]{8}{*}{ Hydrogen Sulfide } & 1.83 & Propane & 6.0 \\
\hline & & $i$-Butane & 3.0 \\
\hline & & $n$-Butane & 3.0 \\
\hline & & $i$-Pentane & 1.0 \\
\hline & & $n$-Pentane & 1.0 \\
\hline & & Nitrogen & 5.0 \\
\hline & & Carbon Dioxide & 1.0 \\
\hline & & Helium & 0.6 \\
\hline
\end{tabular}

The feed, residue and permeate streams in the test system were sampled with three $150 \mathrm{~cm}^{3}$ stainless steel canisters. These containers were then attached to the GC sample port as shown in 
Figure 25. As the tests progressed, we found that the best results were obtained if the gas was fed to the $\mathrm{GC}$ at approximately $30 \mathrm{psig}$.

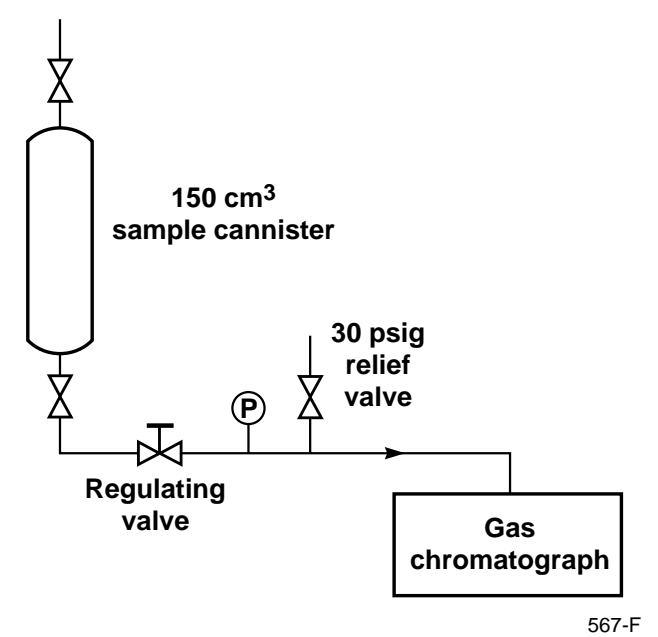

Figure 25. Schematic diagram showing the method of connecting sample canisters to gas chromatograph.

\section{Tutweiler Test For Hydrogen Sulfide Determination}

The Tutweiler test is an iodometric titration technique that accurately determines the amount of hydrogen sulfide in a gas sample. This analytical technique is based on the following irreversible reaction between hydrogen sulfide and iodine:

$$
\mathrm{H}_{2} \mathrm{~S}+\mathrm{I}_{2} \rightarrow 2 \mathrm{HI}+\mathrm{S}
$$

A $0.1 \mathrm{~N}$ standardized iodine solution and a starch indicator are the only chemicals necessary for the test. Both chemicals are commercially available from Ricca Chemical Company (Arlington, TX). The test is carried out in a specially designed Tutweiler buret, a diagram of which is shown in Figure 26. A diagram of the complete testing apparatus is shown in Figure 27.

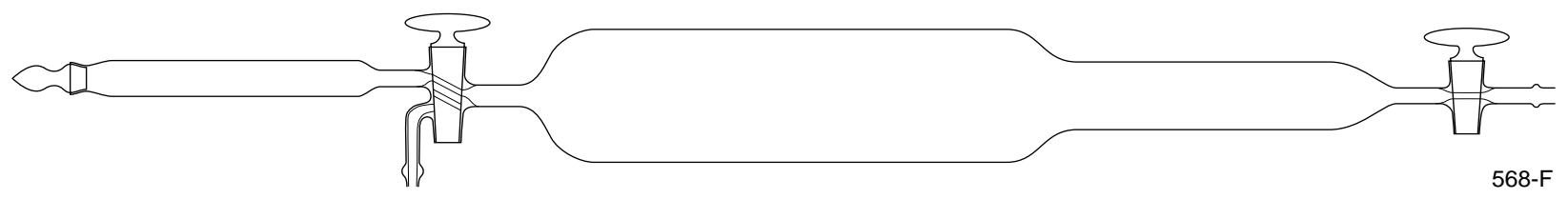

Figure 26. Schematic diagram of a Tutweiler buret. 


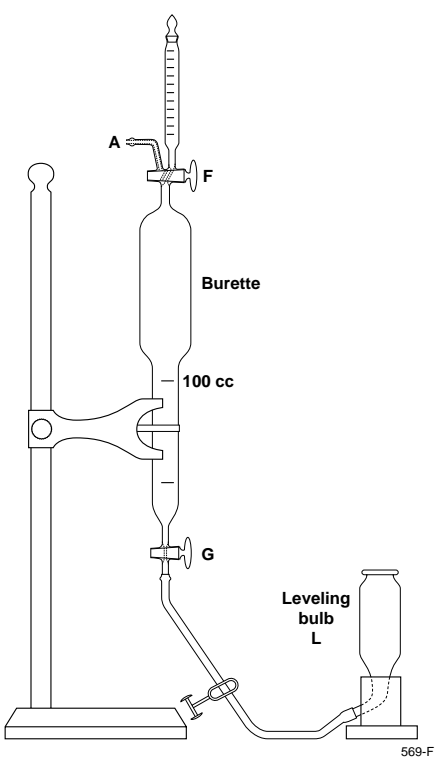

Figure 27. Schematic diagram of the Tutweiler testing apparatus.

During a test, the leveling bulb, marked L in Figure 27, is first filled with starch solution. The bulb portion of the buret is filled with starch indicator by removing the clip and then raising the leveling bulb until the starch water runs out of the gas inlet tube, marked A. Next, a line from the gas sampling location is attached to the gas inlet tube. The gas is allowed to flow into the buret until the level of the starch solution drops below the $100 \mathrm{cc}$ mark. At this point, the stopcock marked $\mathrm{F}$ is closed and the leveling bottle is moved up so that the level of the starch water ends up exactly at the $100 \mathrm{cc}$ mark. Then, stopcock G is closed, and leveling bulb is detached from the buret. Stopcock F is opened to the atmosphere and then closed again to release any extra pressure in the bulb portion of the buret. Now, the iodine solution is slowly added to the gas sample until the starch solution turns a dark blue. This indicates that the hydrogen sulfide in the gas sample has been completely exhausted, according to equation (3). The amount of iodine used (ml) multiplied by 1.16 gives the concentration of hydrogen sulfide in the gas sample in volume $\%$.

\subsection{Description of Field Test}

The system arrived at the Bryans Mill gas processing plant in early February, 1997. The system was first started up on February 25, 1997 during MTR's first trip to the plant. MTR engineers visited the site four times during the 6-month field test. A summary of these trips is given in Table 7. As shown in the table, the system was operated with a sour gas stream for 57 days during the field test. The longest continuous run was the two-month period from mid-June to mid-August. 
Table 7. Summary of Trips to Bryans Mill Field Test Site.

\begin{tabular}{|c|c|l||}
\hline \hline Trip & Dates & \multicolumn{1}{c|}{ Summary of Trip } \\
\hline 1 & $2 / 24-2 / 26 / 97$ & $\begin{array}{l}\text { Received hydrogen sulfide safety training, had plant orientation, } \\
\text { made several modifications to system, started up system, tested } \\
\text { both modules at different feed pressures and flow rates, shut } \\
\text { down system because modules flooded. }\end{array}$ \\
\hline 2 & $4 / 8-4 / 13 / 97$ & $\begin{array}{l}\text { Installed manual drain on coalescing filter, removed old modules } \\
\text { and installed new modules, finished installing steam tracing on } \\
\text { feed side, re-started system, performed tests on both modules, } \\
\text { shut down system because of overnight freezing due to } \\
\text { abnormally cold conditions. }\end{array}$ \\
\hline 3 & $6 / 18-6 / 20 / 97$ & $\begin{array}{l}\text { Installed feed-to-residue bypass line, removed old modules and } \\
\text { installed new modules, restarted system, performed series of } \\
\text { pressure and flow rate variation experiments using Tutweiler } \\
\text { test for hydrogen sulfide determination. System left online. }\end{array}$ \\
\hline 4 & $8 / 11-8 / 14 / 97$ & $\begin{array}{l}\text { Performed series of tests on same modules, system shut down } \\
\text { and disconnected from plant. End of field test. }\end{array}$ \\
\hline
\end{tabular}

Several design changes were made to the system during the field test to address a significant operational issue. We realized during our first trip that liquid was building up in the module housings, attributable to condensation in the line from the separator vessel on BMU-12 to the membrane system. The amount of liquid build-up observed could severely decrease membrane performance. Therefore, to minimize the condensation, the following four changes were made to the system:

1. Installation of a mechanical-switch-operated liquid drain pot on the coalescing filter. In our test system, any liquid entering the system would drop out into the coalescing filter housing. This drain provided automatic draining of any built-up liquid.

2. Insulation of the 0.5 -in stainless steel tubing used to connect the test skid to BMU-12. This assumed that condensation was occurring in this line because it was exposed to ambient air. Insulation would help to minimize temperature loss through the line.

3. Steam-tracing of the feed portion of the test skid. This helped to maintain the temperature of the gas within the system and thus minimize the formation of liquid droplets. 
4. Installation of a feed-to-residue bypass line. The tubing from BMU-12 ran along the ground to the test skid, then it went up about 3 feet to the feed entrance to the skid. The bypass line ran from where the tubing left the ground to the residue line. A regulating stem valve was installed in the bypass. This valve was opened slightly during operation so that liquids that might have formed in the line from BMU-12 could flow directly to the residue and bypass the modules.

These system changes virtually eliminated the liquid build-up problems.

During the field test, a change in module design was also made. Results obtained during the first two trips to the site indicated that some of the natural gas might have been bypassing the mechanical seals used in the membrane modules. To prevent this from recurring, we redesigned our end-cap so that a Viton U-cup gasket, which is more of an industry standard, could be used as a mechanical seal. After this change, there were no further indications of bypassing.

A list of the modules manufactured for the field tests is shown in Table 8. Modules 735 and 736 were exposed to natural gas for 2 days. The next two modules installed, numbers 932 and 935 , were exposed to gas for 4 days. The final two modules, 967 and 968, were exposed to gas continually for 51 days and remained in good condition.

Table 8. List of Modules Manufactured for the Field Test.

\begin{tabular}{||c|l|c|l||}
\hline $\begin{array}{c}\text { Module } \\
\text { No. }\end{array}$ & Membrane & $\begin{array}{c}\text { Initial Selectivity } \\
\left(\mathrm{CO}_{2} / \mathrm{N}_{2}\right)\end{array}$ & \multicolumn{1}{||}{ Comments } \\
\hline 735 & Pebax 4011 & 51 & Installed 2/25/97; removed, flooded with liquid \\
\hline 736 & Pebax 4011 & 63 & Installed 2/25/97; removed, flooded with liquid \\
\hline 930 & Pebax 4011 & - & Never tested in system, bad membrane lot \\
\hline 931 & Pebax 4011 & 33 & Never tested in system, bad membrane lot \\
\hline 932 & Pebax 4011 & 54 & Installed 4/9/97; removed, bad membrane lot \\
\hline 933 & Pebax 4011 & 58 & Never tested in system, bad membrane lot \\
\hline 935 & Pebax 4011 & 56 & Installed 4/9/97; removed, bad membrane lot \\
\hline 967 & Pebax 4011 & 68 & Installed 6/18/97; still in system, good membrane \\
\hline 968 & Pebax 4011 & 69 & Installed 6/18/97; still in system, good membrane \\
\hline 969 & Pebax 4011 & 69 & Good membrane, stored for future use \\
\hline 970 & Pebax 4011 & 71 & Good membrane, stored for future use \\
\hline \hline
\end{tabular}




\subsection{Results and Discussion of Field Test Data}

As described above, four separate trips were made to the Bryans Mill plant. This section describes the results obtained during each trip and the conclusions based on the results.

\subsubsection{Trip $1(2 / 24 / 97-2 / 26 / 97)$}

For this first test, module 735 was installed in tube 1 and module 736 was installed in tube 2. After leak testing the system, feed gas flow was started through module 735 only. The pressure was raised to about $410 \mathrm{psig}$. After the system had run for 30 minutes to reach steady-state operating conditions, samples of the feed, residue and permeate streams were taken. After about 2 hours of operation, the flow in the module became erratic. We found that the feed stream entering the membrane system was flooded with liquid, which had completely filled the front-end coalescing filter and subsequently flooded the module. We switched to the second module, number 736 , only to have the same liquid build-up problem occur after about 2 hours of operation.

We were able to acquire data from both modules before the condensation problems arose. The operating conditions for these tests are shown in Table 9, and the results obtained in the low-pressure tests are shown in Table 10.

Table 9. System Operating Conditions at Field Site.

\begin{tabular}{||l|l||}
\hline \multicolumn{1}{|c|}{ Parameter } & \multicolumn{1}{|c||}{ Value } \\
\hline Feed Pressure & $425-435$ psia \\
\hline Permeate Pressure & $15 \mathrm{psia}$ \\
\hline Feed Flow Rate & $50-60 \mathrm{scfm}$ \\
\hline Feed Temperature & $10-15^{\circ} \mathrm{C}$ (weather changed during the \\
& testing) \\
\hline Feed Composition (mol\%) & 12.3 \\
Nitrogen & 76.3 \\
Methane & 1.22 \\
Carbon Dioxide & 5.8 \\
Ethane & 3.13 \\
Hydrogen Sulfide & 1.18 \\
Propane & \\
\hline
\end{tabular}

The permeate hydrogen sulfide composition for module 736 was about 34 mol\% and for module 735 was about $37 \mathrm{~mol} \%$. 
Table 10. Results of Low-Pressure Tests on Pilot System Modules.

\begin{tabular}{||c|c|c|c|c|c||}
\hline \multirow{2}{*}{ Module Number } & \multicolumn{3}{|c|}{$\begin{array}{c}\text { Permeation Flux } \\
\left(10^{-6} \mathrm{~cm}^{3}(\mathrm{STP}) / \mathrm{cm}^{2} \cdot \mathrm{s} \cdot \mathrm{cmHg}\right)\end{array}$} & \multicolumn{2}{c|}{$\begin{array}{c}\text { Module Selectivity } \\
(-)\end{array}$} \\
\cline { 2 - 6 } & $\mathrm{CH}_{4}$ & $\mathrm{CO}_{2}$ & $\mathrm{H}_{2} \mathrm{~S}$ & $\mathrm{H}_{2} \mathrm{~S}_{\mathrm{CH}_{4}}$ & $\mathrm{CO}_{2} / \mathrm{CH}_{4}$ \\
\hline 736 & 5 & 62 & 140 & 28 & 12.4 \\
\hline 735 & 4.8 & 63 & 160 & 33 & 13.1 \\
\hline
\end{tabular}

The following conclusions can be drawn from the results given in Table 10 .

- The methane flux through the membrane was about $5 \times 10^{-6} \mathrm{~cm}^{3}(\mathrm{STP}) / \mathrm{cm}^{2} \cdot \mathrm{s} \cdot \mathrm{cmHg}$. This is similar to the flux obtained during laboratory tests with the same membrane material.

- The hydrogen sulfide and carbon dioxide fluxes were slightly lower than those obtained in the laboratory, which led to lower methane selectivities.

These initial results were very encouraging, considering that this was the first time the membrane had been exposed to an actual natural gas stream. Also, the feed concentration of hydrogen sulfide was about twice that of any concentration that we had been able to use in the laboratory.

\subsubsection{Trip $2(4 / 7 / 97-4 / 12 / 97)$}

The system was re-started on April 7, 1997, after retrofitting the test skid with the mechanical drain, steam tracing and insulation described in Section 5.4.

For this series of experiments, the modules used during the first test were replaced with new modules: module 935 in tube 1 and module 932 in tube 2 . For five days, the modules were tested individually under various feed flow rate and feed pressure conditions. Tables 11 and 12 show the results obtained from experiments on modules 935 and 932, respectively. 
Table 11. Results of Pressure and Flow Rate Variation Experiments on Module 935.

\begin{tabular}{||c|c|c|c|c|c|c|c||}
\hline \multirow{2}{*}{$\begin{array}{c}\text { Feed } \\
\text { Pressure } \\
\text { (psig) }\end{array}$} & \multicolumn{2}{|c|}{$\begin{array}{c}\text { Flow Rate } \\
(\mathrm{scfm})\end{array}$} & \multicolumn{2}{c|}{$\begin{array}{c}\text { Pressure-normalized Flux } \\
\left(10^{-6} \mathrm{~cm}^{3}(\mathrm{STP}) / \mathrm{cm}^{2} \cdot \mathrm{s} \cdot \mathrm{cmHg}\right)\end{array}$} & \multicolumn{2}{c||}{ Selectivity } \\
\cline { 2 - 8 } & Feed & Permeate & $\mathrm{CH}_{4}$ & $\mathrm{CO}_{2}$ & $\mathrm{H}_{2} \mathrm{~S}$ & $\mathrm{H}_{2} \mathrm{~S} / \mathrm{CH}_{4}$ & $\mathrm{CO}_{2} / \mathrm{CH}_{4}$ \\
\hline 400 & 127 & 0.5 & 4.3 & 43 & 118 & 28 & 10 \\
\hline 660 & 59 & 0.6 & 8.2 & 45 & 66 & 8.0 & 5.5 \\
\hline 640 & 130 & 0.6 & 7.7 & 46 & 95 & 12 & 6.0 \\
\hline 670 & 152 & 0.6 & 7.5 & 41 & 76 & 10 & 5.4 \\
\hline
\end{tabular}

Table 12. Results Obtained from Pressure and Flow Rate Variation Experiments on Module 932.

\begin{tabular}{|c|c|c|c|c|c|c|c||}
\hline \multirow{2}{*}{$\begin{array}{c}\text { Feed } \\
\text { Pressure } \\
\text { (psig) }\end{array}$} & \multicolumn{2}{|c|}{$\begin{array}{c}\text { Flow Rate } \\
(\mathrm{scfm})\end{array}$} & \multicolumn{2}{c|}{$\begin{array}{c}\text { Pressure-normalized Fluxes } \\
\left(10^{-6} \mathrm{~cm}^{3}(\mathrm{STP}) / \mathrm{cm}^{2} \cdot \mathrm{s} \cdot \mathrm{cmHg}\right)\end{array}$} & \multicolumn{2}{c||}{ Selectivity } \\
\cline { 2 - 8 } & Feed & Permeate & $\mathrm{CH}_{4}$ & $\mathrm{CO}_{2}$ & $\mathrm{H}_{2} \mathrm{~S}$ & $\mathrm{H}_{2} \mathrm{~S}_{\mathrm{CH}_{4}}$ & $\mathrm{CO}_{2} / \mathrm{CH}_{4}$ \\
\hline 530 & 129 & 0.4 & 4.6 & 49 & 207 & 46 & 11 \\
\hline 660 & 56 & 0.4 & 4.5 & 37 & 97 & 22 & 8.2 \\
\hline 640 & 121 & 0.5 & 5.2 & 42 & 85 & 16 & 8.1 \\
\hline \hline
\end{tabular}

For both modules the membrane performance, specifically the hydrogen sulfide/methane and carbon dioxide/methane membrane selectivities, was not as good as expected. Further pure gas tests on the membrane used to manufacture these modules indicated that the support layer was defective. The support layer should only provide a support matrix for the selective membrane layer. In this case, the support layer was acting as another selective layer, thereby reducing the performance of the composite membrane.

The system operated successfully for four days. The design changes made to inhibit module flooding with liquid were successful. Unfortunately, during an overnight run, the temperature at the test site dropped to below freezing; we suspect that water in the feed stream froze in the inlet stream, filter and housing. Therefore, the system was shut down before leaving the test site.

\subsubsection{Trip $3(6 / 18 / 97-6 / 20 / 97)$}

Field testing was re-started at Bryans Mill during the week of June 16, 1997. The modifications described in Section 5.4 were made to the system. First, we installed the feed-to-residue bypass line. We also changed the design of the end-caps on the module elements from a Teflon 
mechanical seal to a U-cup gasket. This was expected to eliminate any possible feed-to-residue bypass inside the module housing.

Two new modules, numbers 967 and 968, were installed in the system. These modules were manufactured using a new membrane lot. This new lot had excellent pure gas test results, which indicated that we had eliminated the support layer problem of the previous membrane. The operating conditions and the results of four tests performed by the MTR engineers at the site are shown in Tables 13 and 14, respectively.

Table 13. Feed and Residue Conditions for Four Tests Performed at the Bryans Mill Field Site.

\begin{tabular}{||c|c|c|c|c|c|c|c||}
\hline \hline \multirow{2}{*}{$\begin{array}{c}\text { Test } \\
\text { No. }\end{array}$} & $\begin{array}{c}|c| \\
\text { Pressure } \\
(\mathrm{psig})\end{array}$ & $\begin{array}{c}\text { Flow Rate } \\
(\mathrm{scfm})\end{array}$ & $\begin{array}{c}\text { Residue } \\
\text { Pressure } \\
(\mathrm{psig})\end{array}$ & $\begin{array}{c}\text { Pressure } \\
(\mathrm{psig})\end{array}$ & $\begin{array}{c}\text { Flow Rate } \\
(\mathrm{scfm})\end{array}$ & $\begin{array}{c}\text { Pressure } \\
(\mathrm{psig})\end{array}$ & $\begin{array}{c}\text { Flow } \\
\text { Rate } \\
(\mathrm{scfm})\end{array}$ \\
\hline 1 & 775 & 147 & 575 & 0 & 0.43 & 0 & 0.35 \\
\hline 2 & 725 & 113 & 620 & 0 & 0.40 & 0 & 0.39 \\
\hline 3 & 620 & 101.5 & 505 & 0 & 0.31 & 0 & 0.26 \\
\hline 4 & 795 & 140 & 620 & 0 & 0.46 & 0 & 0.38 \\
\hline
\end{tabular}

Table 14. Performance of Modules Tested at the Bryans Mill Field Site.

\begin{tabular}{|c|c|c|c|c|c|c|c|}
\hline \multirow[b]{2}{*}{$\begin{array}{l}\text { Test } \\
\text { No. }\end{array}$} & \multicolumn{4}{|c|}{$\begin{array}{l}\text { Hydrogen Sulfide } \\
\text { Concentration } \\
(\mathrm{mol} \%)\end{array}$} & \multicolumn{2}{|c|}{$\begin{array}{c}\text { Permeation Flux } \\
\left(10^{-6} \mathrm{~cm}^{3}(\mathrm{STP}) /\right. \\
\left.\mathrm{cm}^{2} \cdot \mathrm{s} \cdot \mathrm{cmHg}\right)\end{array}$} & \multirow{2}{*}{$\begin{array}{c}\text { Module } \\
\text { Selectivity } \\
\left(\mathrm{H}_{2} \mathrm{~S} / \mathrm{CH}_{4}\right)\end{array}$} \\
\hline & Feed & Residue & $\begin{array}{c}\text { Permeate } \\
\quad \# 1\end{array}$ & $\begin{array}{c}\text { Permeate } \\
\quad \# 2\end{array}$ & $\mathrm{CH}_{4}$ & $\mathrm{H}_{2} \mathrm{~S}$ & \\
\hline 1 & 3.16 & 2.86 & 45.6 & 44.4 & 3.7 & 135 & 37 \\
\hline 2 & 3.16 & 2.80 & 43.3 & 42.9 & 3.7 & 122 & 33 \\
\hline 3 & 3.16 & 2.86 & 44.1 & 43.7 & 3.4 & 124 & 37 \\
\hline 4 & 3.16 & 2.92 & 45.4 & 44.5 & 3.8 & 136 & 36 \\
\hline
\end{tabular}

The hydrogen sulfide analysis for these tests was performed using the Tutweiler test described in Section 5.3. The data shown in Tables 13 and 14 lead to the following conclusions. 
- Significant hydrogen sulfide enrichment was obtained. The concentration of hydrogen sulfide increased from $3.16 \%$ in the feed stream to $44.5 \%$ in the permeate stream.

- Based on the data obtained, we estimate the hydrogen sulfide/methane membrane selectivity to be between 33 and 37 and the carbon dioxide/methane selectivity to be approximately 10 . This selectivity is close to that expected from laboratory measurements on these membranes.

- The hydrogen sulfide flux increased as the flow rate increased. This occurred because the actual velocity across the surface of the membrane increased; this tends to decrease concentration polarization effects.

The results obtained during this trip were very encouraging. The system remained in operation after the MTR personnel left the plant under the operations conditions listed in Table 15.

Table 15. Operating Conditions of System Upon Departure from Test Site after Trip 3.

\begin{tabular}{||l|c||}
\hline \multicolumn{1}{|c|}{ Parameter } & Value \\
\hline Feed Pressure & $825 \mathrm{psig}$ \\
\hline Permeate Pressure & $0.5 \mathrm{psig}$ \\
\hline Feed Flow Rate & $103 \mathrm{scfm}$ \\
\hline Module 1 Permeate Flow Rate & $0.46 \mathrm{scfm}$ \\
\hline Module 2 Permeate Flow Rate & $0.4 \mathrm{scfm}$ \\
\hline
\end{tabular}

\subsubsection{Trip $4(8 / 11 / 97-8 / 14 / 97)$}

We revisited the field test site in August 1997, after the system had been operating continuously for approximately six weeks. On arrival at the site, however, we found that the operating conditions at the plant had changed significantly. The feed pressure to the membrane system had decreased from about 650-700 psig to about 350-400 psig. This low feed pressure would not allow us to operate the test system as planned, and so the system was shut down and shipped back to MTR. Because the feed pressure had dropped so drastically, we were unable to obtain any mixed gas measurements at the end of the test. These would have helped to assess the long-term stability of the membrane performance.

At MTR, we removed the two modules from the system and performed a series of pure gas tests to check if the membrane performance had changed at all during the field test. The results of the pure gas tests showed very low pressure-normalized fluxes for both nitrogen and carbon dioxide. 
Such results indicate possible contamination on the surface of the membrane. A dissection of the module confirmed this hypothesis; the entire surface of the membrane was coated with a yellow film.

We removed several small samples of the membrane and attempted to run a series of pure gas stamp tests. No measurable flux was obtained for either nitrogen or carbon dioxide; this can be attributed to the oil contamination. To remove the oil from the stamps, we soaked them in two solvents: methyl ethyl ketone and hexane. After drying the stamps in a vacuum oven for one hour, the pure gas tests were repeated. This time measurable and expected fluxes were obtained, as shown in Table 16.

Table 16. Averaged Results from Stamp Tests on Hydrogen Sulfide Module Before and After Field Test.

\begin{tabular}{||c|c|c||}
\hline \multicolumn{1}{|c|}{ Parameter } & Before Field Test & After Field Test \\
\hline Pressure-Normalized Flux $\left(10^{-6} \mathrm{~cm}^{3}(\mathrm{STP}) / \mathrm{cm}^{2} \cdot \mathrm{s} \cdot \mathrm{cmHg}\right)$ & & \\
Nitrogen & 0.9 & 1.1 \\
Carbon Dioxide & 68.2 & 55 \\
\hline Carbon Dioxide/Nitrogen Selectivity & 76 & 52 \\
\hline
\end{tabular}

The nitrogen permeation flux increased only slightly, but that of carbon dioxide decreased. This is probably attributable to the presence of hydrocarbon oil in the membrane resulting in decreased sorption of carbon dioxide, therefore a lower permeation flux. However, these results are encouraging and indicate that the membrane is able to withstand high hydrogen sulfide concentrations. Formation of the yellow oil film on the membrane surface can probably be avoided by installation of a better oil-mist separator in front of the system.

The results obtained from the field test are compared to those obtained in the laboratory using stamps and spiral-wound modules in Figures 28 and 29. Figure 28 shows the hydrogen sulfide/methane selectivity as a function of feed pressure. For comparison, the results include those obtained from membrane stamps, results from module tests and the results obtained at the Bryans Mill site. The selectivity of hydrogen sulfide over methane is the highest in membrane stamps. In spiralwound elements the selectivity was somewhat lower, but was still close to that obtained in the stamps. In the field tests, in a real-natural gas stream, the hydrogen sulfide/methane selectivity was only about $15 \%$ lower than in stamps. This was a very encouraging result. Figure 29 shows an equivalent plot of the carbon dioxide/methane selectivity, which shows a similar trend. Figures 28 and 29 also show results for some earlier modules that were tested at the Bryans Mill site. These modules used an inferior membrane (see Table 8). Overall, the results from the field test were encouraging. 


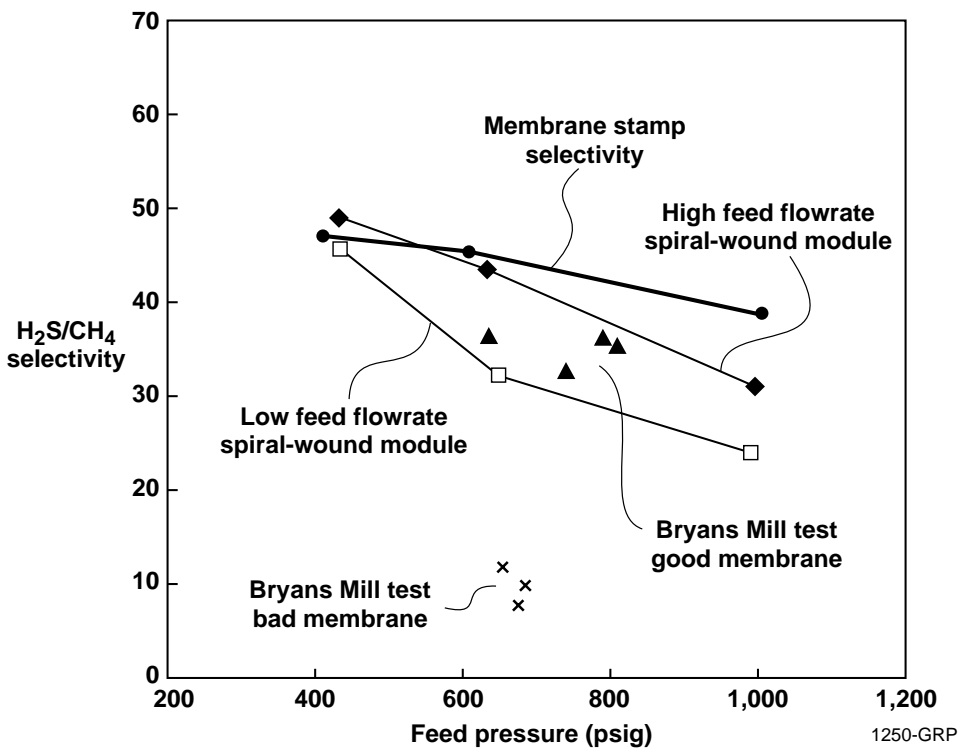

Figure 28. Hydrogen sulfide/methane selectivity over a range of feed pressures for module tests in the field compared with the results obtained for membrane stamps and modules in the laboratory.

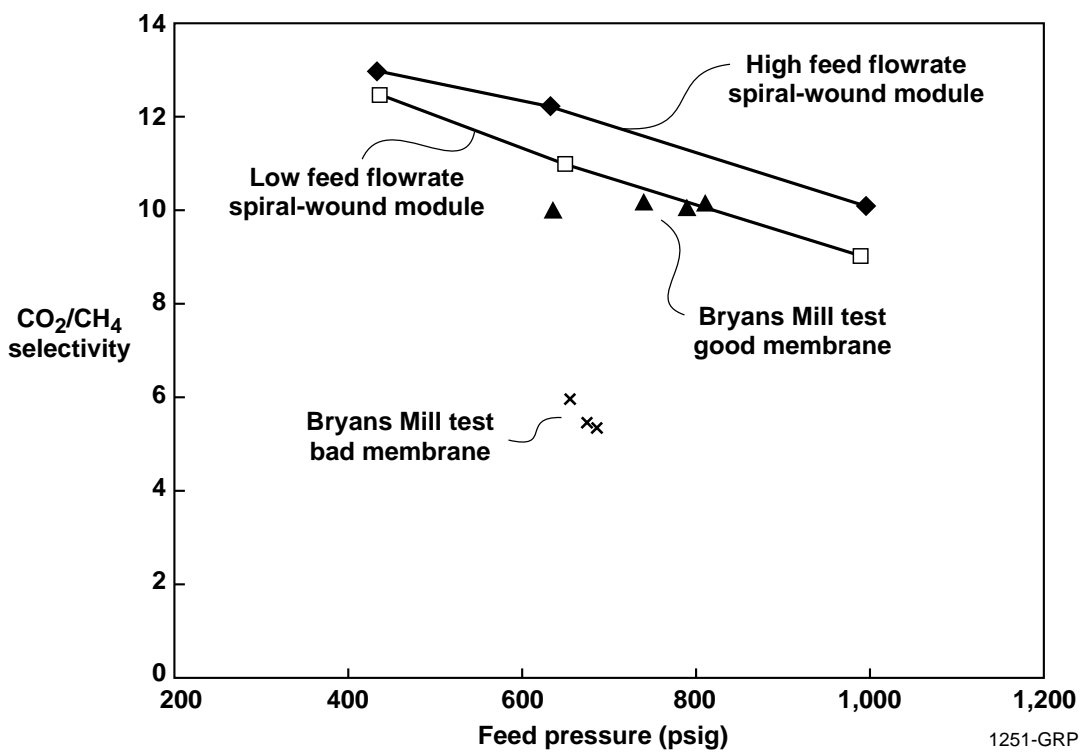

Figure 29. Carbon dioxide/methane selectivity over a range of feed pressures for module tests in the field compared with results obtained for modules in the laboratory. 


\section{POTENTIAL MEMBRANE APPLICATIONS}

\subsection{Identification of Hydrogen Sulfide-Contaminated Formations and Fields}

We have identified the range of feed compositions of natural gas streams that contain hydrogen sulfide. According to a GRI report, about $13 \%$ of known raw non-associated natural gas reserves reside in hydrogen sulfide-prone formations. ${ }^{1}$ The GRI report states that a similar percentage of undiscovered resources will be contaminated with hydrogen sulfide. The report further states that since the determination of hydrogen sulfide is difficult, there have been very few studies to characterize hydrogen sulfide content in natural gas. Therefore, it is possible that the actual volume of natural gas containing hydrogen sulfide may actually be higher than these estimates.

Hydrogen sulfide is generally associated with carbonate (limestone and dolomite) reservoirs, but can also be found in sandstone reservoirs. Non-associated hydrogen sulfide is found in the Paleozoic carbonates in the Rockies, Mid-Continent, Permian, Michigan, and Illinois Basins. It is also found in the Cretaceous and Jurassic carbonates and in the sandstone of the Gulf Coast and East Texas. ${ }^{1}$

Major hydrogen sulfide-prone formations exist at the following locations:

1. The Cotton Valley and Smackover formations in the E. Texas Basin.

2. The Madison formation in the Green River Basin in Wyoming.

3. The Smackover and Norphlet formations in the Gulf Coast.

4. The Devonian and Ellenburger formations in the Permian Basin in West Texas.

5. The Edwards formation on the Texas Gulf Coast.

\subsection{Subquality Gas Compositions}

Data obtained from a topical report to the Gas Research Institute by Radian Corporation ${ }^{2}$ are plotted in Figure 30, which shows the range of feed compositions of acid gases in streams from various gas fields in the Lower-48 states. Figure 21 shows that over $90 \%$ of the subquality natural gas streams fall into the concentration range $0.02-5 \%$ hydrogen sulfide, and $1-10 \%$ carbon dioxide. 


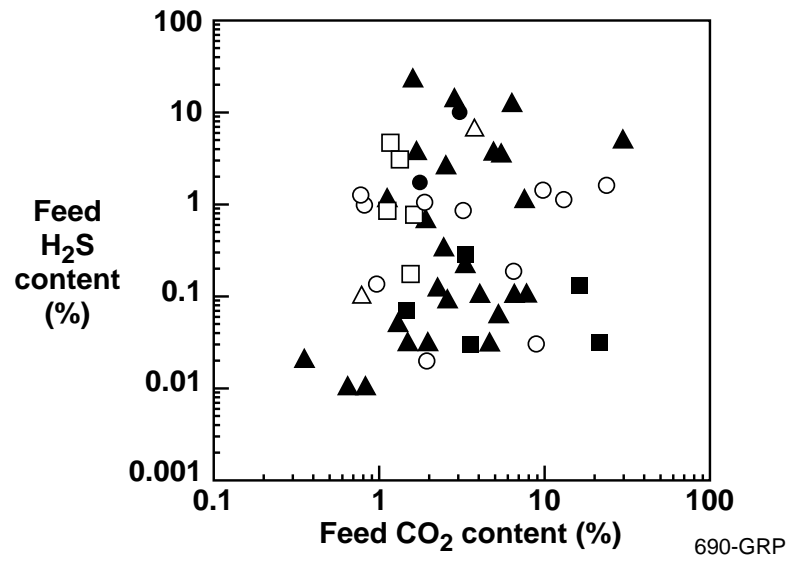

Figure 30. Hydrogen sulfide and carbon dioxide content of natural gas reserves in eight states (indicated by different symbols) that are known to contain hydrogen sulfide-prone formations.

Currently, gas streams that contain substantial amounts of acid gases are usually treated by an amine process. The hydrogen sulfide stream produced in these absorption processes is either vented, flared, or sent to a sulfur-recovery plant depending on the concentration of hydrogen sulfide. We believe that a membrane process will produce a stream of hydrogen sulfide concentrated enough to be sent directly to a Claus plant for sulfur recovery, thereby reducing sulfur emissions to the atmosphere significantly.

\subsection{Survey of Potential Applications and Possible Membrane Process Designs}

The separation of sulfur from subquality natural gas involves two distinct steps:

1. Removal of hydrogen sulfide and other acid gases (carbon dioxide etc.) from natural gas

2. Fixing/recovering the sulfur in hydrogen sulfide 
Figure 31 shows an overall treatment scheme for subquality natural gas.

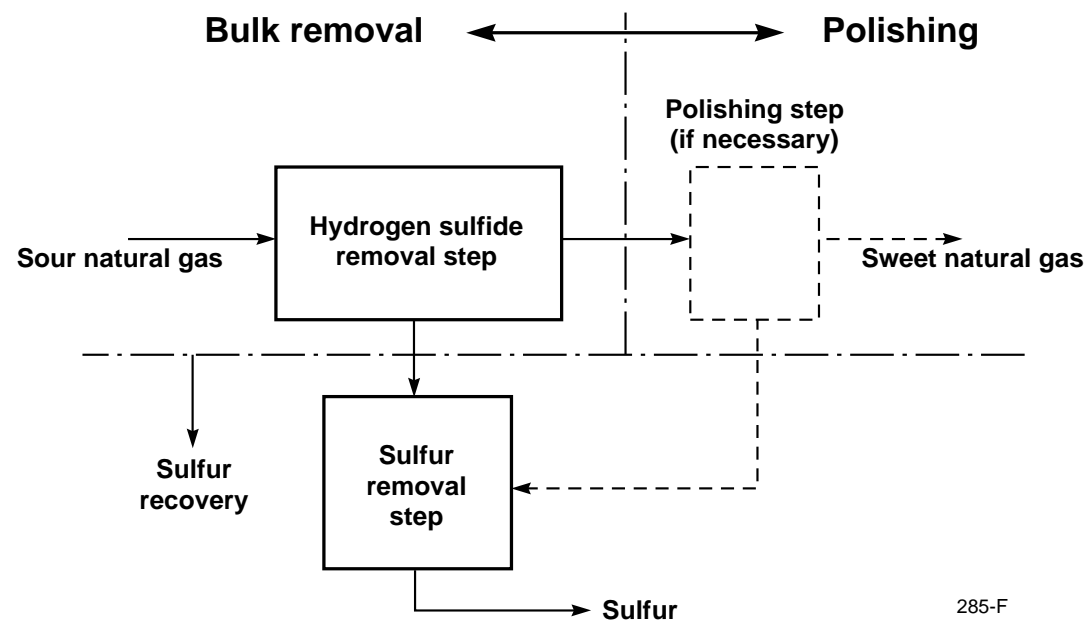

Figure 31. Overall treatment scheme for hydrogen sulfide-contaminated, subquality gas.

Two alternative processes, amine absorption or membranes, can be used for the bulk removal of the acid gases. The application areas of these processes are summarized in Table 17.

Table 17. Options for Bulk Removal of Acid Gases from Subquality Natural Gas.

\begin{tabular}{||c|l|l|l|l||}
\hline \multirow{2}{*}{ Process } & \multicolumn{2}{|c||}{ Suitable Operating Conditions } & \multirow{2}{*}{$\begin{array}{c}\text { Technology } \\
\text { Standing }\end{array}$} \\
\cline { 2 - 4 } & \multicolumn{1}{|c|}{ Feed Rate } & $\begin{array}{c}\text { Feed } \\
\text { Composition }\end{array}$ & Acid Gas Stream & \multicolumn{1}{||}{} \\
\hline $\begin{array}{l}\text { Amine } \\
\text { absorption }\end{array}$ & $\begin{array}{l}\text { Medium to high } \\
(>10 \mathrm{MMscfd})\end{array}$ & $\begin{array}{l}\mathrm{CO}_{2}:<20 \% \\
\mathrm{H}_{2} \mathrm{~S}:<2-5 \%\end{array}$ & $\begin{array}{l}\text { Concentrated (total } \\
\text { acid gas 95\%) }\end{array}$ & $\begin{array}{l}\text { Mature but } \\
\text { expensive }\end{array}$ \\
\hline $\begin{array}{l}\text { Membrane } \\
\text { (single stage })\end{array}$ & $\begin{array}{l}\text { Low to medium } \\
(<20 \mathrm{MMscfd})\end{array}$ & $\begin{array}{l}\mathrm{CO}_{2}:>2 \% \\
\mathrm{H}_{2} \mathrm{~S}:>200 \mathrm{ppm}\end{array}$ & $\begin{array}{l}\text { Leaner (Total acid } \\
\text { gas }>20 \%)\end{array}$ & $\begin{array}{l}\text { Relatively new and } \\
\text { less expensive }\end{array}$ \\
\hline $\begin{array}{l}\text { Membrane } \\
\text { (two stage })\end{array}$ & $\begin{array}{l}\text { Medium to high } \\
(>50 \mathrm{MMscfd})\end{array}$ & $\begin{array}{l}\mathrm{CO}_{2}:>5 \% \\
\mathrm{H}_{2} \mathrm{~S}:>10 \%\end{array}$ & $\begin{array}{l}\text { Variable Typically } \\
90 \%\end{array}$ & $\begin{array}{l}\text { Relatively new } \\
\text { simple/economical }\end{array}$ \\
\hline
\end{tabular}

Both bulk separation processes remove up to $80-90 \%$ of the acid gases, and typically meet the carbon dioxide pipeline specifications. The residue stream, particularly from the amine absorption process, may also meet the pipeline specification for hydrogen sulfide of $4 \mathrm{ppm}$. If not, a polishing step is added. Depending on the feed flow rate and the composition, one of the polishing steps given in Table 18 would be used. 
Table 18. Options for Secondary Polishing Treatment to Meet Pipeline Specification.

\begin{tabular}{|c|c|c|c|c|}
\hline \multirow{2}{*}{ Process } & \multicolumn{3}{|c|}{ Suitable Operating Conditions } & \multirow{2}{*}{$\begin{array}{l}\text { Technology } \\
\text { Standing }\end{array}$} \\
\hline & Feed Rate & Feed Composition & $\begin{array}{c}\text { Final Disposition of } \\
\text { Sulfur } \\
\end{array}$ & \\
\hline $\begin{array}{l}\text { SulfaTreat } \\
\text { fixed bed }\end{array}$ & $\begin{array}{l}\text { Low to Medium } \\
(<10 \text { MMscfd })\end{array}$ & $\begin{array}{l}\mathrm{CO}_{2}:<2 \% \\
\mathrm{H}_{2} \mathrm{~S}:<100 \mathrm{ppm} \\
\text { Ttl. sulfur: }<0.5 \mathrm{t} / \text { day } \\
\end{array}$ & $\begin{array}{l}\text { Absorbent } \\
\text { land filled }\end{array}$ & $\begin{array}{l}\text { Mature and } \\
\text { inexpensive }\end{array}$ \\
\hline Redox & $\begin{array}{l}\text { Low to Medium } \\
(<10 \text { MMscfd })\end{array}$ & $\mathrm{CO}_{2}:<2 \%$ & $\begin{array}{l}\text { Fixed to elemental } \\
\text { sulfur }\end{array}$ & $\begin{array}{l}\text { Relatively new, } \\
\text { high operating } \\
\text { expenses at high } \\
\text { pressure }\end{array}$ \\
\hline
\end{tabular}

Both bulk removal processes yield an enriched acid gas stream, which then passes to a secondary treatment step to fix the sulfur. Depending on the gas flow rate and the composition of the permeate stream from the membrane process, one of the sulfur-fixing processes shown in Table 19 would be used.

Table 19. Options for Recovery of Sulfur from Hydrogen-Sulfide-Enriched Stream.

\begin{tabular}{|c|c|c|c|c|}
\hline \multirow{2}{*}{ Process } & \multicolumn{3}{|c|}{ Suitable Operating Conditions } & \multirow{2}{*}{$\begin{array}{l}\text { Technology } \\
\text { Standing }\end{array}$} \\
\hline & Feed Rate & $\begin{array}{c}\text { Feed } \\
\text { Composition } \\
\end{array}$ & Sulfur Quality & \\
\hline Flare/Vent & $\begin{array}{l}\text { Low } \\
\text { (>1 LT/day) }\end{array}$ & - & $\begin{array}{l}\text { Emitted to } \\
\text { atmosphere }\end{array}$ & Mature and cheap \\
\hline Claus & $\begin{array}{l}\text { High } \\
\text { (>10 LT/day) }\end{array}$ & $\begin{array}{l}\mathrm{H}_{2} \mathrm{~S}:>10 \% \\
\mathrm{H}_{2} \mathrm{~S} / \mathrm{CO}_{2}: 1 / 6\end{array}$ & $\begin{array}{l}\text { High quality, } \\
\text { bright yellow }\end{array}$ & $\begin{array}{l}\text { Mature, expensive } \\
\text { tail-gas clean up }\end{array}$ \\
\hline Redox & $\begin{array}{l}\text { Low to medium } \\
(<10 \mathrm{LT} / \text { day })\end{array}$ & - & $\begin{array}{l}\text { Low quality, } \\
\text { requires treatment }\end{array}$ & $\begin{array}{l}\text { Relatively new, high } \\
\text { operating expenses }\end{array}$ \\
\hline
\end{tabular}

Figure 32 shows the application envelopes within which absorption and membrane processes would be most suitable, based on a natural gas stream containing about $5 \%$ carbon dioxide and varying amounts of hydrogen sulfide. The diagrams are not quantitative, but do represent the probable area of feasibility of these processes, based on the information collected to date. 
(a)

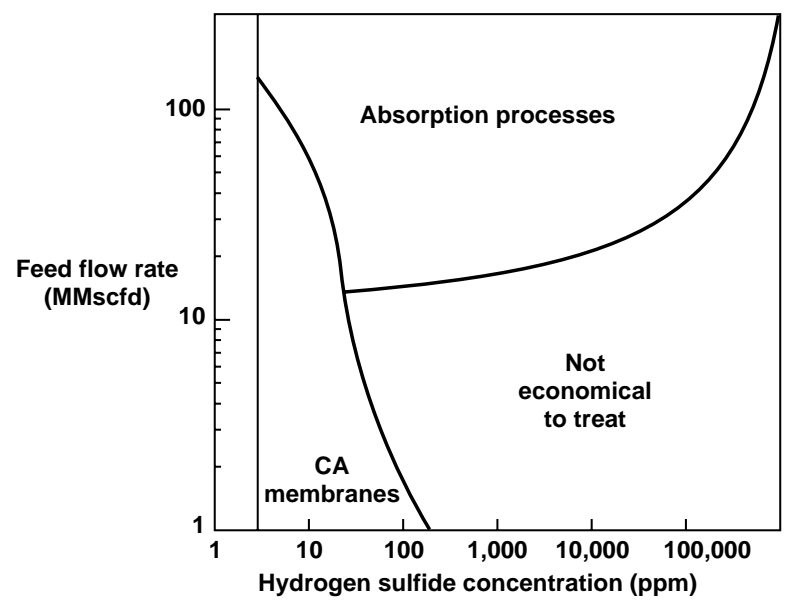

(b)

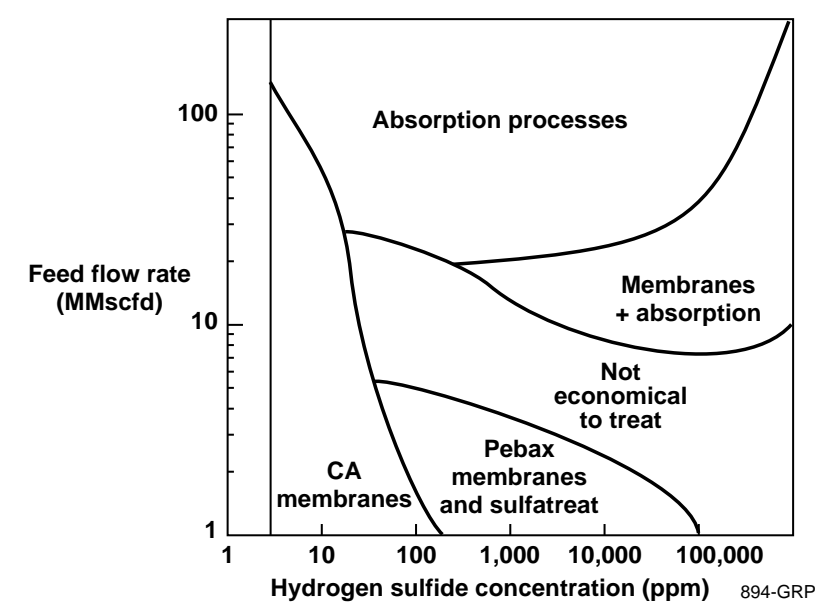

Figure 32. Application envelopes for absorption and membrane processes to treat sour gas streams.

Figure 32(a) shows the application areas for absorption (physical and chemical) processes and a membrane process using state-of-the-art cellulose acetate (CA) membranes. Absorption processes are currently the most widely used acid gas treatment process. The plants are typically large and complicated, and require constant supervision. The high cost of building and installation make them most suitable for large throughputs of natural gas, due to economies of scale. Because the operating expenses of these processes increase significantly with increased acid gas content, due to increased solvent recirculation and regeneration costs, they are less suitable for treatment of natural gas with a high acid gas content. Cellulose acetate membranes are most suitable for low throughput applications in which the total hydrogen sulfide content is also low. Although cellulose acetate membranes can treat gas containing a wide range of carbon dioxide concentrations (2-25\%), they cannot treat gas with higher concentrations of hydrogen sulfide because their hydrogen sulfide/methane selectivity is low.

Figure 32(b) shows the probable impact of Pebax membranes on the application ranges of the treatment processes. We expect Pebax membranes to increase the amount of subquality natural gas that can be economically produced. The high hydrogen sulfide/methane selectivity of Pebax membranes will allow treatment of streams containing greater amounts of hydrogen sulfide than is possible with the cellulose acetate membranes. Both membrane processes require a polishing step such as the SulfaTreat process to reach pipeline specification for hydrogen sulfide.

At high total acid gas content, conventional absorption processes become less suitable, because the cost of regenerating spent solvent also increases. Under such conditions, a combined process, in which the membranes remove the bulk of the acid gases and the absorption process removes the remainder to the desired pipeline specification, is a likely winner. In this hybrid design, both processes operate in their most favorable regime. By performing the bulk separation, the membrane process reduces the solvent recirculation in the amine process, thereby decreasing system size, and operating expenses associated with the regeneration of the solvent. The membrane system 
size is also small, and methane losses in the permeate are also greatly reduced. Overall, therefore, the membrane/absorption hybrid process appears attractive for high throughput, high acid- gasconcentration natural gas streams.

For the same reasons, Pebax membranes would provide an excellent drop-in retrofit for debottlenecking existing absorption processes. As natural gas fields age, the acid gas content tends to increase, raising the load on an installed absorption system. As a result, the absorption process does not achieve the design and pipeline specifications. A retrofitted membrane process could remove a fraction of the acid gases before the absorption process, allowing the existing system to continue to meet pipeline specifications. Similarly, the throughput of natural gas in any existing sour-gas treatment facility can be increased by retrofitting a membrane system. The membrane system will compensate for additional acid gases entering the system due to the increased capacity, thereby debottlenecking the existing treatment system.

In any of the above applications, the optimum membrane process configuration will depend on the feed conditions and the choice of the final sulfur disposal step. The following membrane process configurations, shown in Figure 33, are the most likely candidates:

a. A single-stage system with no moving parts

b. A two-stage system with permeate recompression and recycle

c. A two-and-one-half-stage system with permeate recompression and recycle

(a)

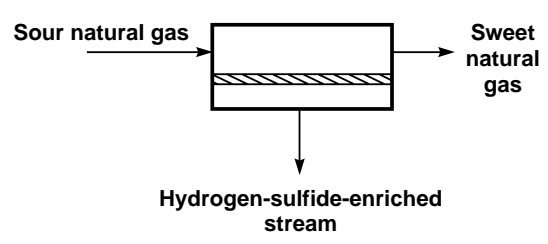

(c)

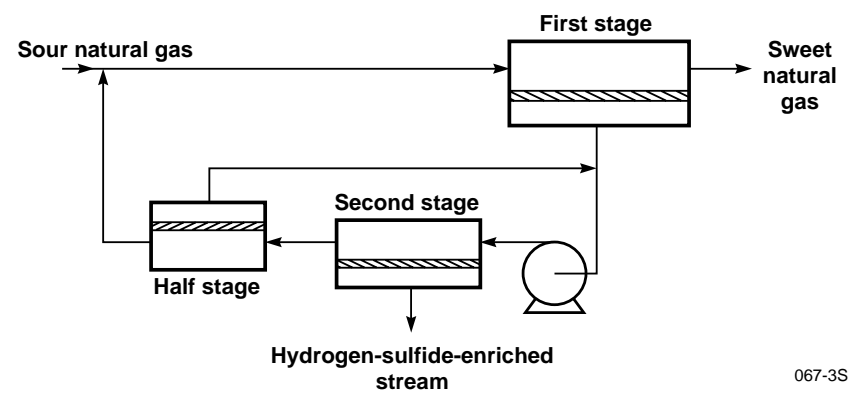

(b)

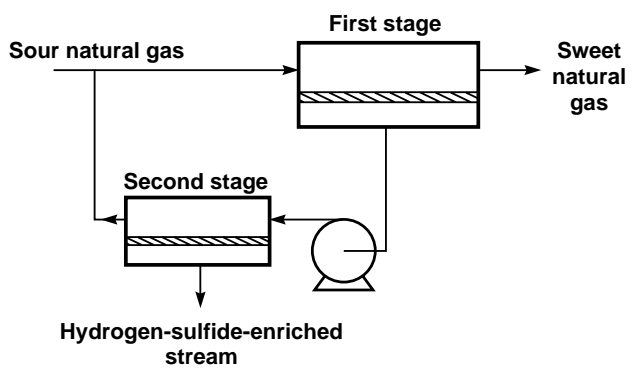

wows

Figure 33. Three possible membrane process configurations for sour gas treatment. 
The characteristics and performance of the single- and multi-stage systems, calculated using in-house computer simulation packages, are discussed in detail in Appendix A. The conclusion from the analysis is that membrane processes are ideal for the bulk separation of acid gases from natural gas, particularly at lower throughputs. However, if more than $99 \%$ of the acid gas in the feed stream is to be removed, the cost of the membrane system increases significantly compared to that for $90 \%$ removal. Pipeline specification requires less than $4 \mathrm{ppm}$ hydrogen sulfide in the treated gas. Because such a low concentration is difficult to achieve with a membrane system alone, except when significant quantities of carbon dioxide are also present, a hybrid process has to be used. First, a membrane process comprising a Pebax membrane or a combination of a carbon dioxide-selective membrane with the Pebax membrane will remove the bulk (up to 90\%) of the acid gases. The acidgas-depleted stream, which will meet pipeline specification for carbon dioxide ( $2 \mathrm{~mol} \%$ ), will then be treated in a fixed-bed SulfaTreat or similar process to remove the remaining hydrogen sulfide to pipeline specification.

\section{TECHNICAL AND ECONOMIC ANALYSIS}

Our application analysis identified two regions within the natural gas processing envelope in which the membrane process would be effective in lowering the cost of separating acid gas from lowquality natural gas. Extensive technical and economic analyses were performed for both of these potential application regions, which are:

1. For low-throughput, low-quality natural gas, i.e. $<20 \mathrm{MMscfd}$ and >500 ppm hydrogen sulfide - Membrane/SulfaTreat hybrid.

2. 1.For high throughput, low-quality natural gas, i.e. $>50 \mathrm{MMscfd}$ and $>10 \mathrm{~mol} \%$ hydrogen sulfide - Membrane/Amine Absorption hybrid.

\subsection{Low-Flow Applications: Membrane/SulfaTreat Hybrid Process}

For the relatively small flow rate applications in which DOE is particularly interested, we have concluded that a single-stage membrane system combined with a SulfaTreat process as the polishing step is the most economically viable option. To define the effects of various feed conditions, we performed an economic analysis on process designs based on this combination. The results of this analysis are discussed below.

\subsubsection{Process Design}

A schematic diagram of the membrane/SulfaTreat hybrid process is shown in Figure 34. The membrane processing step removes the bulk of the acid gases, typically up to about $90 \%$. The residual gas from the membrane system is then sent to a SulfaTreat system, in which the gas is contacted with a proprietary solid based on iron chemistry. The residual hydrogen sulfide is removed in the SulfaTreat tower to pipeline specifications. In the overall process, the membrane system has to meet the pipeline specifications for carbon dioxide, because the SulfaTreat process does not 
remove any carbon dioxide. The gas discharged from the SulfaTreat process would meet pipeline specifications for both carbon dioxide and hydrogen sulfide. Further treatment to remove natural gas liquids and/or water may be required before the gas is routed to the pipeline.

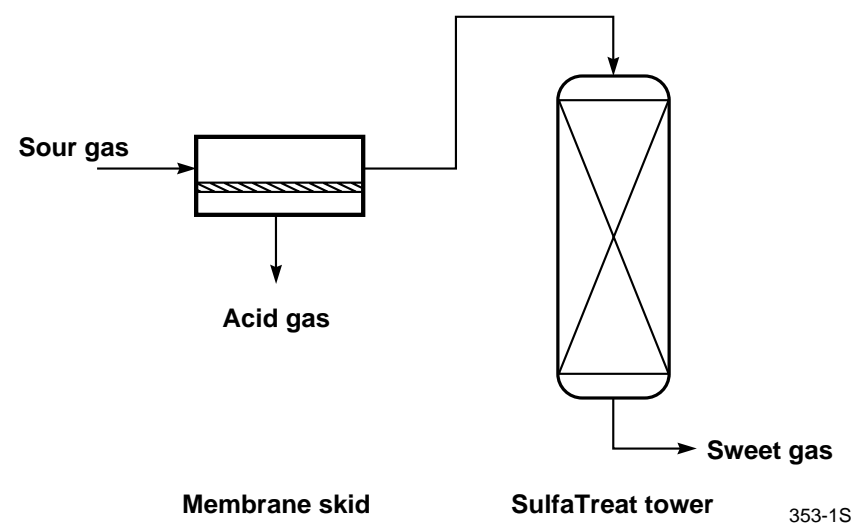

Figure 34. Schematic diagram of the membrane/SulfaTreat® hybrid process. SulfaTreat is a registered trademark of the SulfaTreat Company (Chesterfield, MO).

The hybrid membrane/SulfaTreat process was compared with amine-based adsorption. A schematic of the amine process is given in Figure 35. An amine absorption process consists of a scrubbing column for chemically absorbing acid gases into an amine solution and a regeneration column for stripping the acid gas from the amine solution at high temperature before it is recycled. The cost of the amine process depends on the recirculation rate of the amine solution, which in turn depends on the acid gas content in the feed, and feed throughput. 


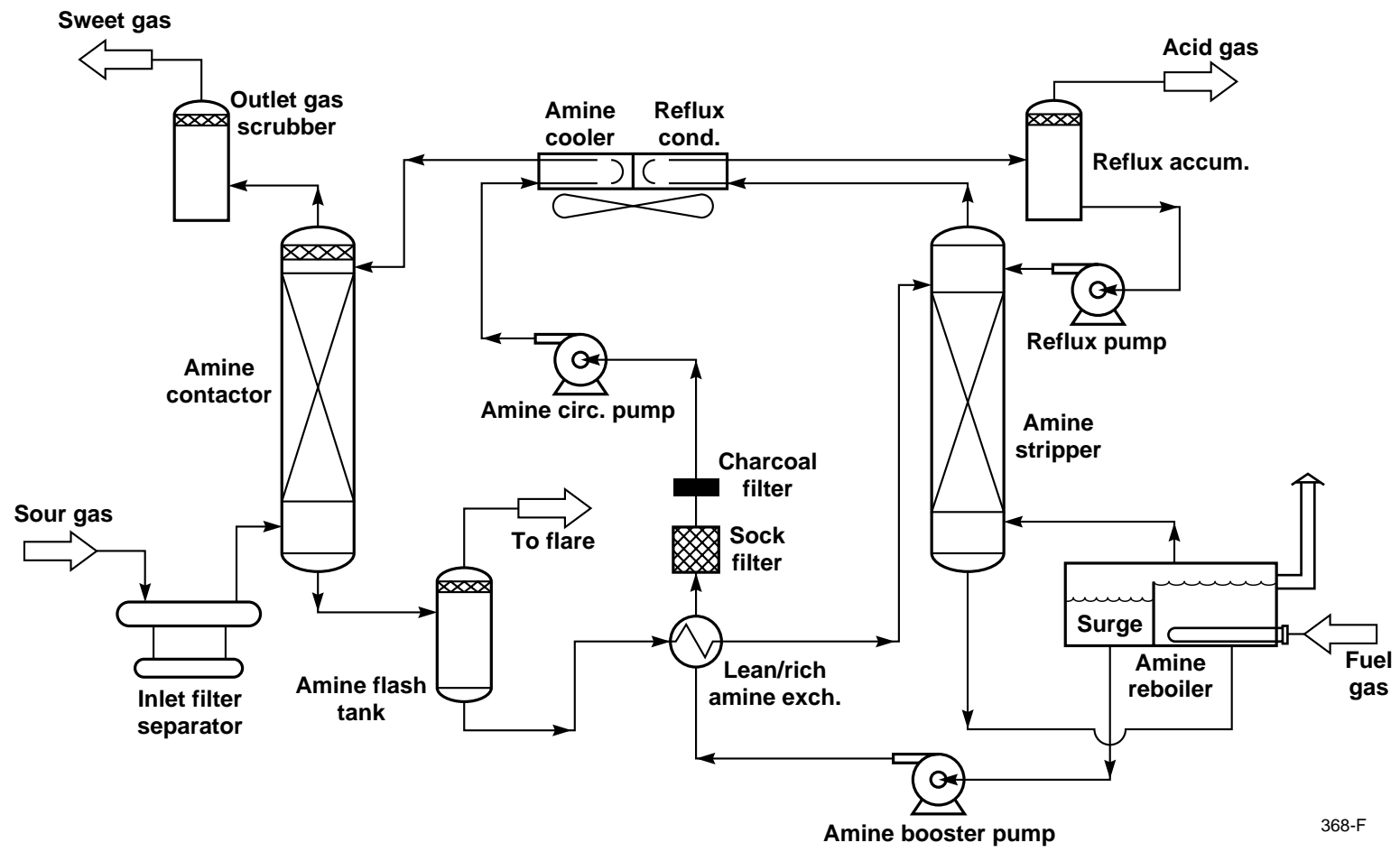

Figure 35. Schematic diagram of amine adsorption process.

In the economic analysis, the effect of the following variables was evaluated:

1. Feed flow rate

2. Feed hydrogen sulfide concentration

3. Feed carbon dioxide concentration

Table 20 gives the various feed compositions and flow rates that were covered in this evaluation. The natural gas stream is considered here to be a ternary mixture containing methane, carbon dioxide, and hydrogen sulfide. A total of 125 combinations results from these conditions; each of these was analyzed. 
Table 20. Natural Gas Compositions Used in the Design and Economic Evaluation.

\begin{tabular}{||c|c|c||}
\hline $\begin{array}{c}\text { Feed Flow Rate } \\
\text { (MMscfd) }\end{array}$ & $\begin{array}{c}\text { Hydrogen sulfide } \\
\text { Concentration } \\
(\mathrm{ppm})\end{array}$ & $\begin{array}{c}\mathrm{CO}_{2} \text { Concentration } \\
(\%)\end{array}$ \\
\hline 2 & 500 & 2 \\
\hline 5 & 1,000 & 5 \\
\hline 10 & 5,000 & 10 \\
\hline 20 & 10,000 & 15 \\
\hline 50 & 50,000 & 20 \\
\hline
\end{tabular}

The base-case process-related conditions used in the economic calculations for the membrane process are given in Table 21.

Table 21. Base-Case Process-Related Conditions Used in Economic Calculations for Membrane Process.

\begin{tabular}{||l|l||}
\hline \multicolumn{1}{|c|}{ Parameter } & \multicolumn{1}{c|}{ Value } \\
\hline Feed pressure & $1,000 \mathrm{psig}$ \\
Feed temperature & $75^{\circ} \mathrm{F}$ \\
Feed flow rate & $2 \mathrm{MMscfd}$ \\
Methane permeation flux & $2 \times 10^{-6} \mathrm{~cm}^{3}(\mathrm{STP}) / \mathrm{cm}^{2} \cdot \mathrm{s} \cdot \mathrm{cmHg}$ \\
$\mathrm{CO}_{2} / \mathrm{CH}_{4}$ selectivity & 12 \\
$\mathrm{H}_{2} \mathrm{~S} / \mathrm{CH}_{4}$ selectivity & 40 \\
Membrane residue $\mathrm{H}_{2} \mathrm{~S}$ concentration & $500 \mathrm{ppm}$ or lower if required to \\
& meet $\mathrm{CO}_{2}$ residue concentration \\
SulfaTreat residue $\mathrm{H}_{2} \mathrm{~S}$ concentration & $4 \mathrm{ppm}$ \\
Membrane residue $\mathrm{CO}_{2}$ concentration & $2 \%$ or lower \\
\hline
\end{tabular}

Tables 22 and 23 show the cost assumptions used in the economic calculations for the membrane process and the amine process, respectively. The data for the SulfaTreat Process was obtained from literature supplied by The SulfaTreat Company. Estimates of amine plant cost given in Table 23 were obtained from published literature. 
Table 22. Cost Assumptions Used in Economic Calculations for the Membrane/SulfaTreat Process.

\begin{tabular}{||ll||}
\hline Capital Cost & \\
Membrane/module/housing costs & $\$ 500 / \mathrm{m}^{2}$ \\
Piping/filtration/skid & $15 \%$ equipment cost \\
Fabrication & $20 \%$ of total plant cost \\
Margin & $30 \%$ of total plant cost \\
Cost of SulfaTreat vessel & $\$ 10,000$ \\
& \\
Operating Cost (per annum) & $\$ 250 / \mathrm{m}^{2}$ \\
Module replacement cost (3-year membrane life) & $\$ 18 / \mathrm{hr}$ \\
Labor cost (1 operator, 1 hr/day) & $5 \%$ capital cost \\
Maintenance/parts & $\$ 1 / \mathrm{MMBtu}$ \\
Methane losses via membrane permeate/fuel cost & $\$ 0.26 / \mathrm{lb}$ \\
Cost of SulfaTreat sorbent & \\
Processing Cost & $18 \%$ capital cost \\
Capital related cost (includes depreciation, & \\
return on investment taxes and royalties) & Annual operating expenses \\
\hline
\end{tabular}

Table 23. Cost Assumptions Used in Economic Calculations for the Amine Absorption Process.

\begin{tabular}{||ll||}
\hline Capital Cost & \\
Equipment cost & $\$ 69,415 \times(\mathrm{gpm})^{0.604} *$ \\
Installation cost & $2 \times$ equipment cost \\
Annual Operating Costs & \\
Heating/cooling & $\$ 0.03 / \mathrm{kWh}$ \\
Fuel Cost & $\$ 1 / \mathrm{MMBtu}$ \\
Labor (one operator/8-hour shift) & $\$ 18 / \mathrm{hr}$ \\
Amine replacement (1\% amine loss/year) & $\$ 0.3 / \mathrm{lb}$ \\
Maintenance and parts & $5 \%$ capital cost \\
& \\
Processing Costs & $18 \%$ capital cost \\
Capital-related cost (includes depreciation, & \\
return on investment, taxes, and royalties) & Annual operating expenses \\
Operating expenses & \\
\hline
\end{tabular}

*This cost correlation was obtained from Gas Conditioning and Processing, Volume 4: Gas and Liquid Sweetening. ${ }^{6}$ The reference cited therein is Jones. The above correlation was scaled to 1993 from 1977 by using the M\&S cost index. The calculation for the total gpm (gallons/minute) of amine recirculation rate was 
calculated using two approaches. The first was to calculate the recirculation based on loading and amine concentration data from the literature. An amine loading of 0.45 $\mathrm{mol}$ acid gas/mol amine, and a solution amine concentration of $25 \mathrm{wt} \%$ were assumed. The second approach used unpublished correlations from a large gas processing manufacturing company. The second approach gave somewhat lower recirculation rates. We used the second approach to calculate the recirculation rate of amine in gpm and the cost correlation given above. Typical installation costs for amine processes are high; we used a installation cost of twice the equipment cost.

Based on these cost assumptions, the effect of varying feed composition on installed capital cost and on processing cost for the membrane and amine processes was analyzed. For both processes, the processing costs were calculated per total feed MMBtu for the amine and membrane process.

\section{Effect of Varying Feed Composition on Installed Capital Cost}

Figure 36 shows the effect of varying the feed composition on the installed capital costs for the membrane and the amine absorption process (DEA based) at feed flow rates ranging from 2 to $20 \mathrm{MMscfd}$. In this figure, the thin line represents the cost of the amine absorption process, and the thicker lines correspond to the cost of the membrane/SulfaTreat hybrid process. Each thick line represents a certain carbon dioxide content in the feed stream. Along each line, the hydrogen sulfide content of the feed gas changes from $500 \mathrm{ppm}$ to $5 \%$. For example, the left-hand cost line in each case corresponds to a feed containing 3\% carbon dioxide and 500 ppm hydrogen sulfide (i.e. 3.05\% acid gas) up to $3 \%$ carbon dioxide and $5 \%$ hydrogen sulfide (i.e. $8 \%$ acid gas). 
(a) Feed flow rate: 2 MMscfd

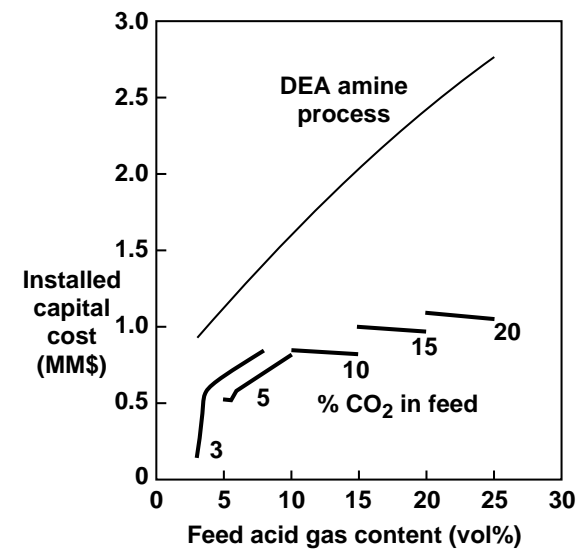

(c) Feed flow rate: 10 MMscfd

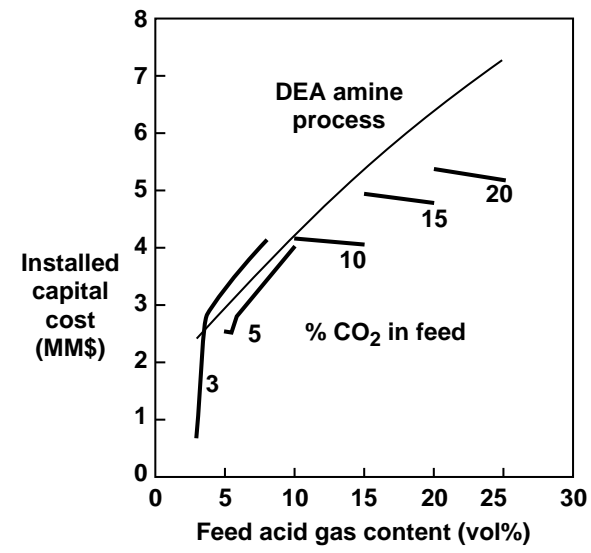

(b) Feed flow rate: 5 MMscfd

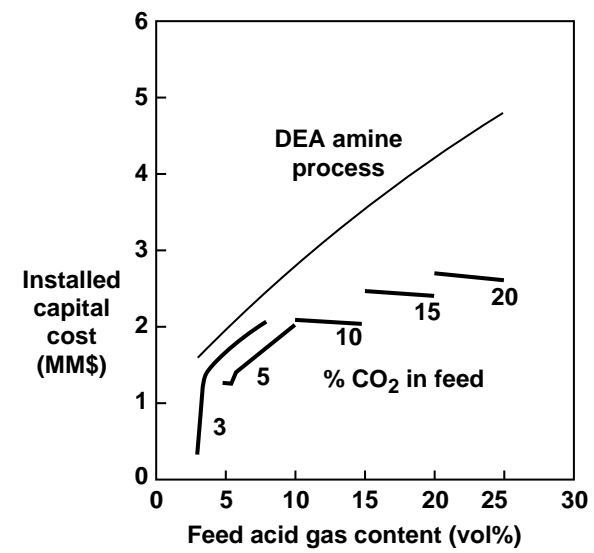

(d) Feed flow rate: 20 MMscfd

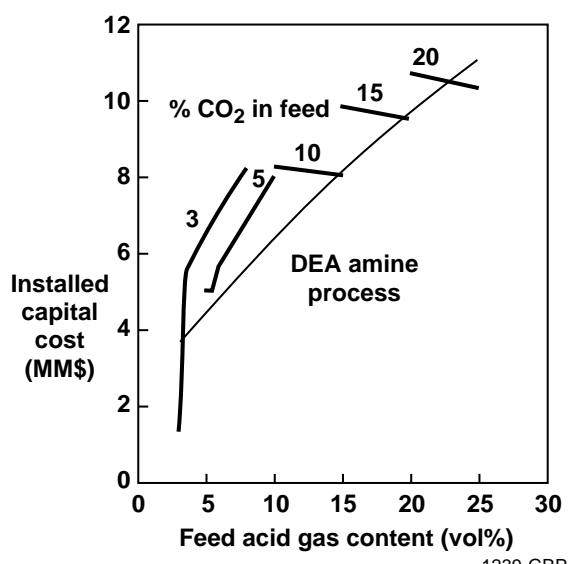

Figure 36. Effect of varying hydrogen sulfide and carbon dioxide feed concentration on the installed capital cost at a feed flow rates from 2 to 20 MMscfd. The thin line represents the amine process; the thicker lines represent the membrane/SulfaTreat hybrid at the carbon dioxide concentration indicated.

The following conclusions can be drawn from this capital cost analysis:

- At flow rates below about 10 MMscfd, the installed capital cost of the membrane/SulfaTreat process is lower than that of the amine process. At feed flows higher than about 10 MMscfd, the capital cost of the membrane process exceeds that of the amine process, especially for a lower total acid gas content. At feed flow rates exceeding $20 \mathrm{MMscfd}$, the membrane/SulfaTreat hybrid process is not competitive with the amine process.

The reason for this pattern is clear. The amine absorption process gains significantly from economies of scale, whereas the membrane process scales almost linearly with the flow rate. Therefore, higher feed flow rates favor the 
conventional absorption process, whereas lower flow rates favor the membrane process.

- In general, at a fixed feed flow rate, the capital cost of the membrane/SulfaTreat process increases with increasing acid gas content, leveling off at higher total acid gas contents. At higher feed flow rates, the cost tends to level off at higher and higher total acid gas content. Overall, therefore, it appears that the membranes process is better for treating natural gas containing higher levels of acid gases.

Based on capital costs, we conclude that the membrane/SulfaTreat process is best suited for lower feed flow rates and for natural gas containing higher total acid gases.

If the membrane area is determined by the carbon dioxide removal requirement rather than by the hydrogen sulfide removal requirement, the capital costs for the membrane process can be lowered by using a two-membrane process configuration. In this process, a standard cellulose acetate membrane, which has a higher carbon dioxide/methane selectivity, would be used in series with a Pebax membrane, which has a higher hydrogen sulfide/methane selectivity. By segregating the two resulting permeate streams, it would be possible to obtain a carbon-dioxide-rich permeate stream from the cellulose acetate modules and an hydrogen-sulfide-rich stream from the Pebax modules. Subsequent treatment, if required, would then be easier.

\section{Effect of Varying Feed Composition on Processing Cost}

Figure 37 shows the effect of varying the feed composition on the processing costs in $\$ / M M B t u$ (feed) for the membrane process and the amine absorption process (DEA based) at various feed flow rates ranging from 2 to $20 \mathrm{MMscfd}$ The significance of the lines in the plots is the same as for Figure 36. 
(a)

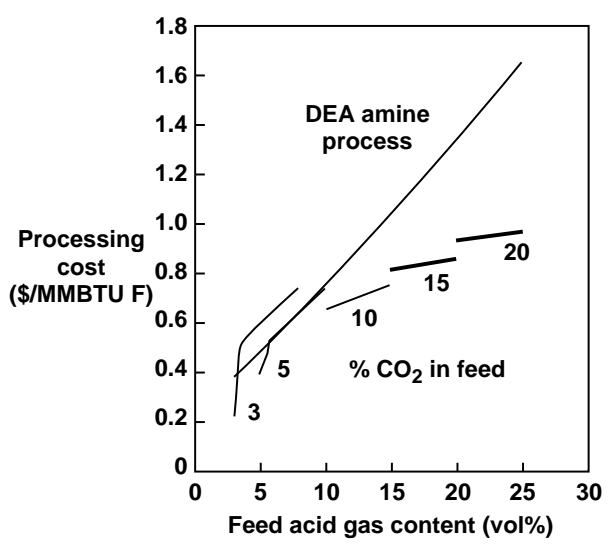

(c) Feed flow rate: 10 MMscfo

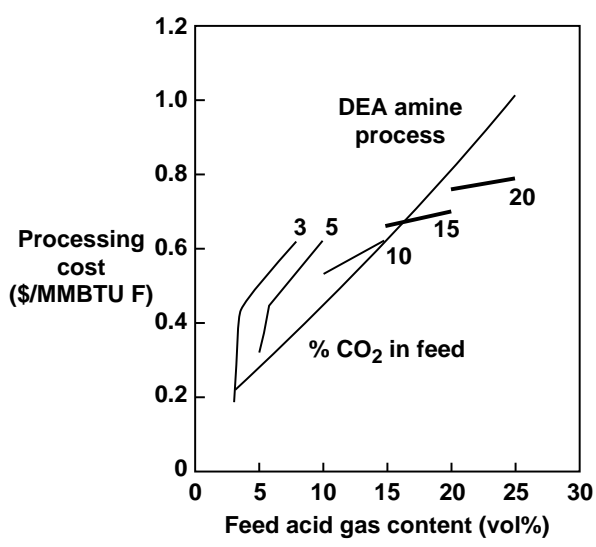

(b)

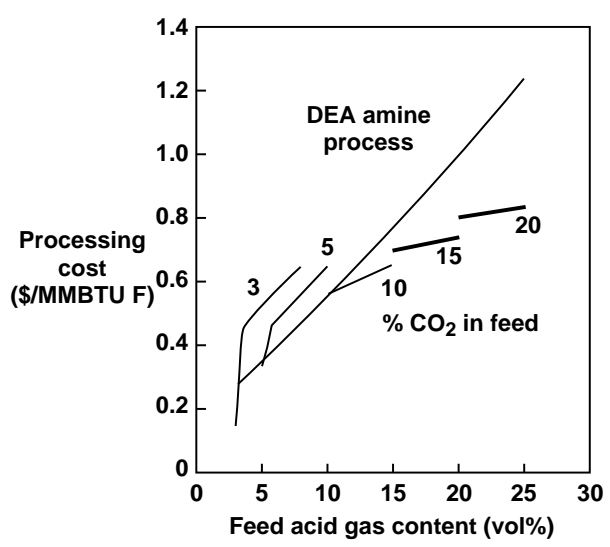

(d)

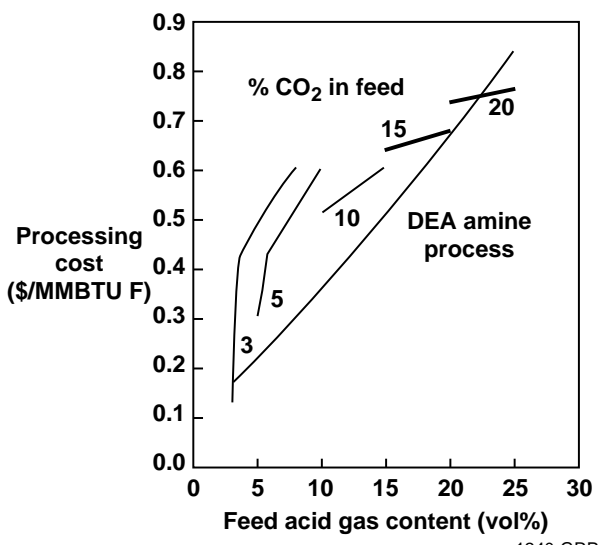

Figure 37. Effect of varying hydrogen sulfide and carbon dioxide feed concentration on the installed capital cost at feed flow rates from 2 to $20 \mathrm{MMscfd}$. The thin line represents the amine process; the thicker lines represent membrane/SulfaTreat hybrid at the carbon dioxide concentration indicated.

The following conclusions can be drawn from these processing cost calculations:

- At lower feed flow rates, the processing cost of the membrane/SulfaTreat hybrid process is lower than that of the amine process for all compositions of acid gases. At feed flow rates greater than $5 \mathrm{MMscfd}$, the difference between the amine absorption process and the membranes process is only marginal, the amine process being more expensive at the higher acid gas concentrations.

- For the membrane hybrid process, the processing cost increases with increasing total acid gas in the feed stream. The reason for this is twofold. First, the total capital cost increases with increasing acid gas in the feed stream; therefore, the capital-related component in the processing cost also increases. Secondly, as feed 
acid gas content increases, the total methane lost to meet pipeline specifications increases, resulting in an increased processing cost.

- The processing cost of the amine process increases substantially with an increase in the total acid gas in the feed stream, due to increasing operating expenses. Higher acid gas content increases the solvent requirement, which in turn increases the solvent recirculation rate in the amine train and leads to increased energy costs associated with the regeneration system. Thus, the processing cost at higher acid gas content for the amine process is significantly higher than for the membrane process.

We conclude that membrane processes are suitable for lower feed flow rates over almost the entire range of acid gas content in the feed stream, and are also economical at higher flow rates for feeds with higher acid gas. Our calculations also indicate that amine processes and membrane processes are suitable for two different ranges of acid gas content. Membrane processes are most suitable for bulk separation of acid gases and can perform this separation at a low operating cost, whereas amine processes are well suited for meeting pipeline specifications and for treating gas with a low acid gas content.

- The membrane/SulfaTreat process has an operating cost advantage over amine absorption at high acid gas concentrations. This suggests that a membrane/amine hybrid process (without a SulfaTreat step) would be economically viable. In this hybrid process, the membrane portion will remove most of the acid gases whereas the amine process would further treat the gas to meet the pipeline specifications. This application has also been studied-the results are discussed in Section 7.2.

\subsubsection{Design and Cost of an Industrial-Scale Plant}

A preliminary design of a complete sulfur removal/recovery system using a membrane process as the primary sulfur removal step was prepared. Figure 38 shows the design of such a system. The process comprises three parts: a bulk hydrogen sulfide removal step using Pebax membranes, a polishing step (SulfaTreat) to achieve pipeline specifications for hydrogen sulfide, and a Locat-II sulfur recovery step to treat the membrane permeate stream.

The feed gas conditions for a plant to treat 0.1 ton sulfur (as hydrogen sulfide) per day are shown in Table 24. The specific equipment requirements for the main components of the bulk hydrogen sulfide step and for the sulfur recovery step are given in Tables 25 and 26, respectively. 


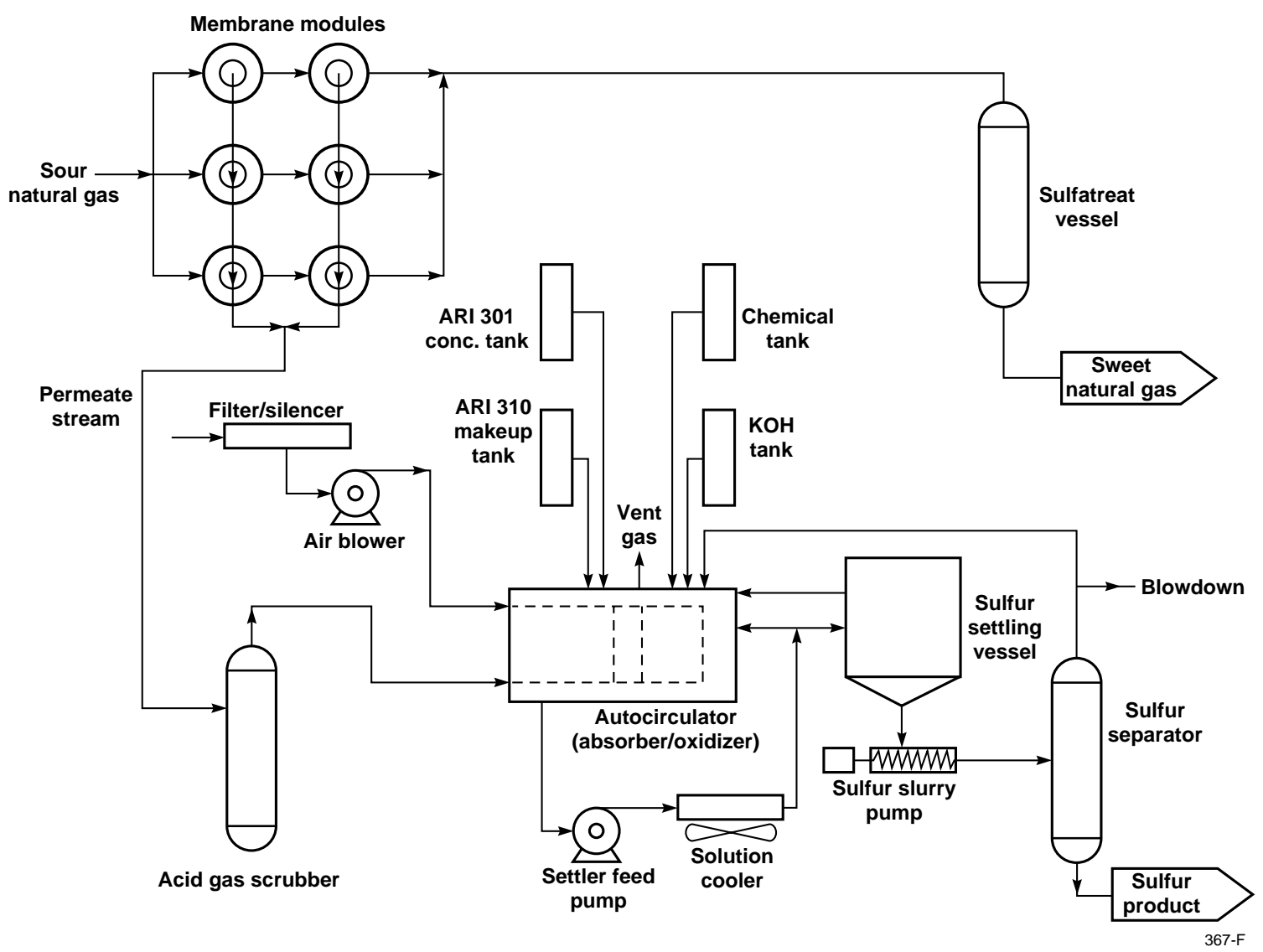

Figure 38. Design for a complete sulfur removal/recovery system for the removal of hydrogen sulfide from subquality natural gas.

Table 24. Feed Gas Conditions for 0.1 Ton Sulfur (as hydrogen sulfide)/Day Plant.

\begin{tabular}{||l|l||}
\hline \multicolumn{1}{|c|}{ Parameter } & \multicolumn{1}{|c||}{ Value } \\
\hline Feed flow rate & $2.6 \mathrm{MMscfd}$ \\
Feed hydrogen sulfide content & $0.1 \mathrm{~mol} \%$ \\
Feed carbon dioxide content & $5 \mathrm{~mol} \%$ \\
Feed methane content & $94.9 \mathrm{~mol} \%$ \\
Feed temperature & $75^{\circ} \mathrm{F}$ \\
Feed pressure & $1,000 \mathrm{psig}$ \\
\hline
\end{tabular}


Table 25. Main Equipment Requirements for Hydrogen Sulfide Removal Step.

\begin{tabular}{||l|l|l||}
\hline \multicolumn{1}{|c|}{ Item } & \multicolumn{1}{|c|}{ Size/Capacity/Duty } & \multicolumn{1}{c|}{ Material } \\
\hline $\begin{array}{l}\text { Membrane } \\
\text { Modules }\end{array}$ & $\begin{array}{l}750 \mathrm{~m}^{2}, 8 \text { inch modules, } \\
30 \text { in number (6 tubes each } \\
\text { containing 5 modules) }\end{array}$ & $\begin{array}{l}\text { Membrane material: } \\
\text { Pebax 4011 } \\
\text { Tubes: 304 L }\end{array}$ \\
\hline $\begin{array}{l}\text { SulfaTreat Vessel } \\
\text { and Charge }\end{array}$ & $\begin{array}{l}\text { 60 inch ID x 18 ft H/T } \\
24721 \mathrm{lbs} \text { SulfaTreat } \\
\text { Sorbent }\end{array}$ & $304 \mathrm{~L}$ \\
\hline
\end{tabular}

Table 26. Main Equipment Requirements for Locat-II Sulfur Recovery Step.

\begin{tabular}{|c|c|c|}
\hline Item & Size/Capacity/Duty & Material \\
\hline Sour gas scrubber & 6 inch ID x $4 \mathrm{ft} \mathrm{H} / \mathrm{T}$ vessel & Carbon steel \\
\hline Locat solution cooler & $25 \mathrm{ft}^{2}$, aerial, $0.04 \mathrm{MMBtu} / \mathrm{h}$ & $304 \mathrm{~L}$ \\
\hline Cooler fan & $1 \mathrm{Hp}$, forced draft & $304 \mathrm{~L}$ \\
\hline Autocirculator (Absorber/oxidizer) & - & $304 \mathrm{~L}$ \\
\hline Sulfur settler/separator & 6 inch ID $\times 4 \mathrm{ft} \mathrm{H} / \mathrm{T}$ vertical vessel & Cast iron \\
\hline Locat solution sump & 1.5 inch $\mathrm{ID} \times 8 \mathrm{ft} \mathrm{H} / \mathrm{T}$ horizontal vessel & $304 \mathrm{~L}$ \\
\hline ARI 301 conc. tank & $9.5 \mathrm{inch} \mathrm{ID} \times 3 \mathrm{ft} \mathrm{H} / \mathrm{T}$ vertical vessel & FRP \\
\hline ARI 301 makeup tank & 18 inch ID $\times 5 \mathrm{ft} H / T$ vertical vessel & FRP \\
\hline $\mathrm{KOH}$ tank & 12 inch $\mathrm{ID} \times 5 \mathrm{ft} \mathrm{H} / \mathrm{T}$ vertical vessel & FRP \\
\hline Air compressor & $30 \mathrm{scfm}$, centrifugal & Cast iron \\
\hline Air compressor motor & $10 \mathrm{Hp}$, electrical & - \\
\hline Solution recirculation pump/motor & 100 gpm @ 70 psi centrifugal, 8 Hp & - \\
\hline ARI 301C pump/motor & $<1 / 4 \mathrm{Hp}$, metering & - \\
\hline ARI 310M pump/motor & $<1 / 4 \mathrm{Hp}$, metering & - \\
\hline $\mathrm{KOH}$ pump/motor & $<1 / 4 \mathrm{Hp}$, metering & - \\
\hline Chemical pump/motor & $<1 / 4 \mathrm{Hp}$ & - \\
\hline
\end{tabular}


The overall process shown in Figure 38 will bring the feed gas to pipeline specifications for both carbon dioxide and hydrogen sulfide. The methane loss associated with the separation of the hydrogen sulfide and carbon dioxide is approximately $9 \%$. This methane is available for fuel as a vent gas from the LOCAT sulfur recovery system. It is important to note the advantage of the entire LOCAT system operating at close to atmospheric pressure, compared to the high-pressure operation required when it is used to treat the natural gas directly.

A preliminary cost estimate of the overall process is shown in Table 27. The cost assumptions for the membrane/SulfaTreat hybrid process are the same as those listed in Table 22.

Table 27. Capital and Processing Costs for Complete 0.1 Ton Sulfur (as Hydrogen Sulfide)/Day Sulfur Removal/Recovery Process Plant.

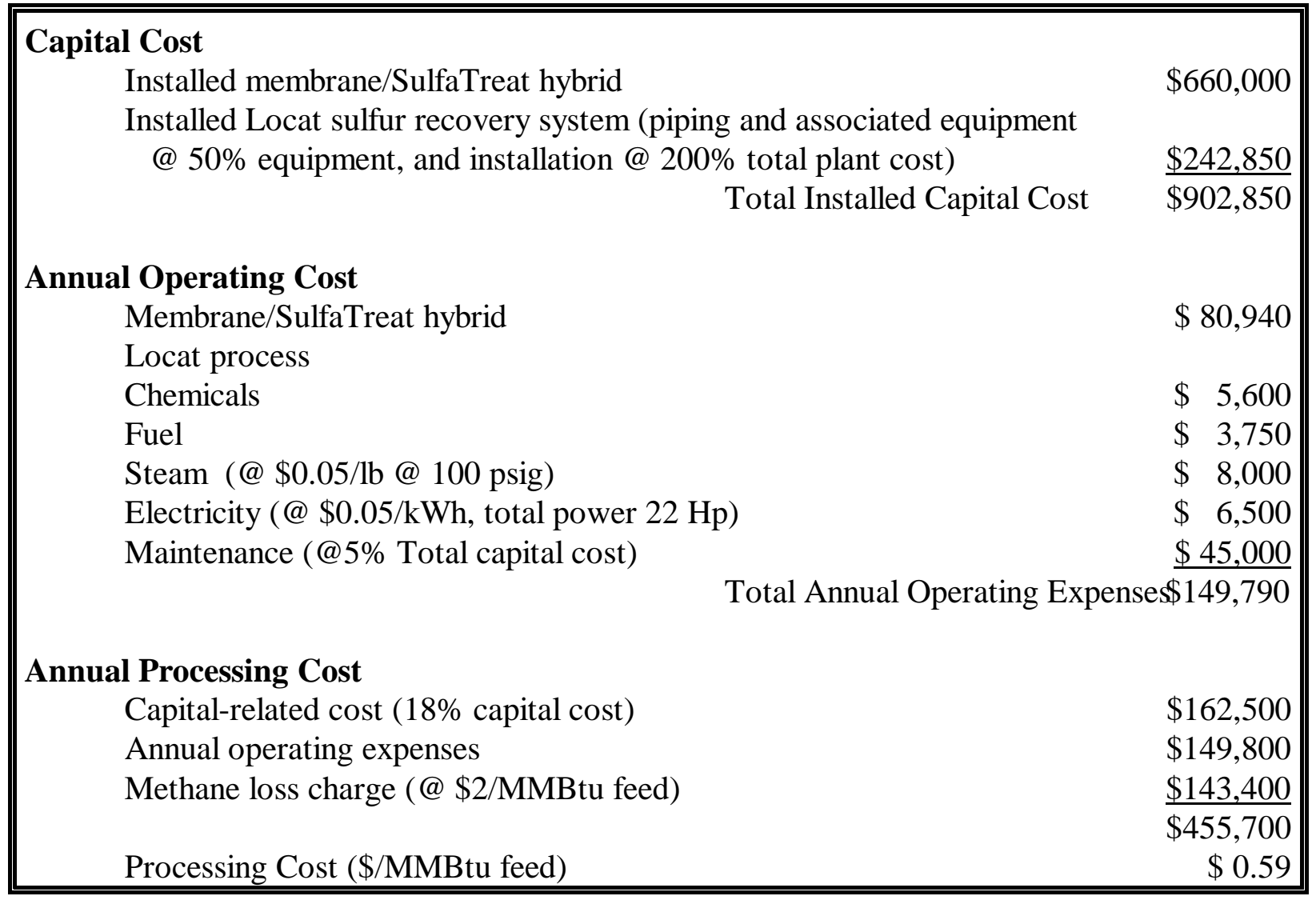

The calculation shows that the overall cost of treating subquality natural gas containing approximately 0.1 ton/day of sulfur as hydrogen sulfide is approximately $\$ 0.59 / \mathrm{MMBtu}$ feed. At a current selling price for new contracts of \$2.0-2.10/MMBtu, the operator has a margin of about $\$ 1.4 / \mathrm{MMBtu}$ before taxes, royalty, and any associated land lease payments.

The corresponding cost for an amine-absorption system would be significantly higher, making the profit margin for the producer smaller and unattractive. Therefore, if the process described above 
proves to be technically and commercially viable, it would bring significant benefit to smaller producers and allow the tapping of low-flow-rate gas fields, to increase the total amount of gas producible in the Lower-48 states of the United States.

\subsection{High-Flow/High-Hydrogen-Sulfide-Content Applications: Membrane-Amine Hybrid Process}

Based on our analysis of market opportunities for the hydrogen sulfide membrane, we concluded that our membrane process can also be economically used for bulk separation of hydrogen sulfide from high flow rates of natural gas (50-200 MMscfd) containing high concentrations of hydrogen sulfide (>10 mol\%). Such applications exist in Canada and other countries such as those that constituted the former Soviet Union. Also, such streams are typically produced in association with crude oil. This section describes the results of a parametric design study addressing the opportunity. We have responded to at least three inquiries for this application, and the initial reactions of potential users have been positive. These case studies are discussed in detail in Section 7.3 that follows. Tables 28 and 29 respectively show the base-case feed conditions and process conditions used in the design study of this application.

Table 28. Base-Case Feed Conditions for Membrane/Amine Hybrid Process.

\begin{tabular}{||l|c||}
\hline \multicolumn{1}{|c|}{ Parameter } & Value \\
\hline Temperature & $40^{\circ} \mathrm{C}$ \\
\hline Pressure & 1,265 psia \\
\hline Total Flow & $50 \mathrm{MMscfd}$ \\
\hline Composition (\%) & \\
Carbon Dioxide & 5 \\
Hydrogen Sulfide & 15 \\
Methane & 70.9 \\
Ethane & 6.0 \\
Propane & 3.0 \\
Water & 0.1 \\
\hline
\end{tabular}


Table 29. Base-Case Process Conditions for Membrane/Amine Hybrid Process.

\begin{tabular}{||l|c||}
\hline \multicolumn{1}{|c|}{ Parameter } & Value \\
\hline Methane Permeation Flux & $5 \times 10^{-6} \mathrm{~cm}^{3}(\mathrm{STP}) / \mathrm{cm}^{2} \cdot \mathrm{s} \cdot \mathrm{cmHg}$ \\
\hline Carbon Dioxide/Methane Selectivity & 10 \\
\hline Hydrogen Sulfide/Methane Selectivity & 32 \\
\hline Fractional Removal of Hydrogen Sulfide by Membrane & $10-70 \%$ \\
\hline Composition of Hydrogen Sulfide in Feed & $5,10,15 \mathrm{~mol} \%$ \\
\hline Composition of Carbon Dioxide in Feed & $5 \mathrm{~mol} \%$ \\
\hline Feed Flow Rate & $50 \mathrm{MMscfd}$ \\
\hline
\end{tabular}

\subsubsection{Process Design}

Figure 39 shows a process flow diagram of the membrane/amine absorption hybrid system and the disposition of the acid gases.

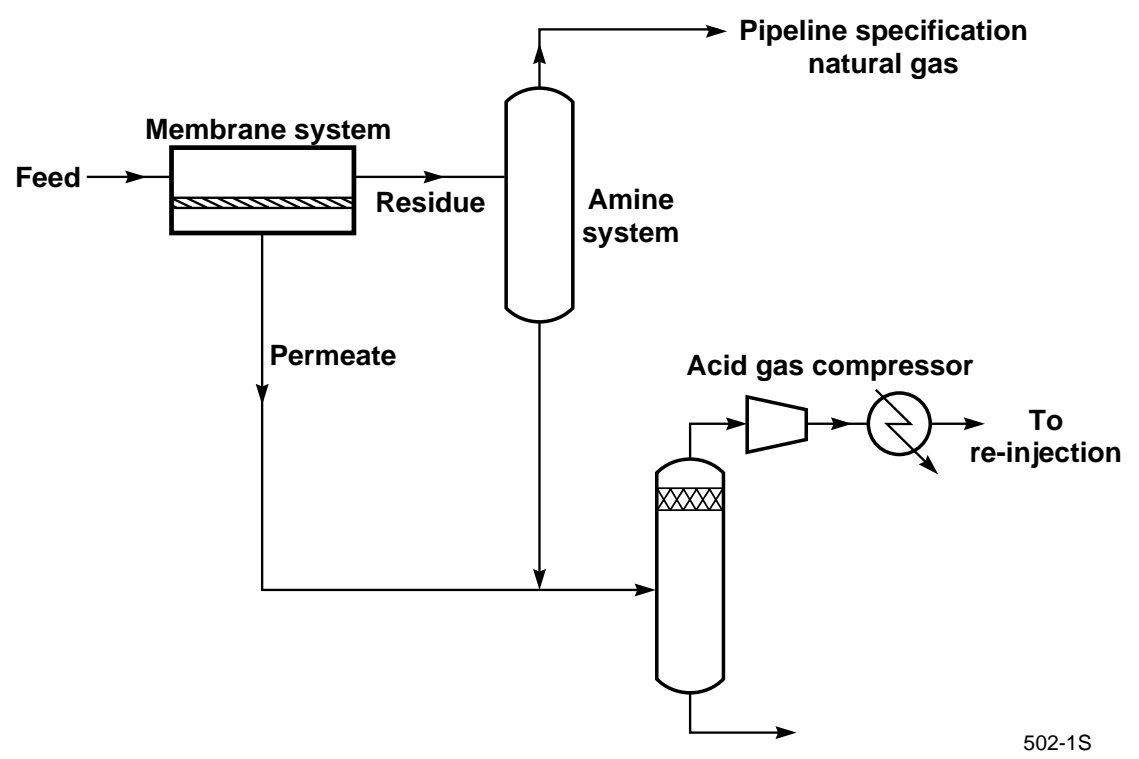

Figure 39. Flow diagram of membrane/amine absorption hybrid process

The calculations following are based on the flow diagram in Figure 39. The feed gas, containing between 5 and 15 vol\% hydrogen sulfide, enters a membrane system which performs the bulk separation of hydrogen sulfide. In the calculations, the fractional removal of hydrogen sulfide varied between 10 to $70 \%$. The remaining hydrogen sulfide and carbon dioxide in the gas are then removed in a conventional DEA amine process to reduce the acid gas content to pipeline 
specifications. The acid gases generated from the amine system and the acid-gas-enriched permeate stream from the membrane system are combined and compressed for reinjection into the formation. Therefore, this analysis assumes that the hydrogen sulfide is not converted to sulfur in a Claus plant. If this was the case, a two-stage membrane system design would be required to produce a Claus process treatable acid gas stream.

\subsubsection{Economic Analysis}

\section{Effect of Feed Hydrogen Sulfide Concentration on Installed Capital Cost and Processing}

Figure 40 compares the installed capital cost of a membrane/amine hybrid process and an amine stand-alone process for removing hydrogen sulfide from natural gas for three different feed inlet concentrations of hydrogen sulfide. The x-axis represents the fraction of hydrogen sulfide removed by the membrane portion of the membrane/amine hybrid process. Figure 41 shows the same cost comparison for processing costs, which include the operating costs of each configuration and the associated capital recovery costs. In both figures 40 and 41, the solid lines indicate the cost of the stand-alone amine system, and the lines with the symbols indicate the cost of the hybrid system. The three separate pairs of lines are for the three different hydrogen sulfide contents.

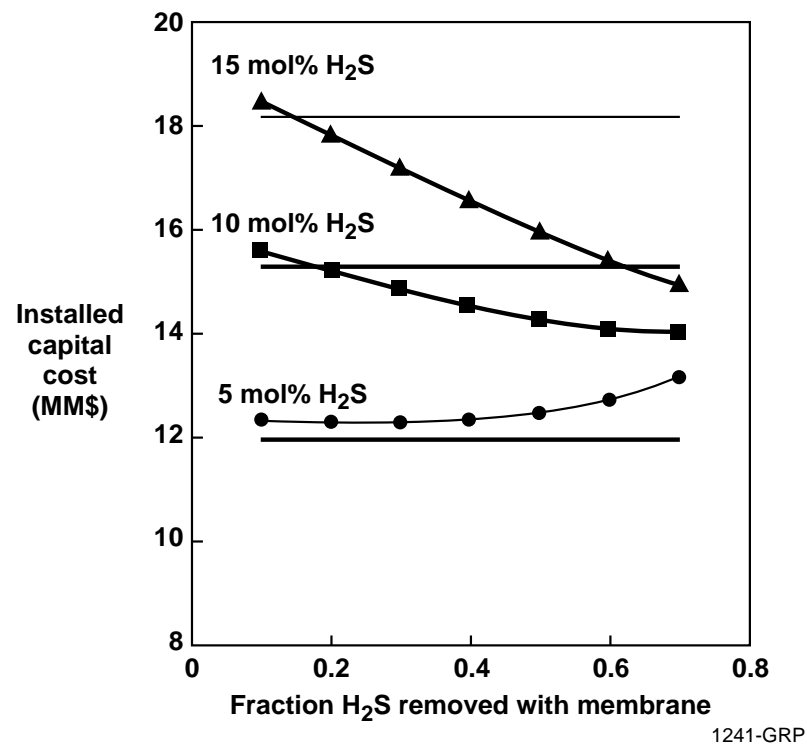

Figure 40. Comparison of installed capital cost for a membrane/amine hybrid process (lines with symbols) and an amine stand-alone process (solid lines). 


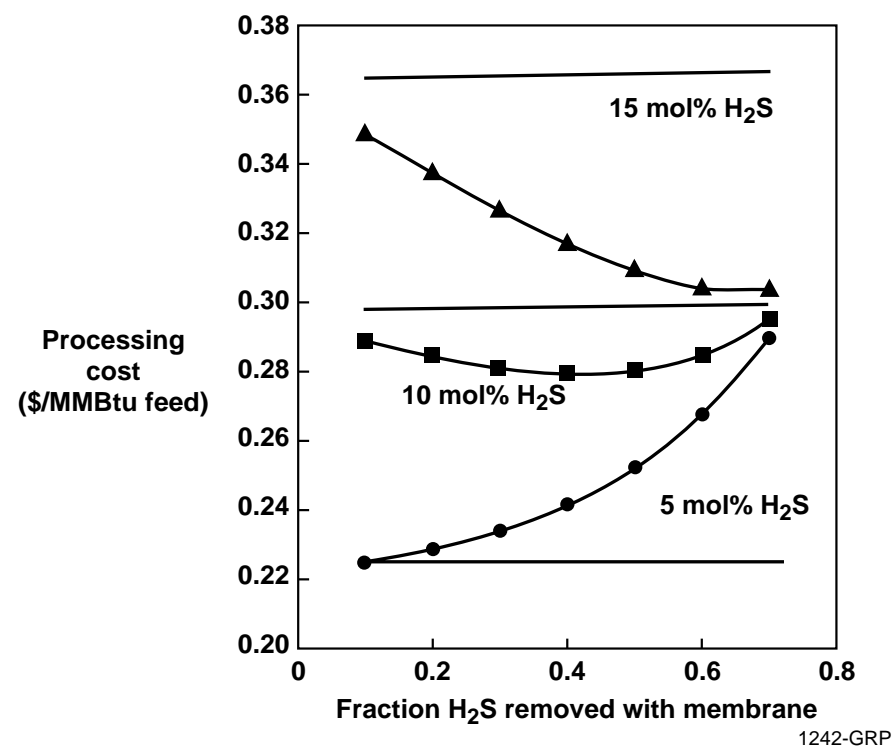

Figure 41. Comparison of processing costs for a membrane/amine hybrid process (lines with symbols) and an amine stand-alone process (solid lines).

The following main conclusions can be drawn from Figures 40 and 41:

- The capital cost of the systems increases as the hydrogen sulfide content of the feed gas increases. This is expected because an increase in hydrogen sulfide in the feed gas requires both more membrane area and a larger amine system to bring the gas to pipeline specifications. Similarly, the processing cost also increases for both the hybrid and amine stand-alone processes, because in both cases the operating costs and the capital recovery cost increase with increasing hydrogen sulfide content.

- The installed capital cost of the membrane/amine hybrid process is higher than that of the stand-alone amine system when the feed hydrogen sulfide acid gas content is $5 \mathrm{vol} \%$. Therefore, at that level of hydrogen sulfide in the feed gas, the hybrid process is not economically justified. This is also true for the processing cost, which is also higher for the hybrid process at this hydrogen sulfide concentration.

- At an acid gas concentration of $10 \mathrm{vol} \%$, the installed capital cost of the hybrid system decreases, approaching a minimum at about $80 \%$ removal of hydrogen sulfide. At that point the capital cost of the hybrid system is lower then the standalone amine system, but only by about 5-8\%. The processing cost for this 10 -vol\% hydrogen sulfide case also shows a minimum at about $50 \%$ removal of hydrogen sulfide by the membrane in the hybrid process. The operating expenses are about 5-8\% lower then the stand-alone amine process. These cost advantages 
are only marginal; therefore, the hybrid process may not necessary make sense at this hydrogen sulfide concentration in the feed stream.

- At 15 vol\% hydrogen sulfide in the feed stream, the economics of the membrane/amine hybrid process appear to be significantly better then the standalone amine process. Both capital cost and processing cost of the hybrid system are $15-20 \%$ lower than for the stand-alone amine process.

These numbers suggest that the membrane/amine hybrid process may be a suitable economic alternative to a stand-alone amine membrane process for streams with high flow rates and a high concentration of hydrogen sulfide. Membrane processes are best suited for bulk separation of hydrogen sulfide, and in that duty will afford significant capital and operating expenses over technologies involving chemical absorption of the acid gases. The savings arise from the decrease in the capital cost of the conventional system, because the membrane system off-loads the amine process. This lowers the recirculation rate of the amine and also decreases the operating expenses of regenerating the amine solution.

\section{Effect of Fuel Cost on Processing Costs}

Figure 42 shows the effect of using different numbers for the fuel cost on the processing cost for both configurations. The figure shows that the processing cost is a strong and almost linear function of the fuel cost. Fuel is required in both the hybrid and the stand-alone process for the amine re-boiler and the compressor power generation device. The cost of the fuel also reflects, in many cases, the cost of natural gas. Figure 42 shows that when the fuel gas cost is low, which is typically the case in places where the natural gas has little or no value due to a lack of markets, the processing cost of producing the pipeline quality natural gas is about the same as the cost of fuel. This implies that, in such cases, there is no economic gain in processing the natural gas. However, the gas would have to be treated if it is produced as associated gas with oil production. This is so in many of the former Soviet Union countries such as Kazakstan. If the natural gas produced has a higher value, the margin between the cost of the natural gas and the processing cost increases, yielding positive revenue from processing the natural gas. However, since the cost of fuel is also higher, the total processing cost increases. For the case considered in Figure 42, 50\% removal of hydrogen sulfide by membranes, the processing cost of the membrane hybrid process is lower than the amine process. 


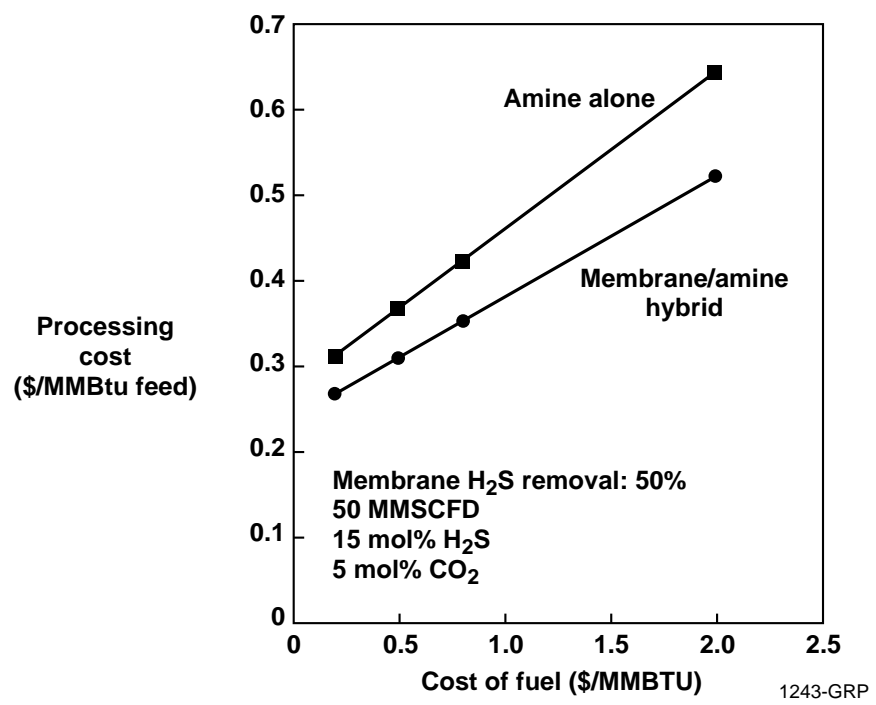

Figure 42. Effect of fuel gas cost on the processing cost for the two configurations studied.

\section{Effect of Membrane Cost on Capital and Processing Costs}

Figure 43 shows the effect of the cost of the membrane $\left(\$ / \mathrm{m}^{2}\right)$ on the economics of the hybrid process. As the cost of the membrane increases, the cost of the membrane portion of the membrane/amine hybrid process also increases linearly. The base-case membrane system cost is $\$ 825 / \mathrm{m}^{2}$. The spread of the membrane cost indicates the potential spread of the actual cost of manufacturing the membrane modules and system, the cost being higher and closer to $\$ 1,250 / \mathrm{m}^{2}$ for small systems and then decreasing for larger systems as the cost of fabricating the modules decreases. Figure 43 shows that the cost of the hybrid system is lower then the stand-alone amine system cost over this entire range of membrane costs.

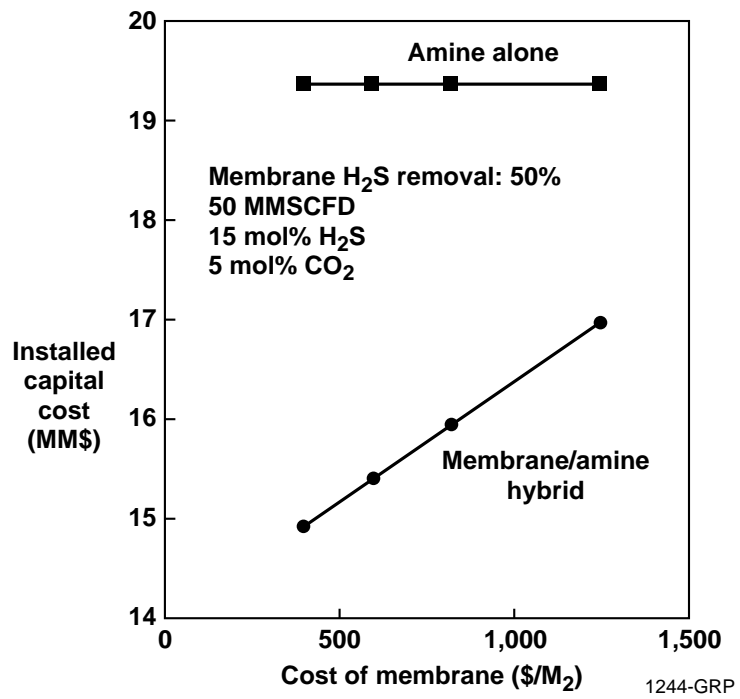

Figure 43. Effect of membrane cost on the installed capital cost for the two configurations studied. 
Figure 44 shows the effect of the membrane cost on the processing expenses. Again, as the membrane cost increases, the processing cost of the hybrid process increases. The impact of the membrane cost, although important, is not crucial in the processing cost. Again for this case, the processing cost for the hybrid system is lower than that of the stand-alone system.

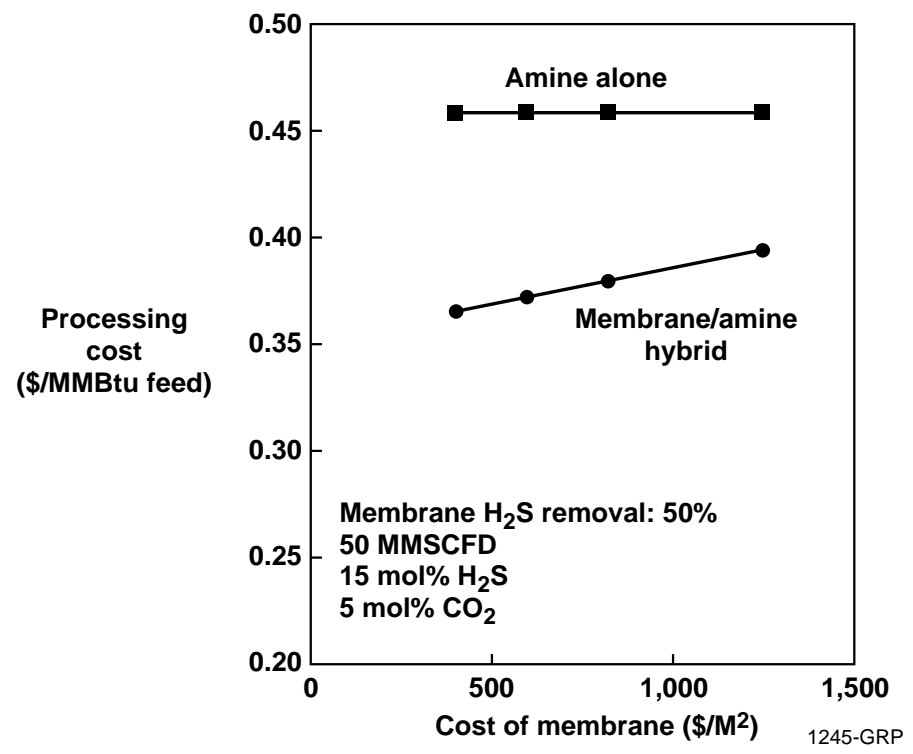

Figure 44. Effect of membrane cost on the processing cost for the two configurations studied.

\subsection{Specific Case Studies}

We performed four specific case studies. The first two involved the use of MTR membranes for debottlenecking applications: one for natural gas treatment and one for a refinery application. Two other case studies were performed to design a membrane system for bulk acid gas separation. In one of the cases the membrane portion was a two-stage process to produce Claus-quality acid gas and in the other we considered a membrane process suitable for reinjection into one formation. These case studies attempt to give a flavor of the actual applications possible for MTR's membranes for hydrogen sulfide separation.

\subsubsection{Case Study No. 1: Debottlenecking Absorption Trains}

Existing operating absorption trains based on amines or other solvents can be debottlenecked using MTR's membrane technology. For example, if increased production is anticipated from a given field, and the absorption capacity of the existing train is exhausted, a membrane step could be added in front of the absorption train to remove a fraction of the acid gases and to reduce the acid gas loading in the absorption train. The concentrated acid gases from the membrane unit can either be added to the acid gases from the stripper of the amine system, or otherwise disposed of by burning or reinjecting. Similarly, if the hydrogen sulfide concentration in the feed increases, and the absorption system is unable to meet pipeline specifications, a membrane system can be added to remove the 
excess acid gas. Being modular in nature, additional membrane steps can be added as the need arises, allowing capital investment to be deferred. Two situations are discussed below.

\section{Debottlenecking for Increased Natural Gas Production}

Consider an amine absorber treating 50 MMscfd of natural gas with a feed gas composition as shown in Table 30. This facility is operating at its highest capacity, but now an additional 25 MMscfd of gas needs to be brought into production. The table shows that the hydrogen sulfide content of the sweet gas will not now meet pipeline specification. However, the addition of a membrane system will allow the same unit to meet pipeline specifications. The total membrane area required is about $1,700 \mathrm{~m}^{2}$. The membrane system will comprise 24 pressure tubes each containing five 8-inch elements, and will cost about $\$ 1$ million. The membrane system will be a skid-mounted single-stage system; the installation cost will be minimal. The additional gas capacity will yield revenues of about $\$ 12$ million. The membrane system can be designed to be added in steps as the production capacity increases.

Table 30. Situation 1: Debottlenecking Amine Absorbers for Increased Production.

\begin{tabular}{|c|c|c|c|c|c|c|c|}
\hline Process & $\begin{array}{l}\text { Inlet Flow Rate } \\
\text { (MMscfd) }\end{array}$ & $\begin{array}{r}\text { Fee } \\
\text { Com } 1\end{array}$ & $\begin{array}{l}\text { as } \\
\text { tion }\end{array}$ & $\begin{array}{l}\text { Sw } \\
\text { Con }\end{array}$ & $\begin{array}{l}\text { Gas } \\
\text { sition }\end{array}$ & $\begin{array}{c}\text { Acid Gas } \\
\text { Composition }\end{array}$ & $\begin{array}{l}\text { Methane } \\
\text { Recovery }\end{array}$ \\
\hline Amine System & 50 & $\begin{array}{l}\mathrm{H}_{2} \mathrm{~S}: \\
\mathrm{CO}_{2}:\end{array}$ & $\begin{array}{l}3 \% \\
8 \%\end{array}$ & $\begin{array}{l}\mathrm{H}_{2} \mathrm{~S}: \\
\mathrm{CO}_{2} \text { : }\end{array}$ & $\begin{array}{r}4 \mathrm{ppm} \\
1.3 \%\end{array}$ & $\begin{array}{lr}\mathrm{H}_{2} \mathrm{~S}: & 29.2 \% \\
\mathrm{CO}_{2}: & 66.3 \% \\
\mathrm{CH}_{4}: & 4.1 \%\end{array}$ & $99.5 \%$ \\
\hline Amine System & 75 & $\begin{array}{l}\mathrm{H}_{2} \mathrm{~S}: \\
\mathrm{CO}_{2}:\end{array}$ & $\begin{array}{l}3 \% \\
8 \%\end{array}$ & $\begin{array}{l}\mathrm{H}_{2} \mathrm{~S}: \\
\mathrm{CO}_{2} \text { : }\end{array}$ & $\begin{array}{r}1.07 \% \\
3.7 \%\end{array}$ & $\begin{array}{lr}\mathrm{H}_{2} \mathrm{~S}: & 29.2 \% \\
\mathrm{CO}_{2}: & 66.3 \% \\
\mathrm{CH}_{4}: & 4.1 \%\end{array}$ & $99.5 \%$ \\
\hline $\begin{array}{l}\text { Membrane + } \\
\text { Amine System }\end{array}$ & 75 & $\begin{array}{l}\mathrm{H}_{2} \mathrm{~S}: \\
\mathrm{CO}_{2}:\end{array}$ & $\begin{array}{l}3 \% \\
8 \%\end{array}$ & $\begin{array}{l}\mathrm{H}_{2} \mathrm{~S}: \\
\mathrm{CO}_{2} \text { : }\end{array}$ & $\begin{array}{r}3 \mathrm{ppm} \\
2.5 \%\end{array}$ & $\begin{array}{ll}\mathrm{H}_{2} \mathrm{~S}: & 28.0 \% \\
\mathrm{CO}_{2}: & 53.6 \% \\
\mathrm{CH}_{4}: & 16.6 \%\end{array}$ & $97.9 \%$ \\
\hline
\end{tabular}

\section{Debottlenecking for Changed Acid Gas Composition}

In the second situation the composition of the feed gas being treated in an amine absorber has changed due to the addition of more sour gas upstream to the processing facility. Table 31 shows an increase in hydrogen sulfide content from about $2 \%$ to about $2.5 \%$, such that the amine system will not be able to deliver pipeline specification gas. A membrane system comprising only about $630 \mathrm{~m}^{2}$ membrane area in front of the amine train will allow the sweet gas produced from the amine absorber to meet pipeline specification. The membrane system will comprise nine tubes each containing five 8 -inch modules and will cost about $\$ 350,000$. 
Table 31. Situation 2: Debottlenecking Amine Absorbers for Changed Acid Gas Composition.

\begin{tabular}{|c|c|c|c|c|c|c|c|}
\hline Process & $\begin{array}{c}\text { Inlet Flow Rate } \\
\text { (MMscfd) }\end{array}$ & $\begin{array}{r}\text { Fee } \\
\text { Com! }\end{array}$ & $\begin{array}{l}\text { Gas } \\
\text { sition }\end{array}$ & $\begin{array}{l}\text { Sw } \\
\text { Con }\end{array}$ & $\begin{array}{l}\text { t Gas } \\
\text { osition }\end{array}$ & $\begin{array}{c}\text { Acid Gas } \\
\text { Composition }\end{array}$ & $\begin{array}{l}\text { Methane } \\
\text { Recovery }\end{array}$ \\
\hline Amine System & 50 & $\begin{array}{l}\mathrm{H}_{2} \mathrm{~S}: \\
\mathrm{CO}_{2} \text { : }\end{array}$ & $\begin{array}{l}2 \% \\
8 \%\end{array}$ & $\begin{array}{l}\mathrm{H}_{2} \mathrm{~S}: \\
\mathrm{CO}_{2}:\end{array}$ & $\begin{array}{r}4 \mathrm{ppm} \\
1.3 \%\end{array}$ & $\begin{array}{lr}\mathrm{H}_{2} \mathrm{~S}: & 21.6 \% \\
\mathrm{CO}_{2}: & 73.5 \% \\
\mathrm{CH}_{4}: & 4.6 \% \\
\end{array}$ & $99.5 \%$ \\
\hline Amine System & 50 & $\begin{array}{l}\mathrm{H}_{2} \mathrm{~S}: \\
\mathrm{CO}_{2}:\end{array}$ & $\begin{array}{r}2.5 \% \\
8 \%\end{array}$ & $\begin{array}{l}\mathrm{H}_{2} \mathrm{~S}: \\
\mathrm{CO}_{2}:\end{array}$ & $\begin{array}{r}0.55 \% \\
1.3 \%\end{array}$ & $\begin{array}{lr}\mathrm{H}_{2} \mathrm{~S}: & 21.6 \% \\
\mathrm{CO}_{2}: & 73.5 \% \\
\mathrm{CH}_{4}: & 4.6 \%\end{array}$ & $99.5 \%$ \\
\hline $\begin{array}{l}\text { Membrane + } \\
\text { Amine System }\end{array}$ & 50 & $\begin{array}{l}\mathrm{H}_{2} \mathrm{~S}: \\
\mathrm{CO}_{2}:\end{array}$ & $\begin{array}{r}2.5 \% \\
8 \%\end{array}$ & $\begin{array}{l}\mathrm{H}_{2} \mathrm{~S}: \\
\mathrm{CO}_{2}:\end{array}$ & $\begin{array}{l}4 \mathrm{ppm} \\
0.58 \%\end{array}$ & $\begin{array}{ll}\mathrm{H}_{2} \mathrm{~S}: & 22.0 \% \\
\mathrm{CO}_{2}: & 65.8 \% \\
\mathrm{CH}_{4}: & 11.1 \% \\
\end{array}$ & $98.5 \%$ \\
\hline
\end{tabular}

\subsubsection{Case Study No. 2: Refinery Debottlenecking}

In refineries, the processing of increasingly sour crude oils has lead to numerous conditions in which the sulfur removal systems - typically amine absorption-are bottlenecks in the process. The following example illustrates possible debottlenecking using a membrane process. Design data for a membrane system for bulk removal of hydrogen sulfide from high-pressure hydrotreater recycle hydrogen stream are given below. Figure 45 shows the proposed membrane process. In the process shown in this figure, a single-stage membrane system is placed in front of the existing amine process. The amine treatment portion was bottlenecked due to increasing hydrogen sulfide content in the feed gas. To allow the system to continue meeting fuel gas specifications, a new amine system would have to be installed. In this application, one membrane system in front of the amine system can remove hydrogen sulfide to a level such that the existing amine train can continue to treat the membrane residue gas to meet the fuel gas specification. 


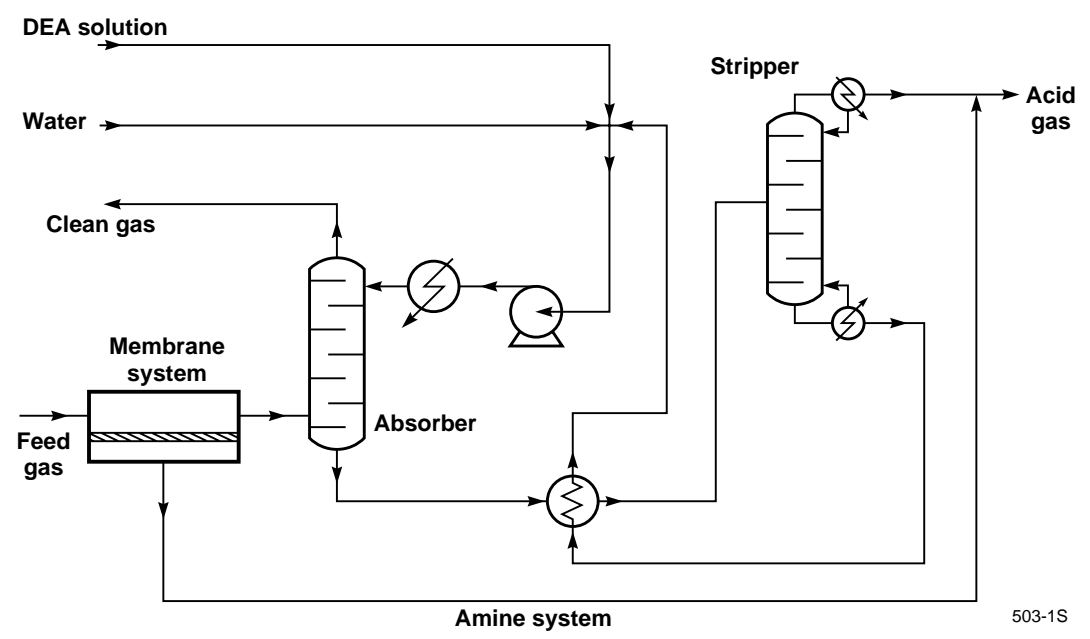

Figure 45. Schematic diagram of membrane system and position in amine train.

Three cases of varying hydrogen sulfide removal were considered. Table 32 shows the feed conditions assumed in these calculations, and Table 33 shows the compositions of the residue and permeate streams from the membrane unit for the three cases.

Table 32. Assumed Feed Conditions for Refinery Debottlenecking Application.

\begin{tabular}{||l|c||}
\hline \multicolumn{1}{|c|}{ Parameter } & Value \\
\hline Pressure & $914.7 \mathrm{psia}$ \\
\hline Flow Rate & $147.5 \mathrm{MMscfd}$ \\
\hline Temperature & $100^{\circ} \mathrm{F}$ \\
\hline Component Concentration (mol\%) & \\
Hydrogen & 66 \\
Methane & 24 \\
Ethane & 4 \\
Propane & 2 \\
Butane & 1 \\
Hydrogen Sulfide & 3 \\
\hline
\end{tabular}


Table 33. Residue and Permeate Compositions and Conditions for Three Cases of Hydrogen Sulfide Removal by the Membrane Process.

\begin{tabular}{||l|c|c|c|c|c|c||}
\hline \multirow{2}{*}{\multicolumn{1}{|c|}{ Component }} & \multicolumn{2}{|c|}{$\begin{array}{c}39.6 \% \text { Hydrogen } \\
\text { Sulfide Removal }\end{array}$} & \multicolumn{2}{c|}{$\begin{array}{c}20.4 \% \text { Hydrogen } \\
\text { Sulfide Removal }\end{array}$} & \multicolumn{2}{c||}{$\begin{array}{c}\text { 10.3\% Hydrogen } \\
\text { Sulfide Removal }\end{array}$} \\
\cline { 2 - 8 } & Residue & Permeate & Residue & Permeate & Residue & Permeate \\
\hline Hydrogen & 68.45 & 42.45 & 67.16 & 41.26 & 66.56 & 40.72 \\
\hline Methane & 23.45 & 29.19 & 23.77 & 28.83 & 23.89 & 28.66 \\
\hline Ethane & 3.69 & 6.92 & 3.86 & 6.93 & 3.93 & 6.94 \\
\hline Propane & 1.66 & 5.21 & 1.84 & 5.37 & 1.92 & 5.44 \\
\hline Butanes + & 0.72 & 3.64 & 0.86 & 3.88 & 0.93 & 4.00 \\
\hline Hydrogen Sulfide & 2.00 & 12.57 & 2.50 & 13.69 & 2.75 & 14.23 \\
\hline Flow Rate (MMscfd) & 133.5 & 13.9 & 140.9 & 6.6 & 144.3 & 3.2 \\
\hline Temperature (of) & 95 & 95 & 95 & 95 & 95 & 95 \\
\hline Pressure (psia) & $\sim 900$ & 40 & $\sim 900$ & 40 & $\sim 900$ & 40 \\
\hline \hline
\end{tabular}

The required membrane areas, system cost and size for the three hydrogen sulfide removal cases are given in Table 34.

Table 34. Membrane Area Requirements and Membrane System Capital Cost Estimates.

\begin{tabular}{||c|c|c|c||}
\hline $\begin{array}{c}\text { Hydrogen Sulfide } \\
\text { Removal }(\%)\end{array}$ & $\begin{array}{c}\text { Membrane Area } \\
\left(\mathrm{m}^{2}\right)\end{array}$ & $\begin{array}{c}\text { Membrane System } \\
\text { Cost }(\$)\end{array}$ & $\begin{array}{c}\text { System Size } \\
{[\mathrm{W}(\mathrm{ft}) \times \mathrm{H}(\mathrm{ft}) \times \mathrm{L}(\mathrm{ft})]}\end{array}$ \\
\hline 39.6 & 645 & 900,000 & $3 \times 10 \times 25$ \\
\hline 20.4 & 300 & 450,000 & $3 \times 5 \times 25$ \\
\hline 10.3 & 150 & 225,000 & $3 \times 3 \times 25$ \\
\hline
\end{tabular}

As Figure 45 shows, the hydrogen sulfide removed by the membrane process bypasses the stripper, and can be combined with acid gases generated in the stripper. The final concentration of hydrocarbons and hydrogen in the stream going to the Claus plant will depend on the acid gas volume generated in the stripper. If the hydrocarbon content in the acid gas become too high for a Claus plant, a two-stage membrane process will be required to further enrich the permeate stream from the membrane process. A process flow diagram for this situation is shown in Figure 46. 


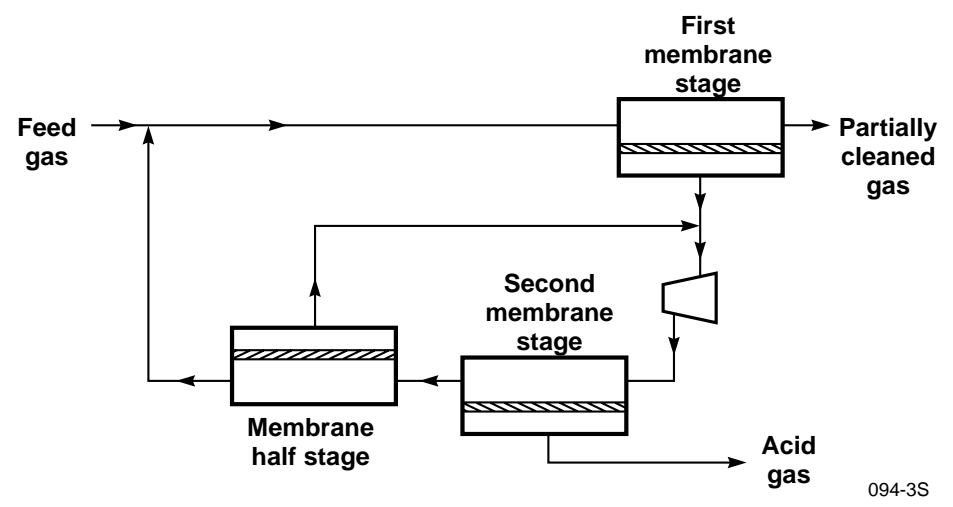

Figure 46. Schematic diagram of a two-and-one-half-stage membrane process for debottlenecking the amine section of a hydrotreater in a refinery.

\subsubsection{Case Study No. 3: Bulk Acid Gas Separation from Natural Gas - Permeate to Claus Plant}

The application discussed in this case study is the bulk separation of hydrogen sulfide from an associated natural gas stream. The bulk separation of the hydrogen sulfide would be carried out by a membrane system in front of a conventional amine system, to eliminate one of the two amine trains otherwise required to treat this gas stream.

Figure 47 shows a process flow diagram of the membrane system for this application. The process has two-and-one-half stages (see Appendix). The feed gas enters the first stage in which the bulk separation of the acid gas from the feed is performed. The acid-gas-enriched permeate stream is then recompressed in three stages. After the first compression stage, the gas is cooled and a portion of the higher hydrocarbon content is recovered in liquid form. Some of the hydrogen sulfide is dissolved in the liquid; this stream is processed and then blended with the oil stream. The off-gas from the knockout drum enters the second membrane stage, which comprises two membrane units. These reduce the hydrogen sulfide content further. Both permeate streams from this stage are very rich in hydrogen sulfide and can be combined with the acid gas stream from the amine process for treatment in a Claus plant or re-injection. The residue stream from the second membrane stage is compressed again and, after cooling, passed to the membrane "half-stage" where the hydrogen sulfide is reduced to the level in the original feed stream. The permeate from this stage is combined with the permeate from the first stage. The hydrogen sulfide content in the residue gas from the membrane half-stage matches that in the feed and is compressed and recombined with the feed stream. Net hydrogen sulfide removal occurs in the permeate from the second stage and through the NGL produced in the permeate recompressor.

The process was designed this way to reduce the amount of liquid forming in the second stage of the system. Upon recompression of the permeate from the first stage, the NGL content of the stream condenses out, pulling in a significant portion of hydrogen sulfide. This happens after the firststage compression (multistage compression is required). By using a membrane between the two 
stages of compression, the horsepower is further decreased, while at the same time the issues of forming hydrogen-sulfide-containing liquid are mitigated to some extent.

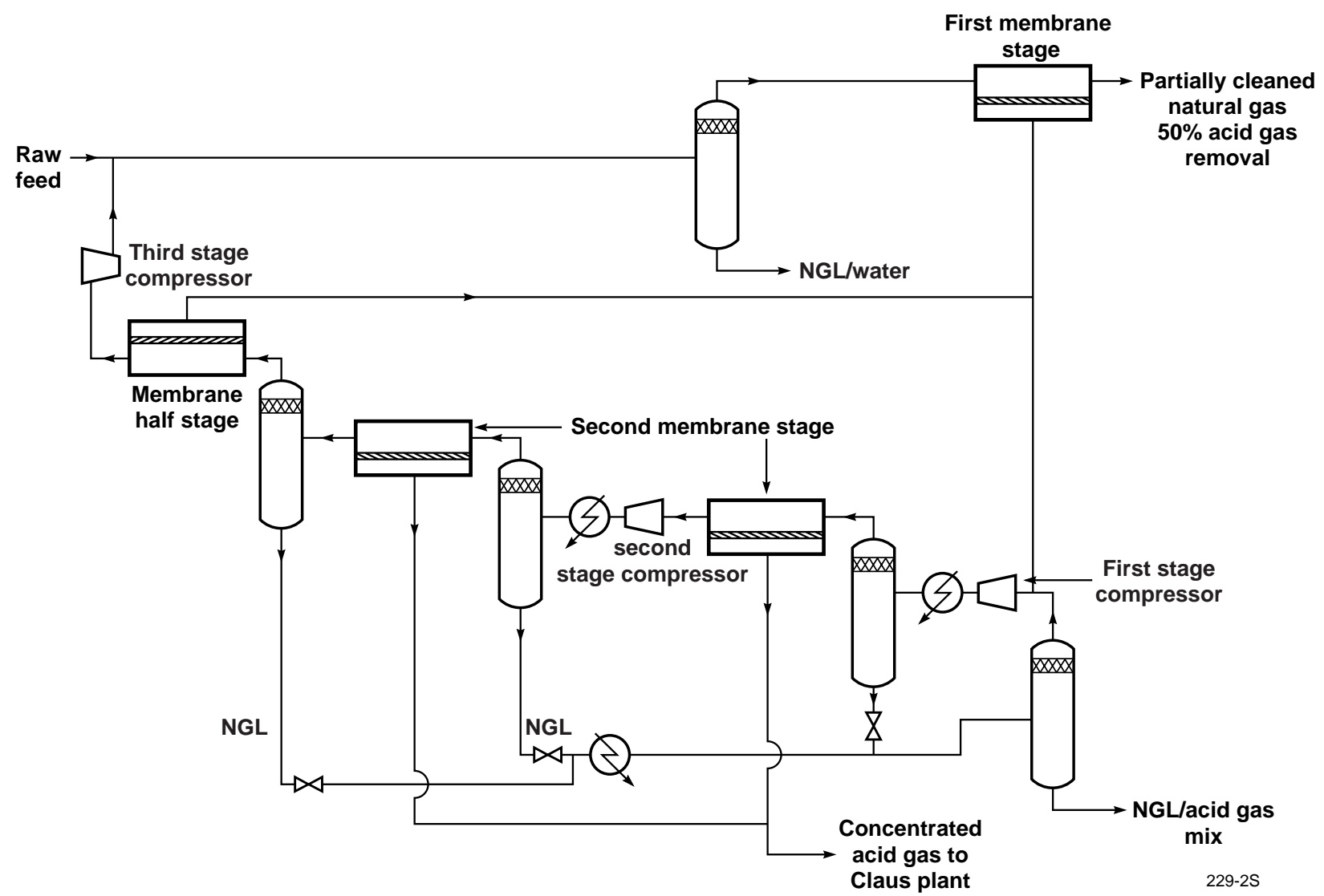

Figure 47. Schematic diagram of two-and-one-half stage membrane process for bulk hydrogen sulfide removal from natural gas.

Table 35 shows the feed characteristics used to calculate the membrane system requirements for such a process. To obtain 50\% removal of the acid gases from the feed stream, a membrane system comprising 3348 -inch spiral-wound modules housed in 67 pressure tubes would be required. The budgetary price $( \pm 25 \%)$ of the membrane skids would be $\$ 4.9$ million. The permeate compressor power is $4,250 \mathrm{hp}$. 
Table 35. Basis for Calculations for Case Study No. 3.

\begin{tabular}{||l|c||}
\hline \multicolumn{2}{|c||}{ Feed Conditions } \\
\hline Temperature & $54^{\circ} \mathrm{C}$ \\
\hline Pressure & $965 \mathrm{psia}$ \\
\hline Total & $281,515 \mathrm{lb} / \mathrm{hr}$ \\
\hline Flow & $99.3 \mathrm{MMscfd}$ \\
\hline Feed Composition (mol\%) & \\
Carbon Dioxide & 2.54 \\
Hydrogen Sulfide & 14.3 \\
Nitrogen & 1.69 \\
Methane & 63.2 \\
Ethane & 9.14 \\
Propane & 5.36 \\
$i$-Butane & 0.68 \\
$n$-Butane & 1.22 \\
$i$-Pentane & 0.40 \\
$n$-Pentane & 0.40 \\
$i$-Hexane & 0.35 \\
$n$-Heptane & 0.72 \\
Water & 0.00 \\
\hline \hline
\end{tabular}

\subsubsection{Case Study No. 4: Bulk Acid Gas Separation - Permeate to Reinject}

This case study was made in response to an inquiry for bulk acid gas separation with the permeate for the membrane system to be reinjected to the formation. The basis of the calculations is shown in Table 36. 
Table 36. Basis for Calculations for Case Study No. 4.

\begin{tabular}{||l|c||}
\hline \multicolumn{2}{|c||}{ Feed Conditions } \\
\hline Feed Pressure & 1000 psig \\
\hline Feed Flow Rate & 450 MMscfd \\
\hline Feed Composition (vol\%) & \\
Methane & 75.7 \\
Carbon Dioxide & 9.25 \\
Hydrogen Sulfide & 15.0 \\
Carbonyl Sulfide & 0.03 \\
Methyl Mercaptan & 0.008 \\
Ethyl Mercaptan & 0.002 \\
\hline
\end{tabular}

Two options were considered for the separation: a single membrane stage only and a twostage membrane system design.

\section{Option 1. Single-Stage System}

A single-stage membrane system is the simplest membrane process possible (see Appendix A). Such a system has a set of membrane modules through which the feed gas flows, producing an acidgas-enriched permeate stream and an acid-gas-depleted residue stream. A total acid gas flow rate of about $35 \mathrm{MMscfd}$ in the membrane permeate stream is assumed in the calculations. In this case a small amount of methane, calculated to be about $2.7 \%$ of the feed, is lost in the permeate stream. The budgetary price (+/-25\%) of the membrane skid for this option is $\$ 11$ million.

\section{Option 2. Two-Stage System}

The loss of methane is reduced by using a two-stage design (see Appendix). The membrane system is placed between two stages of compression, because at the higher discharge pressure the membrane permeate stream from the first stage liquefies. Again the total assumed acid gas flow rate from the second-stage permeate is about $35 \mathrm{MMscfd}$. In this case the methane loss is reduced substantially to only about $0.28 \%$, but with the cost of the additional second membrane stage and a compressor. The budgetary price (+/- 25\%) of the membrane skid for option 2 is $\$ 18$ million

Figure 48 shows a schematic diagram of the membrane process in combination with an amine absorption process. The membrane process will remove between 40 and $75 \%$ of the hydrogen sulfide in the feed gas. Both the single-stage and the two-stage membrane process will produce an acid-gasenriched stream which would be added to the acid gas from amine regeneration. The combined acid gas stream would be reinjected into the formation. Reinjection of acid gas instead of producing solid sulfur in a Claus process is increasingly being considered in markets where sulfur has no value. In these calculations a permeate (acid-gas-enriched stream) pressure of 150 psia is assumed. This 
provides enough pressure ratio, and at the same reduces the compression horsepower requirement. If the pressure of the acid gas stream from the absorption process is different the permeate pressure can be adjusted to match the acid gas pressure. Membrane system cost for three different hydrogen sulfide removal cases are shown in Table 37.

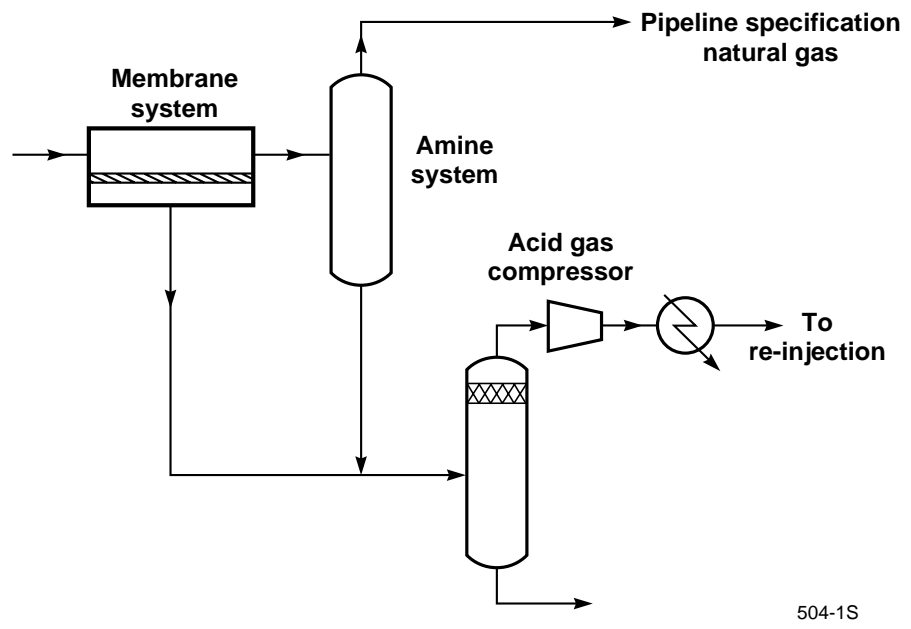

Figure 48. Schematic diagram of a membrane/absorption hybrid process for hydrogen sulfide/carbon dioxide removal.

Table 37. Membrane System Costs for Three Different Hydrogen Sulfide Removals.

\begin{tabular}{|c|c|c|}
\hline $\begin{array}{c}\text { Hydrogen Sulfide in Residue } \\
(\mathrm{mol} \%)\end{array}$ & $\begin{array}{c}\text { Membrane Hydrogen } \\
\text { Sulfide Removal (\%) }\end{array}$ & $\begin{array}{c}\text { Total System Cost } \\
(\mathrm{MM} \$)\end{array}$ \\
\hline 6 & 71.2 & 13.0 \\
\hline 8 & 59.0 & 9.7 \\
\hline 10 & 45.9 & 7.0 \\
\hline
\end{tabular}

The membrane system would be skid-mounted, using 8-inch membrane modules. If size details are important in the plant, calculations of the floor space that the system would occupy for each case can be made. The membrane system will have minimal to no utility consumption. The stream entering the membrane system would pass through a coalescing filter to catch any liquid droplets. Heat tracing would be required in the feed line to the membrane system to avoid condensation due to temperature fluctuations.

\section{SUMMARY AND CONCLUSIONS}

The following conclusions and observations can be made regarding the application of membrane processes to the separation of hydrogen sulfide from natural gas based on the results of this project. 
1. Polyether-polyamide copolymers Pebax ${ }^{\circledR}$, Atochem) are highly selective for hydrogen sulfide over methane, and moderately selective for carbon dioxide. Two grades, Pebax 4011, which had the highest hydrogen sulfide/methane selectivities, and Pebax 1074, were selected for further parametric study.

2. Parametric tests with membrane stamps, using feed gas mixtures containing varying amounts of hydrogen sulfide (from about $0.1 \%$ to $1.8 \%$ ) and carbon dioxide $(0 \%$ to $10 \%)$ at feed pressures ranging from 400 to $970 \mathrm{psig}$, showed that the hydrogen sulfide/methane selectivity of the Pebax 4011 polymer is about 70 at low pressures and acid gas concentrations. At higher pressures, the selectivity levels off to about 50. A similar trend was observed for the Pebax 1074 polymer membrane, and the hydrogen sulfide/methane selectivity is in the range 60-40. These hydrogen sulfide/methane selectivities are higher than any reported in the literature. The carbon dioxide/methane selectivities of these membranes are in the range 15-10 under similar feed conditions.

3. The hydrogen sulfide/methane selectivity decreases by about $20-30 \%$ as the feed temperature is increased from 25 to $40^{\circ} \mathrm{C}$. When exposed to a feed saturated with water vapor, the fluxes of all the gases (11ydrogen sulfide, carbon dioxide, and methane) decrease by about 30-50\%. However, the hydrogen sulfide/methane and carbon dioxide/methane selectivities of the membrane remain constant.

4. Pebax 4011, which had a higher hydrogen sulfide/methane selectivity than Pebax 1074, was chosen for further development. As the optimization of the membrane proceeded, significant modifications were made in the membrane manufacturing process to make the membrane resistant to solvents and high pressures. The result was a membrane with a hydrogen sulfide/methane selectivity between 50 and 40 in the pressure range 400-1000 psig. The membrane flux was improved to about $5 \times 10^{-6} \mathrm{~cm}^{3}(\mathrm{STP}) / \mathrm{s}^{\cdot} \mathrm{cm}^{2} \cdot \mathrm{cmHg}$ ) for methane, which is about two to three times higher than that of conventional cellulose acetate membranes. Scale-up of Pebax 4011 membrane production was successful, and continuous rolls of defectfree, high-performance membrane were made on our commercial-scale 40-inch coating machine.

5. The Pebax 4011 membrane was used to manufacture spiral-wound modules. The optimization of various module internals and rolling procedures resulted in consistent production of high-performance modules with a hydrogen sulfide/methane selectivity with multicomponent mixtures in the same range as that obtained with membrane stamps. As the optimization of the modules proceeded, improved performance was observed.

6. A skid-mounted, complete-recirculation, high-pressure test system was constructed and used to test modules containing 0.1-0.4 $\mathrm{m}^{2}$ Pebax 4011 
membrane. During the module development process, these were tested in this system to evaluate the separation performance. This skid-mounted test system was upgraded during the project by incorporating a two-stage oil-free diaphragm compressor and increasing its flow capacity from $2 \mathrm{scfm}$ to $11 \mathrm{scfm}$. The compressor significantly improved our ability to perform module tests in the operating ranges expected in commercial applications.

7. A significant portion of Task 3 of the project was spent on locating and negotiating a commitment for a field test site. A number of large oil/gas companies (Phillips Petroleum, Chevron CRTC, Elf Aquitaine, Shell Exploration and Production, TX, and Shell R\&D, Amsterdam, Westcoast Energy) were contacted and numerous case studies were performed. Finally, Shell Western E\&P agreed to perform a field test at their Bryans Mill, Texas site. A small test skid incorporating two 3-inch modules was fabricated at MTR according to industrystandard specifications, and the field test was performed during the first half of 1997. The feed gas at the site contained $3.1 \mathrm{~mol} \%$ hydrogen sulfide and was at a pressure of $700-800 \mathrm{psig}$. The test lasted for about 3 months, including a continuous test period of about 2 months with one set of modules. The results were encouraging. The hydrogen sulfide/methane selectivity was between 33 and 37 , which is only about $10-12 \%$ lower than that obtained in tests at MTR with a much lower hydrogen sulfide concentration feed gas. Also, the feed test was performed at a higher temperature. The test was terminated due to changing operating conditions at the plant.

8. An assessment of hydrogen sulfide-prone gas reserves in the United States showed that about $13 \%$ of the known natural gas reserve contains hydrogen sulfide. More than $80 \%$ of these subquality reserves contain $0.02-5 \%$ hydrogen sulfide and $1-10 \%$ carbon dioxide.

9. The technical and economic analysis identified two possible application areas for the membrane technology. The first is small throughput, moderate to high-acidgas content streams. An extensive economic comparison between the membrane/SulfaTreat hybrid process and conventional amine absorption was made. The analysis showed that a hybrid process consisting of a single-stage membrane system followed by a fixed-bed SulfaTreat adsorption process as a polishing step is more economical than amine absorption if the acid gas concentration is higher than $10 \%$. A detailed process design and equipment sizing and economic evaluation using the membrane/SulfaTreat hybrid process for removing hydrogen sulfide and a LOCAT Redox technology to fix the sulfur in the permeate stream was performed. Preliminary economic evaluation shows that the sulfur removal cost is $\$ 0.59 / \mathrm{MMBtu}$ (based on 1,000 ppm hydrogen sulfide at $2.6 \mathrm{MMscfd})$. The main technical hurdle in the application of membrane technology or any technology in this range of gas throughputs (0-10 MMscfd) and 
acid gas contents is the disposition of the acid gases. Dependable economic technologies for fixing the hydrogen sulfide into elemental sulfur are required for treating natural gas to produce pipeline quality gas to be feasible.

The second application envelope for which membrane processes are potentially attractive is for bulk removal of hydrogen sulfide in large-throughput (>50 MMscfd), high-acid-gas-content (>10 vol\% hydrogen sulfide) streams. In this range, calculations show that a membrane/amine hybrid process will be more economical in terms of capital and operating costs than a conventional amine absorption process. The advantage of the membrane process is that bulk acid gas removal decreases the loading in the amine system, thereby lowering the required amine recirculation flow rate. This directly impacts the capital and operating cost of the amine system.

10. Overall, all the original objectives of the project (both tasks 2 and 3) were met or exceeded. The time period for the project was extended so that field test results could be included in the project final report. Delays in procuring a field site required a no-cost extension of the project. The time involved in locating agreeable parties and negotiating a field testing agreement for the demonstration of new technology is extremely time-consuming.

\section{REFERENCES}

1. R.H. Hugman, E.H. Vidas, and P.S. Springer (Energy and Environmental Analysis, Inc.), "Chemical Composition of Discovered and Undiscovered Natural Gas in the Lower-48 United States-Project Summary," Final Report to the Gas Research Institute, Report No. GRI90/0248, NTIS No. PB91-144600 (November 1990).

2. A. Dalrymple, F.D. Skinner, and N.P. Maserole (Radian Corporation), "Investigation of U.S. Natural Gas Reserve Demographics and Gas Treatment Processes," Final Report to the Gas Research Institute, Report No. GRI-91/0019 (January 1991).

3. D. Leppin and H.S. Meyer, "Gas Research Institute Programs in Natural Gas Processing," paper presented at Society of Petroleum Engineers Gas Technology Symposium, Houston, TX (Paper 21505) (January 1991).

4. Clean Air Act (1991).

5. The 1982 Petroleum Institute Gas Plant Survey, originally published as an appendix to the EPA report " $\mathrm{SO}_{2}$ Emissions in the Natural Gas Production Industry." Background Information for Proposed Standards Draft. Report number L-23117, Appendix G. 
6. R.N. Maddox, Gas Conditioning and Processing: Vol. 4 Gas and Liquid Sweetening, Campbell Petroleum Series, 3rd Ed. (1985).

7. D.A. Dalrymple, T.J. Trofe, and J.M. Evans, "An Overview of Liquid Redox Sulfur Recovery,” Chem. Eng. Prog., p.3 (March 1989).

8. D.A. Dalrymple, T.J. Trofe, and J.M. Evans, "Liquid Redox Sulfur Recovery Options, Costs, and Environmental Considerations," Environ. Prog. Vol. 8, No. 4, p. 217 (November 1989).

9. L.C. Hardin, The Low-Cost Hydrogen Sulfide Oxidation Process in Acid and Sour Gas Treatment Processes, S.A. Newman (ed.), Gulf Publishing Co., Houston, TX (1985).

10. D.A. Dalrymple and T.W.Trofe, (eds.), Proceedings of the 1987 Stretford Conference, Austin, Texas, NTIS \#PB88-213222 (October 1987).

11. D. Leppin, J.M. Evans, and D.K. Drist, "Gas Research Institute Programs in Sulfur Recovery Research," paper presented at Liquid Redox Sulfur Recovery Conference, Austin, TX (May 1991).

12. R.W. Baker and I. Blume, "Gas Separation by Permselective Membranes," 232 (1986).

13. V.T. Stannett, W.J. Koros, D.R. Paul, H.K. Lonsdale, and R.W. Baker, "Recent Advances in Membrane Science and Technology,” Adv. Poly. Sci. 32, 69 (1979).

14. I. Blume and I. Pinnau, "Composite Membrane and Method of Use," U.S. Patent 4,963,165 (October 1990). 


\section{APPENDIX A \\ Analysis of Membrane System Configurations for Sour Gas Treatment}

The optimum membrane process configuration to be used in the overall treatment train will depend on the feed conditions and the choice of the final sulfur disposal step. The following membrane process configurations are possible:

a. A single-stage system with no moving parts

b. A two-stage system with permeate recompression and recycle

c. A two-and-one-half-stage system with permeate recompression and recycle

Figure A1 shows a schematic diagram of each configuration. The performance of the singleand multi-stage systems, calculated using in-house computer simulation packages is discussed below.

(a)

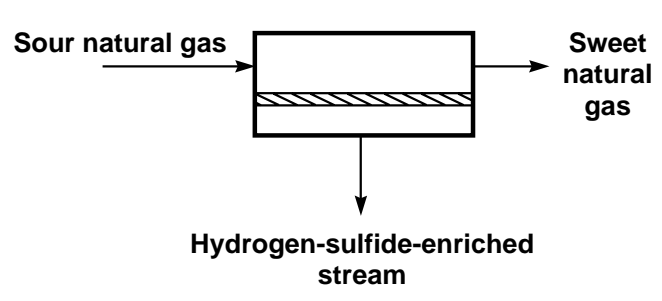

(c)

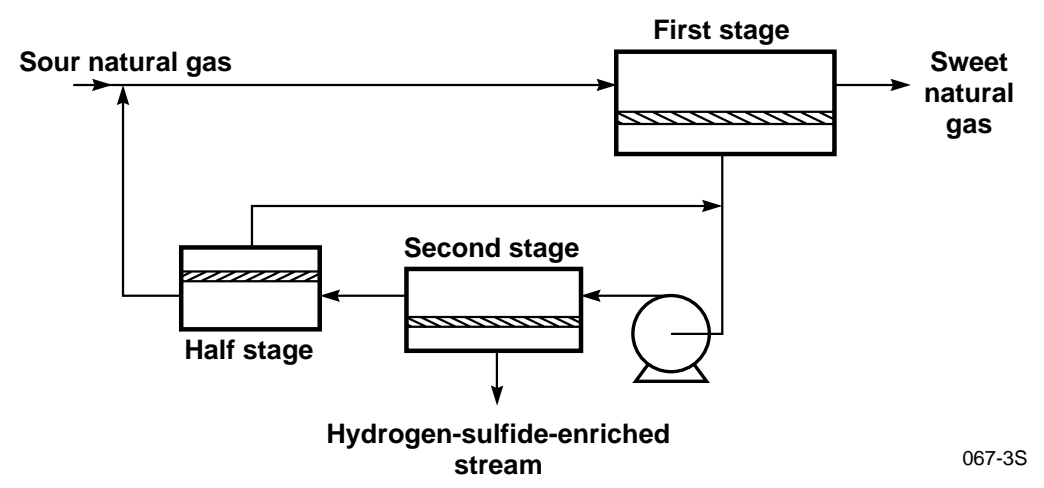

(b)

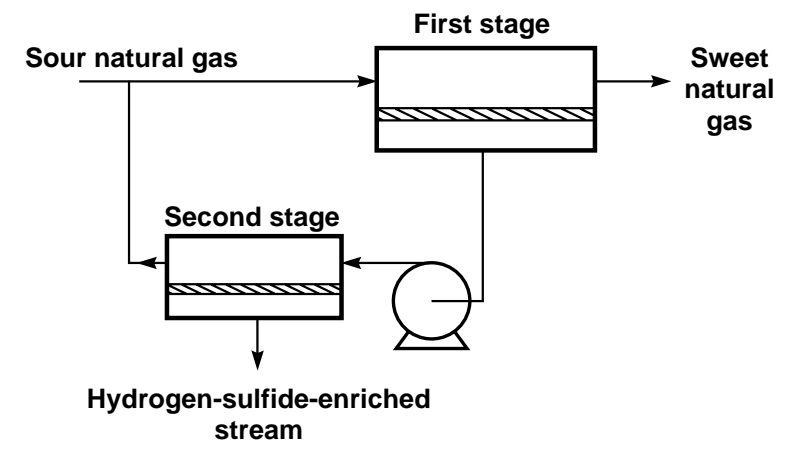

Figure A1. Three possible membrane process configurations for sour gas treatment. 


\section{Single-Stage System}

The single-stage design shown in Figure A1(a) can be used if the hydrogen sulfide content of the feed stream is less than about $200 \mathrm{ppm}$. If carbon dioxide removal is also required, its concentration should be such that pipeline specifications for both gases can be met simultaneously. Typically, such a system would be useful in remote locations and on off-shore platforms, where a minimum of moving parts is desirable. This membrane design provides a good bulk separation step for combination with iron sponge removal or a Redox process, because it can reduce the hydrogen sulfide load on the beds by pretreating the gas. Such a hybrid would greatly increase bed cycle times. Some typical calculations for such a system over the expected range of hydrogen sulfide compositions are shown in Tables A1 through A3.

Table A1. Design Calculations for a Single-Stage Membrane Process Design with a Feed Stream Containing 100 ppm Hydrogen Sulfide, 5\% Carbon Dioxide, and Balance Methane. Feed flow rate: $1,000 \mathrm{scfm}$; feed pressure: 1,000 psia.

\begin{tabular}{||c|c|c|c||}
\hline \hline $\begin{array}{c}\text { Residual } \mathrm{H}_{2} \mathrm{~S} \\
\text { Content }(\mathrm{ppm})\end{array}$ & $\begin{array}{c}\text { Membrane } \\
\text { Area }\left(\mathrm{m}^{2}\right)\end{array}$ & $\begin{array}{c}\text { Methane Loss } \\
(\%)\end{array}$ & $\begin{array}{c}\text { Residual } \mathrm{CO}_{2} \\
\text { Content }(\mathrm{mol} \%)\end{array}$ \\
\hline 4 & 184 & 10 & 1.0 \\
\hline 8 & 145 & 8 & 1.3 \\
\hline 10 & 133 & 7 & 1.4 \\
\hline 20 & 94 & 5 & 1.8 \\
\hline
\end{tabular}

Table A2. Design Calculations for a Single-Stage Membrane Process Design with a Feed Stream Containing 1,000 ppm Hydrogen Sulfide, 5\% Carbon Dioxide, and Balance Methane. Feed flow rate: 1,000 scfm; feed pressure: 1,000 psia.

\begin{tabular}{||c|c|c|c||}
\hline \hline $\begin{array}{c}\text { Residual } \mathrm{H}_{2} \mathrm{~S} \\
\text { Content }(\mathrm{ppm})\end{array}$ & $\begin{array}{c}\text { Membrane } \\
\text { Area }\left(\mathrm{m}^{2}\right)\end{array}$ & $\begin{array}{c}\text { Methane Loss } \\
(\%)\end{array}$ & $\begin{array}{c}\text { Residual } \mathrm{CO}_{2} \\
\text { Content }(\mathrm{mol} \%)\end{array}$ \\
\hline 4 & 295 & 16 & 0.8 \\
\hline 8 & 260 & 15 & 1.0 \\
\hline 10 & 248 & 14 & 1.1 \\
\hline 50 & 164 & 9 & 1.9 \\
\hline 100 & 127 & 7 & 2.4 \\
\hline
\end{tabular}


Table A3. Design Calculations for a Single-Stage Membrane Process Design with a Feed Stream Containing 10,000 ppm Hydrogen Sulfide, 5\% Carbon Dioxide, and Balance Methane. Feed flow rate: 1,000 scfm; feed pressure: 1,000 psia.

\begin{tabular}{|c|c|c|c||}
\hline $\begin{array}{c}\text { Residual } \mathrm{H}_{2} \mathrm{~S} \\
\text { Content }(\mathrm{ppm})\end{array}$ & $\begin{array}{c}\text { Membrane } \\
\text { Area }\left(\mathrm{m}^{2}\right)\end{array}$ & $\begin{array}{c}\text { Methane Loss } \\
(\%)\end{array}$ & $\begin{array}{c}\text { Residual } \mathrm{CO}_{2} \\
\text { Content }(\mathrm{mol} \%)\end{array}$ \\
\hline 4 & 401 & 22 & 0.4 \\
\hline 20 & 324 & 18 & 0.6 \\
\hline 100 & 243 & 14 & 1.1 \\
\hline 500 & 160 & 13 & 1.9 \\
\hline
\end{tabular}

The results shown in Tables A1-A3 are based on feed hydrogen sulfide concentrations between 100 and 10,000 ppm. The single-stage system will result in low methane losses when the hydrogen sulfide concentration in the feed gas is low and/or when the hydrogen sulfide concentration in the residue gas is high. If this membrane design is combined with a hydrogen sulfide scavenging process, such as iron sponge, SulfaTreat, or Redox, the overall capital and operating costs of the system may be reduced further. The single-stage membrane unit can remove up to $90 \%$ of the hydrogen sulfide, thereby reducing the load on the scavenging system and lowering operating expenses significantly. This hybrid would be particularly attractive if the permeate stream from the membrane unit can be used as a heating fuel. A single-stage unit could also be a retrofitted to an existing amine absorption system.

\section{Multistage Systems}

Although the best method of increasing the overall separation performance is to use membranes with higher selectivities in a single-stage membrane process, another option is a multistage configuration. In separating hydrogen sulfide from natural gas, a highly concentrated acid gas stream that can be treated by a sulfur-fixing process is desired. Also, the associated loss of methane in this stream must be minimal. Both goals can be achieved by using either of the two multi-stage membrane processes shown in Figure A1(b) and (c).

In the two-stage process, the permeate stream from the first stage is recompressed and treated in a second membrane stage to increase the concentration of the acid gases further, and to lower the methane loss significantly. In the two-and-one-half-stage membrane process, the permeate stream from the first stage is treated twice more: the second stage removes part of the hydrogen sulfide, and the third or "half" stage removes the remainder down to the concentration in the feed. The third membrane stage in this configuration is designated a "half" stage because it is a relatively small membrane area compared to the first two stages. The key to this configuration is that the permeate from the half stage is remixed with the permeate stream from the first stage, thereby setting up a recirculating loop around the second stage. This loop concentrates the hydrogen sulfide, resulting in 
an increased hydrogen sulfide concentration in the permeate stream produced by the second stage. MTR has recently been issued a U.S. patent on this process design.

\section{Effect of Hydrogen Sulfide and Carbon Dioxide Feed Concentrations}

Tables A4 and A5 show the results of design calculations performed for the two-stage and the two-and-one-half-stage membrane processes, respectively. Parameters such as permeate composition, membrane area and compressor horse power were calculated for different feed concentrations of hydrogen sulfide and carbon dioxide.

Table A4. Design Calculations for a Two-Stage Membrane Process with a Feed Stream Containing Varying Amounts of Hydrogen Sulfide and Carbon Dioxide. Residue concentration is the pipeline specification of 4 ppmv. Feed flow rate: 1,000 scfm; feed pressure: 1,000 psia.

\begin{tabular}{|c|c|c|c|c|}
\hline $\begin{array}{c}\text { Feed } \mathrm{H}_{2} \mathrm{~S} \\
\text { Content } \\
(\%)\end{array}$ & $\begin{array}{c}\text { Permeate } \mathrm{H}_{2} \mathrm{~S} \\
\text { Content } \\
(\%)\end{array}$ & $\begin{array}{c}\text { Permeate } \mathrm{CO}_{2} \\
\text { Content } \\
(\%)\end{array}$ & $\begin{array}{c}\text { Total Membrane } \\
\text { Area } \\
\left(\mathrm{m}^{2}\right)\end{array}$ & $\begin{array}{l}\text { Power } \\
\text { Required } \\
\text { (hp) }\end{array}$ \\
\hline \multicolumn{5}{|c|}{ Feed $\mathrm{CO}_{2}$ content: $5 \%$} \\
\hline 0.1 & 2.3 & 75.9 & 540 & 230 \\
\hline 0.5 & 9.4 & 70.8 & 710 & 310 \\
\hline 1.0 & 16.5 & 65.5 & 790 & 350 \\
\hline 5.0 & 48.4 & 41.2 & 940 & 470 \\
\hline \multicolumn{5}{|c|}{ Feed $\mathrm{CO}_{2}$ content: $2 \%$} \\
\hline 0.1 & 3.7 & 52.2 & 570 & 200 \\
\hline 0.5 & 14.8 & 46.6 & 750 & 270 \\
\hline 1.0 & 25.2 & 41.3 & 820 & 300 \\
\hline 5.0 & 62.5 & 21.7 & 980 & 400 \\
\hline \multicolumn{5}{|c|}{ Feed $\mathrm{CO}_{2}$ content: $0.5 \%$} \\
\hline 0.1 & 5.3 & 19.3 & 600 & 190 \\
\hline 0.5 & 20.6 & 16.6 & 770 & 250 \\
\hline 1.0 & 34.1 & 14.2 & 850 & 280 \\
\hline 5.0 & 73.3 & 6.4 & 1,000 & 380 \\
\hline
\end{tabular}


Table A5. Design Calculations for a Two-and-One-Half-Stage Membrane Process with a Feed Stream Containing Varying Amounts of Hydrogen Sulfide and Carbon Dioxide. Residue concentration is the pipeline specification of 4 ppmv. Feed flow rate: 1,000 scfm. Feed pressure: 1,000 psia.

\begin{tabular}{|c|c|c|c|c|}
\hline $\begin{array}{l}\text { Feed } \mathrm{H}_{2} \mathrm{~S} \\
\text { Content } \\
(\%)\end{array}$ & $\begin{array}{c}\text { Permeate } \mathrm{H}_{2} \mathrm{~S} \\
\text { Content } \\
(\%)\end{array}$ & $\begin{array}{c}\text { Permeate } \mathrm{CO}_{2} \\
\text { Content } \\
(\%)\end{array}$ & $\begin{array}{c}\text { Total Membrane } \\
\text { Area } \\
\left(\mathrm{m}^{2}\right)\end{array}$ & $\begin{array}{c}\text { Power } \\
\text { Required } \\
\text { (hp) }\end{array}$ \\
\hline \multicolumn{5}{|c|}{ Feed $\mathrm{CO}_{2}$ content: $5 \%$} \\
\hline 0.1 & 2.7 & 81.4 & 550 & 260 \\
\hline 0.5 & 11.0 & 75.7 & 720 & 360 \\
\hline 1.0 & 19.2 & 69.3 & 800 & 410 \\
\hline 5.0 & 53.0 & 41.4 & 960 & 590 \\
\hline \multicolumn{5}{|c|}{ Feed $\mathrm{CO}_{2}$ content: $2 \%$} \\
\hline 0.1 & 4.7 & 60.0 & 570 & 210 \\
\hline 0.5 & 18.0 & 53.2 & 760 & 290 \\
\hline 1.0 & 30.0 & 46.1 & 830 & 330 \\
\hline 5.0 & 67.0 & 22.4 & 990 & 460 \\
\hline \multicolumn{5}{|c|}{ Feed $\mathrm{CO}_{2}$ content: $0.5 \%$} \\
\hline 0.1 & 7.2 & 24.6 & 600 & 200 \\
\hline 0.5 & 27.0 & 20.7 & 780 & 260 \\
\hline 1.0 & 42.7 & 17.0 & 860 & 300 \\
\hline 5.0 & 80.3 & 6.7 & 1,020 & 410 \\
\hline
\end{tabular}

The following two conclusions can be drawn from the data in Tables A4 and A5:

1. A 50-fold increase in the hydrogen sulfide feed concentration, from 0.1 to $5 \%$, increases the overall membrane area required to achieve pipeline specifications ( $4 \mathrm{ppmv}$ ) by a factor of less than two. The power requirement of the compressor increases by about the same factor. This is true for the entire $0.5-5 \% \mathrm{CO}_{2}$ feed concentration range studied.

Figure A2, a plot of hydrogen sulfide feed concentration as a function of the membrane area required to achieve pipeline specification, shows this effect for both membrane process 
designs. A striking feature is that the membrane area required increases less than proportionally with the hydrogen sulfide feed concentration. In comparison, the solvent recirculation flow rate of an amine plant would increase proportionally with the hydrogen sulfide feed concentration, resulting in significant increases in column height and regeneration energy requirements. This indicates that a high concentration of hydrogen sulfide favors treatment by a membrane process.

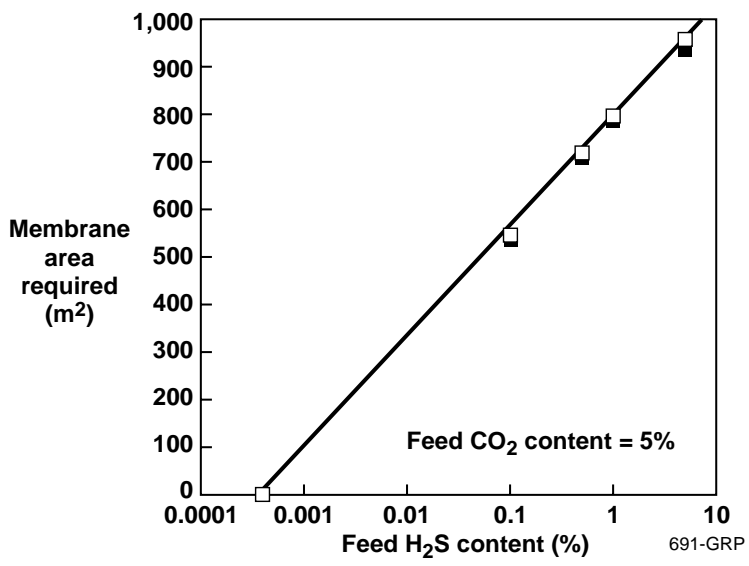

Figure A2. Effect of feed hydrogen sulfide content on membrane area requirement for two-stage and two-and-one-half-stage membrane process designs.

2. By using a multi-stage design, the concentration of hydrogen sulfide in the permeate can be increased significantly. This is shown in Figure A3, in which the feed and permeate hydrogen sulfide concentrations are plotted for the two configurations studied. For example, for a feed gas containing $1 \%$ of hydrogen sulfide and $0.5 \%$ carbon dioxide, the hydrogen sulfide concentration in the permeate stream of the two-stage configuration is as high as $33 \%$, a 33-fold increase. The permeate stream concentration of the two-andone-half stage configuration is even higher, about 44\%, a 44-fold increase. It is important to note that the significantly higher hydrogen sulfide permeate concentration produced by the two-and-one-half-stage system is achieved with only a modest increase in membrane area and compressor horse power.

Permeate streams containing $10 \%$ hydrogen sulfide or higher are suitable for treatment in a Claus plant. For permeate streams with lower concentrations of hydrogen sulfide, processes such as "Clinsulf" offered by Linde AG can be used for sulfur recovery. 


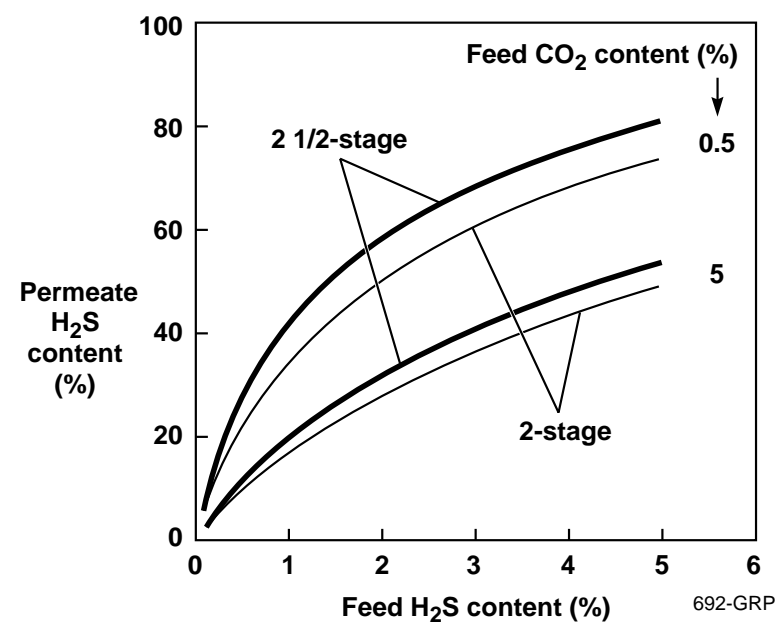

Figure A3. Permeate hydrogen sulfide concentration as a function of the feed concentration for the two-stage and two-and-one-half-stage membrane process designs.

\section{Effect of Hydrogen Sulfide Residue Concentration}

Either multi-stage process configuration can also be used as a bulk separation step in the overall sulfur removal/recovery operation. In this scheme, the desired outlet specification of hydrogen sulfide can be higher than 4 ppmv, and the final polishing step can be performed by a conventional absorption or adsorption process. A membrane process for bulk separation can be used effectively for debottlenecking existing absorption or adsorption facilities, for example, when the acid gas content of the gas produced from the field increases with time. The concentration of the acid gases produced by the membrane process would be very high, and can, therefore, be added directly to the regenerated acid gas stream from the existing sulfur recovery system. Tables A6 and A7 show the results of design calculations performed for the two membrane process configurations. 
Table A6. Design Calculations for a Two-Stage Membrane Process with a Feed Stream Containing 1\% Hydrogen Sulfide and Varying Amounts of Carbon Dioxide. The residue concentration varied from pipeline specification (4 ppmv) to 1,000 ppmv. Feed flow rate: 1,000 scfm; feed pressure: 1,000 psia.

\begin{tabular}{|c|c|c|c|c|}
\hline $\begin{array}{c}\text { Residue } \mathrm{H}_{2} \mathrm{~S} \\
\text { Content } \\
\text { (ppmv) }\end{array}$ & $\begin{array}{c}\text { Permeate } \mathrm{H}_{2} \mathrm{~S} \\
\text { Content } \\
(\%)\end{array}$ & $\begin{array}{c}\text { Permeate } \mathrm{CO}_{2} \\
\text { Content } \\
(\%)\end{array}$ & $\begin{array}{c}\text { Total Membrane } \\
\text { Area } \\
\left(\mathrm{m}^{2}\right)\end{array}$ & $\begin{array}{l}\text { Power } \\
\text { Required } \\
\text { (hp) }\end{array}$ \\
\hline \multicolumn{5}{|c|}{ Feed $\mathrm{CO}_{2}$ content: $5 \%$} \\
\hline 4 & 17.0 & 67.9 & 780 & 350 \\
\hline 10 & 17.4 & 64.7 & 680 & 300 \\
\hline 100 & 21.0 & 61.7 & 440 & 190 \\
\hline 1,000 & 28.4 & 55.3 & 210 & 90 \\
\hline \multicolumn{5}{|c|}{ Feed $\mathrm{CO}_{2}$ content: $2 \%$} \\
\hline 4 & 25.2 & 41.3 & 830 & 300 \\
\hline 10 & 26.4 & 40.8 & 720 & 260 \\
\hline 100 & 31.1 & 38.4 & 460 & 170 \\
\hline 1,000 & 40.2 & 33.1 & 220 & 80 \\
\hline \multicolumn{5}{|c|}{ Feed $\mathrm{CO}_{2}$ content: $0.5 \%$} \\
\hline 4 & 34.1 & 14.2 & 850 & 280 \\
\hline 10 & 35.6 & 14.0 & 740 & 240 \\
\hline 100 & 41.2 & 13.1 & 470 & 160 \\
\hline 1,000 & 51.1 & 11.0 & 230 & 80 \\
\hline
\end{tabular}


Table A7. Design Calculations for a Two-and-One-Half-Stage Membrane Process with a Feed Stream Containing 1\% Hydrogen Sulfide and Varying Amounts of Carbon Dioxide. The residue concentration varied from pipeline specification (4 ppmv) to 1,000 ppmv. Feed flow rate: 1,000 scfm; feed pressure: 1,000 psia.

\begin{tabular}{|c|c|c|c|c|}
\hline $\begin{array}{c}\text { Residue } \mathrm{H}_{2} \mathrm{~S} \\
\text { Content } \\
\text { (ppmv) }\end{array}$ & $\begin{array}{c}\text { Permeate } \mathrm{H}_{2} \mathrm{~S} \\
\text { Content } \\
(\%)\end{array}$ & $\begin{array}{c}\text { Permeate } \mathrm{CO}_{2} \\
\text { Content } \\
(\%)\end{array}$ & $\begin{array}{c}\text { Total Membrane } \\
\text { Area } \\
\left(\mathrm{m}^{2}\right)\end{array}$ & $\begin{array}{l}\text { Power } \\
\text { Required } \\
\text { (hp) }\end{array}$ \\
\hline \multicolumn{5}{|c|}{ Feed $\mathrm{CO}_{2}$ content: $5 \%$} \\
\hline 4 & 19.2 & 69.3 & 800 & 410 \\
\hline 10 & 20.2 & 67.9 & 700 & 350 \\
\hline 100 & 24.1 & 63.3 & 440 & 210 \\
\hline 1,000 & 31.6 & 55.6 & 210 & 100 \\
\hline \multicolumn{5}{|c|}{ Feed $\mathrm{CO}_{2}$ content: $2 \%$} \\
\hline 4 & 30.0 & 46.1 & 830 & 330 \\
\hline 10 & 31.2 & 45.0 & 720 & 280 \\
\hline 100 & 35.9 & 40.8 & 460 & 180 \\
\hline 1,000 & 44.8 & 33.8 & 220 & 90 \\
\hline \multicolumn{5}{|c|}{ Feed $\mathrm{CO}_{2}$ content: $0.5 \%$} \\
\hline 4 & 42.7 & 17.0 & 860 & 300 \\
\hline 10 & 44.1 & 16.4 & 750 & 260 \\
\hline 100 & 49.0 & 14.5 & 480 & 160 \\
\hline 1,000 & 57.6 & 11.4 & 230 & 80 \\
\hline
\end{tabular}

The following two conclusions can be drawn from Tables A6 and A7:

1. By increasing the allowed concentration of hydrogen sulfide in the residue stream from 4 ppmv (pipeline specification) to higher values, the membrane area required, for the separation decreases significantly. Figure A4, a plot of the residue concentration of hydrogen sulfide as a function of the total membrane area required shows this effect. It can be seen that the two-stage and two-and-a-half-stage configurations have equivalent membrane area requirements. 


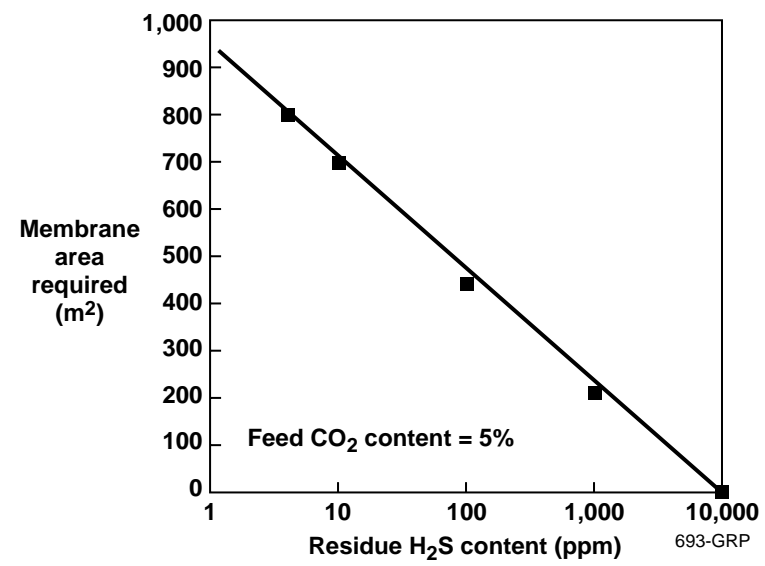

Figure A4. Effect of changing residue hydrogen sulfide content on membrane area requirement for two-stage and two-and-one-half-stage membrane process designs.

2. By increasing the specification of hydrogen sulfide in the residue, the permeate stream is enriched significantly. These concentrated streams are very suitable for a Claus or Clinsulf process and possibly also for Redox processes. Figure A5 shows the variation of the permeate hydrogen sulfide concentration as a function of the changes in the residue concentration of hydrogen sulfide. The two-and-one-half-stage configuration produces the highest hydrogen sulfide permeate concentrations, and the presence of carbon dioxide reduces the hydrogen sulfide permeate concentration.

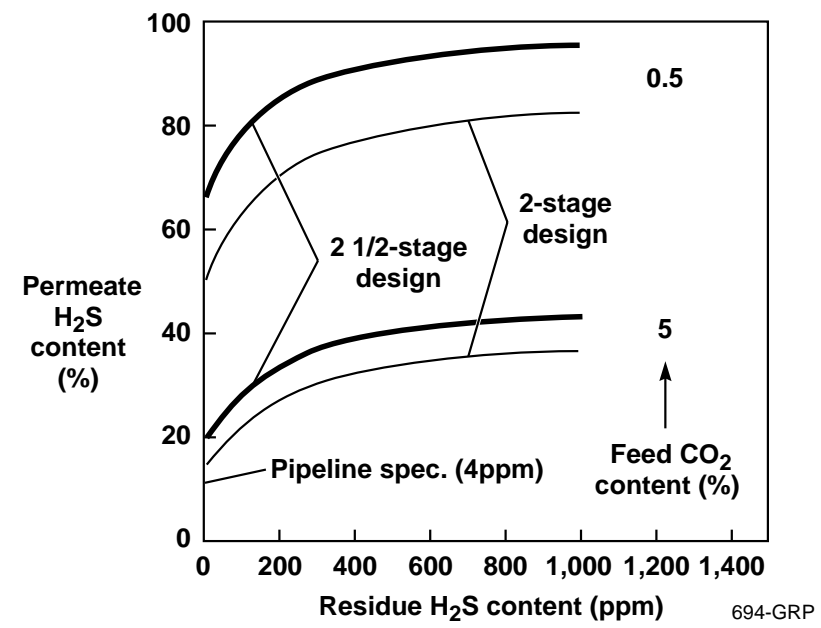

Figure A5. Permeate hydrogen sulfide concentration as a function of the residue hydrogen sulfide concentration for the two-stage and two-and-one-half-stage membrane process designs. Initial feed hydrogen sulfide concentration: $1 \%$. 